\title{
1 Zeta Potential of Artificial and Natural Calcite in
}

\section{Aqueous Solution}

3 Dawoud Al Mahrouqi ${ }^{1,2 *}$, Jan Vinogradov ${ }^{1,3}$ and Matthew D. Jackson ${ }^{1}$

$4{ }^{1}$ Department of Earth Science and Engineering, Imperial College London, SW7 2AZ, United

$5 \quad$ Kingdom

$6 \quad 2$ Petroleum Development Oman, Muscat, P.O. Box 81, P.C. 113, Oman

$7 \quad{ }^{3}$ Now at the School of Engineering, University of Aberdeen, AB24 3UE, United Kingdom

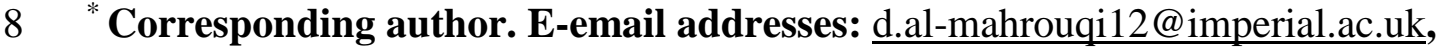

9 dawoud.mahrouqi@gmail.com (D. Al Mahrouqi).

\section{Abstract}

12 Despite the broad range of interest and applications, controls on calcite surface charge in

13 aqueous solution, especially at conditions relevant to natural systems, remain poorly

14 understood. The primary data source to understand calcite surface charge comprises

15 measurements of zeta potential. Here we collate and review previous measurements of zeta

16 potential on natural and artificial calcite and carbonate as a resource for future studies,

17 compare and contrast the results of these studies to determine key controls on zeta potential

18 and where uncertainties remain, and report new measurements of zeta potential relevant to

19 natural subsurface systems.

20 The results show that the potential determining ions (PDIs) for the carbonate mineral surface

21 are the lattice ions $\mathrm{Ca}^{2+}, \mathrm{Mg}^{2+}$ and $\mathrm{CO}_{3}{ }^{2-}$. The zeta potential is controlled by the 
concentration-dependent adsorption of these ions within the Stern layer, primarily at the

23 Outer Helmholtz Plane (OHP). Given this, the Iso-Electric Point (IEP) at which the zeta potential is zero should be expressed as $\mathrm{pCa}$ (or $\mathrm{pMg}$ ). It should not be reported as $\mathrm{pH}$, similar to most metal oxides.

The $\mathrm{pH}$ does not directly control the zeta potential. Varying the $\mathrm{pH}$ whilst holding $\mathrm{pCa}$ constant yields constant zeta potential. The $\mathrm{pH}$ affects the zeta potential only by moderating the equilibrium $\mathrm{pCa}$ for a given $\mathrm{CO}_{2}$ partial pressure $\left(p \mathrm{CO}_{2}\right)$. Experimental studies that appear to yield a systematic relationship between $\mathrm{pH}$ and zeta potential are most likely observing the relationship between $\mathrm{pCa}$ and zeta potential, with $\mathrm{pCa}$ responding to the change in $\mathrm{pH}$. New data presented here show a consistent linear relationship between equilibrium $\mathrm{pH}$ and equilibrium $\mathrm{pCa}$ or $\mathrm{pMg}$ irrespective of sample used or solution ionic strength. The surface charge of calcite is weakly dependent on $\mathrm{pH}$, through protonation and deprotonation reactions that occur within a hydrolysis layer immediately adjacent to the mineral surface. The Point of Zero Charge (PZC) at which the surface charge is zero could be expressed as $\mathrm{pH}$, but surface complexation models suggest the surface is negatively charged over the $\mathrm{pH}$ range 5.5-11.

Several studies have suggested that $\mathrm{SO}_{4}{ }^{2-}$ is also a PDI for the calcite surface, but new data presented here indicate that the value of $\mathrm{pSO}_{4}$ may affect zeta potential only by moderating the equilibrium pCa. Natural carbonate typically yields a more negative zeta potential than synthetic calcite, most likely due to the presence of impurities including clays, organic matter, apatite, anhydrite or quartz, that yield a more negative zeta potential than pure calcite. New data presented here show that apparently identical natural carbonates display differing 44 zeta potential behavior, most likely due to the presence of small volumes of these impurities. 
46 reached prior to taking measurements. Inconsistent values of zeta potential obtained in some

47 studies may reflect a lack of equilibration.

48 The data collated and reported here have broad application in engineering processes including

49 the manufacture of paper and cement, the geologic storage of nuclear waste and $\mathrm{CO}_{2}$, and the 50 production of oil and gas.

51

\section{Keywords}

53 Zeta potential; Streaming potential; Calcite; Carbonate; Wettability alteration; Controlled 54 salinity waterflooding 
56 Abstract

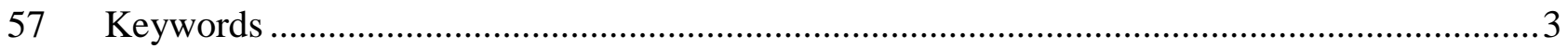

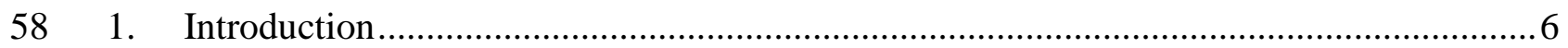

59 2. Zeta potential and the electrical double layer .......................................................

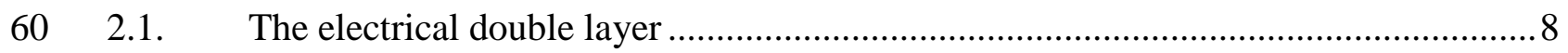

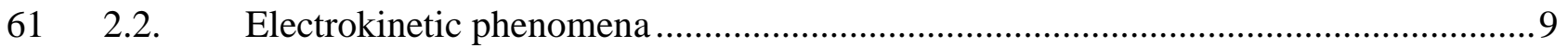

62 3. Development of surface charge on calcite in aqueous solution.................................... 11

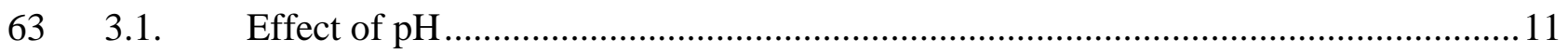

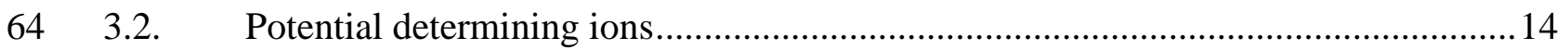

65 4. Experimental measurements of zeta potential ....................................................... 15

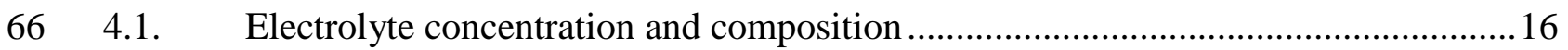

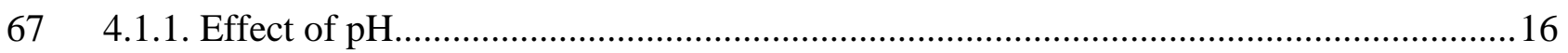

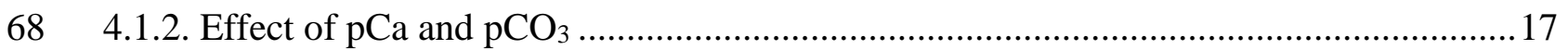

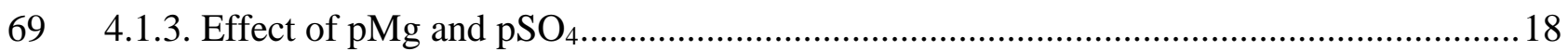

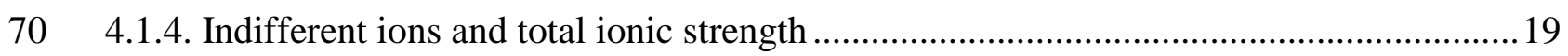

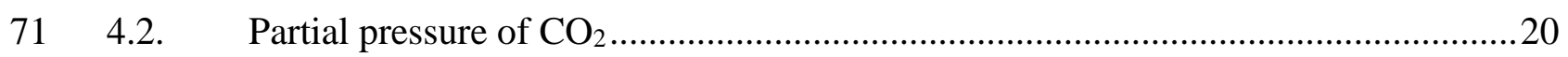

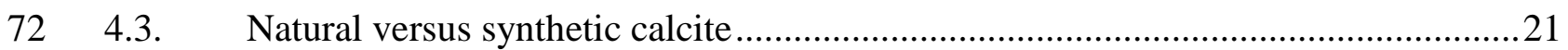

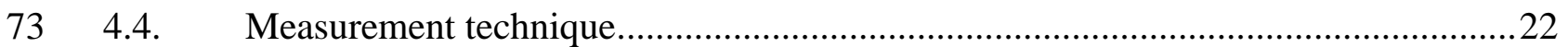

74 4.5. Establishment of equilibrium between sample and electrolyte ...............................23

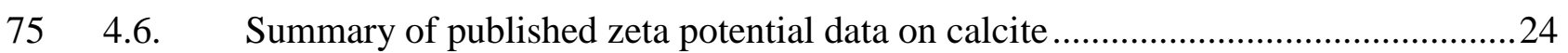

76 5. Measurements of zeta potential on natural limestone rock samples: Impact of rock type,

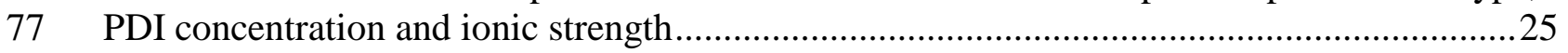

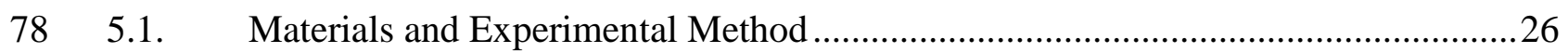

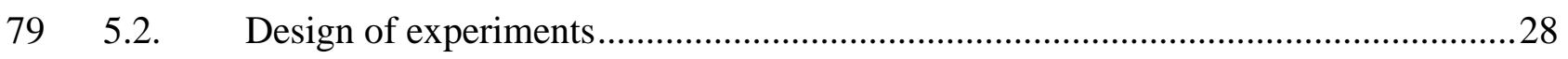

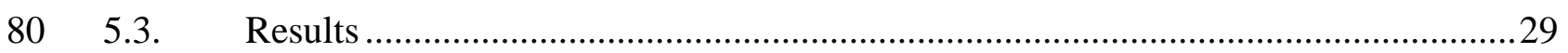

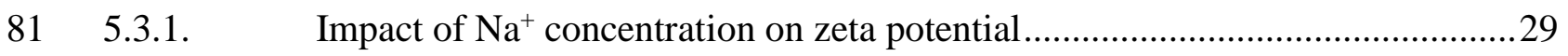

82 5.3.2. Impact of $\mathrm{Ca}^{2+}, \mathrm{Mg}^{2+}$ and $\mathrm{SO}_{4}{ }^{2-}$ concentration on zeta potential......................30

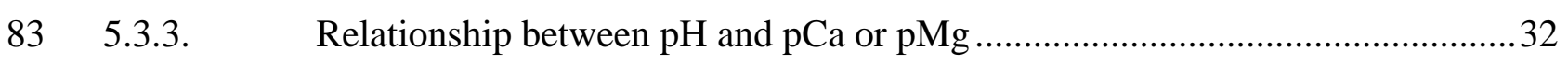

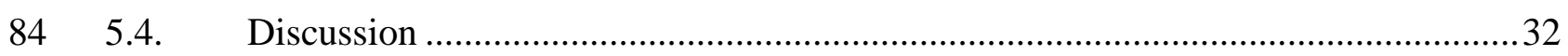

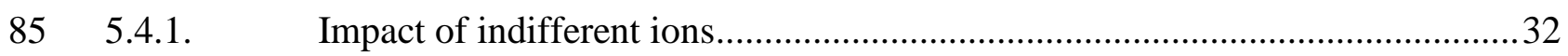

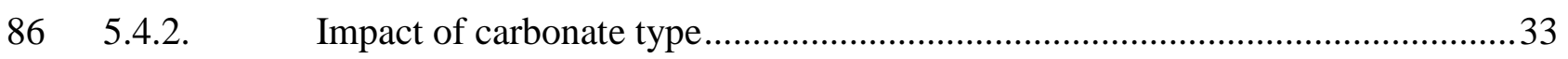

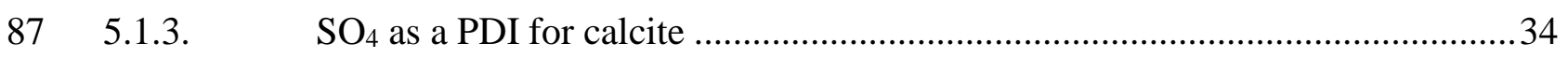

88 5.1.4. Implications for wettability alteration and hydrocarbon recovery in carbonate 89 reservoirs 35

90 6. Conclusions. 


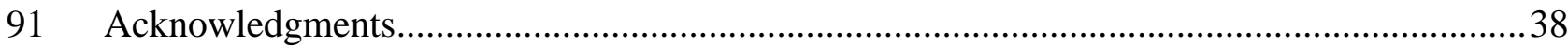

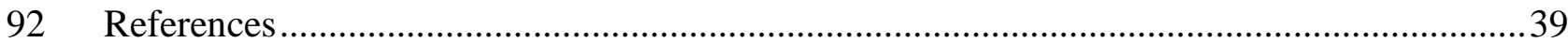

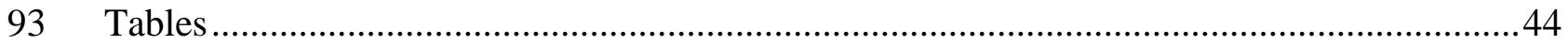

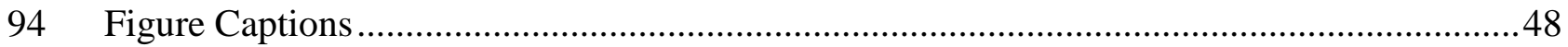

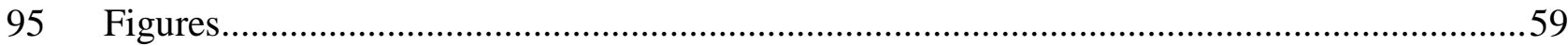

96

97 
The properties of the calcite mineral surface and the interface between calcite and aqueous solution are of broad interest in many areas of science and engineering. Calcite is a common mineral, comprising approximately $4 \%$ of the Earth's crust, and surface reactions on calcite

102 play an important role in many geochemical and environmental systems, as well as many

103 areas of industry, including the manufacture of paper and cement (e.g. [ㄷ]), the geologic

104 storage of nuclear waste and $\mathrm{CO}_{2}$ (e.g. [이), and the production of oil and gas (e.g. $[\underline{9}, \underline{28}, \underline{86}$,

105 88]). However, despite the broad range of interest and applications, controls on calcite surface charge in aqueous solution, especially at conditions relevant to natural systems, remain poorly understood. Numerous papers have reported inconsistent or contradictory data and models, and there is still active debate over the relationship between calcite surface

109 charge and electrolyte $\mathrm{pH}$, the concentration of ions such as $\mathrm{Ca}^{2+}, \mathrm{Mg}^{2+}, \mathrm{CO}_{3}{ }^{2-}$ and $\mathrm{SO}_{4}{ }^{2-}$ in

110 aqueous solution, the partial pressure of $\mathrm{CO}_{2}$, the difference between natural and artificial

111 calcite, and the role of dissolution and/or precipitation.

112 The focus of this paper is the zeta potential of artificial and natural calcite in aqueous

113 solution. The zeta potential is an important measure of the electrical potential at the mineral 114 surface, and the magnitude and sign of the zeta potential control the electrostatic interactions

115 between the mineral surface and polar species in aqueous solution, between the mineral

116 surface and other charged interfaces such as the water-air and water-oil interfaces, and

117 between mineral particles in suspension including flocculation and dispersion. Measurements

118 of zeta potential in low concentration solutions and at laboratory conditions are relatively

119 straightforward, and most studies of the calcite mineral surface have reported measurements

120 of zeta potential or the closely related property of electrophoretic mobility. Other approaches

121 to determine surface charge, such as potentiometric titration, are challenging to apply in

122 calcite because rapid dissolution kinetics and the buffering effect of carbonate ions in 
123 solution can affect the results. Thus the primary data source to understand calcite surface 124 charge comprises measurements of zeta potential. Where relevant, we use the results of 125 spectroscopic, microscopic, surface diffraction, modelling and theoretical studies to help 126 explain experimentally determined values of zeta potential. However, a comprehensive

127 review of these studies is beyond the scope of the paper; a companion paper of comparable 128 length would be required to do justice to this work.

129 The aims of the paper are therefore threefold; (1) to collate and review previous

130 measurements of zeta potential on natural and artificial calcite and carbonate as a resource for

131 future studies, (2) to compare and contrast the results of these studies to determine key

132 controls on zeta potential and where uncertainties remain, and (3) to report new

133 measurements of zeta potential relevant to natural subsurface systems. There has been no

134 comprehensive review of zeta potential measurements in calcite and natural carbonate to

135 date, although Wolthers et al. [85] collated published zeta potential data to constrain their

136 new surface complexation model. Moreover, there are a lack of data which can be applied to

137 natural systems owing to the comparatively high ionic strength (typically $>0.01 \mathrm{M}$ and often

$138>2 \mathrm{M}$ ) and complex compositions (including $\mathrm{Na}^{+}, \mathrm{Ca}^{2+}, \mathrm{Mg}^{2+}, \mathrm{Cl}^{-}, \mathrm{CO}_{3}^{2-}, \mathrm{SO}_{4}^{2-}$ ) of natural

139 brines, compared to the simple, dilute aqueous solutions typically used in laboratory

140 experiments.

141 We report new data obtained using (intact) natural samples saturated with electrolytes

142 relevant to natural systems and an experimental methodology specifically designed to allow

143 this parameter space to be explored. Data obtained in this parameter space are still very

144 scarce, despite the broad range of interest. Our results demonstrate that apparently identical

145 natural carbonates can exhibit differing zeta potential behaviour, suggesting that small

146 variations in the type and content of impurities in the mineral lattice can significantly impact 
147 the surface charge. However, the effect of the lattice ions $\mathrm{Ca}^{2+}$ and $\mathrm{Mg}^{2+}$ on the zeta potential

148 of a given carbonate is identical within experimental error. The presence of apparently

149 indifferent ions such as $\mathrm{Na}^{+}$and $\mathrm{Cl}^{-}$at the high concentrations typical of natural brines can

150 significantly shift the iso-electric point expressed as $\mathrm{pCa}$ and $\mathrm{pMg}$. We demonstrate

151 experimentally that equilibrium $\mathrm{pH}$ is strongly correlated to equilibrium $\mathrm{pCa}$ and $\mathrm{pMg}$, and

152 apparent trends in zeta potential with $\mathrm{pH}$ reflect trends in zeta potential with $\mathrm{pCa}$ and $\mathrm{pMg}$.

$153 \mathrm{Ca}^{2+}$ and $\mathrm{Mg}^{2+}$ are the potential determining ions (PDIs) for the calcite surface. We provide

154 experimental evidence suggesting that $\mathrm{SO}_{4}{ }^{2-}$, which has previously been suggested as a PDI,

155 may not directly control the zeta potential of calcite; rather, varying $\mathrm{pSO}_{4}$ causes variations in

156 pCa which can be correlated with observed changes on zeta potential. These new results have

157 broad application to subsurface engineering processes such as the geologic storage of nuclear 158 waste and $\mathrm{CO}_{2}$, and the production of oil and gas.

\section{Zeta potential and the electrical double layer}

\subsection{The electrical double layer}

162 The immersion of a calcite mineral in aqueous solution leads to a separation of electrical

163 charge at the mineral-solution interface. An excess of charge at the mineral surface is

164 balanced by a region of equal but opposite charge in the adjacent solution, in an arrangement

165 often termed the electrical double layer (EDL; e.g. [25, 26]; see Fig. 1). The charge at the

166 mineral surface is balanced by a relative decrease in the concentration of co-ions (i.e. ions

167 with the same charge as the surface) and increase in the concentration of counter-ions (i.e.

168 ions with the opposite charge as the surface) in the adjacent solution. The region immediately

169 adjacent to the mineral surface is typically termed the Stern layer, and contains ions that are

170 attached to the mineral surface; the Stern layer may be further divided into the inner and outer 
171 Helmoltz layers, defined by the inner and outer Helmoltz planes (the IHP and OHP shown in

172 Fig. 1a; note the inner and outer Helmholtz layers and associated planes are also sometimes termed the inner and outer Stern layers and planes). The IHP defines the location of ions that

174 closely approach the mineral surface and are attached to surface sites (Fig. 1a). The OHP

175 defines the location of larger, typically hydrated ions that cannot enter the inner Helmholtz

176 plane but which are nevertheless attached to the mineral surface [6]

177 In most cases, the charge in the Stern layer does not exactly balance the surface charge,

178 giving rise to a 'diffuse' or 'Gouy-Chapman' layer that contains the remaining excess charge

179 in the solution required to ensure electrical neutrality of the EDL (e.g. [43]). The difference

180 between the Stern and diffuse layers is that the co- and counter-ions in the diffuse layer are

181 not attached to the mineral surface. At low ionic strength $(\lesssim 0.1 \mathrm{M})$, the ion concentration in

182 the diffuse layer decreases exponentially with distance from the OHP (Fig. 1a). The electrical

183 potential corresponding to the charge distribution within the EDL decreases linearly with

184 distance from the mineral surface through the Stern layer, although there may be a difference

185 in gradient between the inner and outer Helmholtz layers, and exponentially with distance

186 from the OHP through the diffuse layer, falling to zero in the uncharged solution (Fig. 1b).

\subsection{Electrokinetic phenomena}

Electrokinetic phenomena arise when there is a relative motion between the excess charge in the diffuse layer of the EDL and the charged surface [34]. It is typically assumed that the excess charge in the diffuse layer is mobile only beyond a plane termed the 'shear' or 'slip'

191 plane that lies a small distance away from the OHP (Fig. 1). The zeta potential is the

192 electrical potential at the shear plane. In some models of the EDL, it is assumed that the shear plane and the OHP are identical, in which case the zeta potential also represents the electrical potential at the OHP. Methods to determine the zeta potential make use of electrokinetic 
195 phenomena, most typically (1) electrophoresis, which is the mobilisation of charged particles,

196 relative to a stationary solution, under the influence of an applied electrical field, and (2)

197 streaming potential, which is the potential difference that arises when a solution is moved

198 relative to a stationary solid under the influence of an applied pressure gradient [15].

199 The electrophoretic method (termed here EPM) used to determine zeta potential is conducted on powdered samples suspended in the solution of interest. An electrical field $E$ is applied across the suspension and the resulting velocity $\boldsymbol{v}_{e}$ of the charged particles is measured with respect to the solution. The velocity is then normalized by the electrical field to yield the electrophoretic mobility $u_{e}$, which is typically treated as an isotropic quantity that can be related to the zeta potential by the Helmholtz-Smoluchowski equation for electrophoresis

$u_{e}=\frac{\varepsilon \zeta}{\mu}$

where $\varepsilon$ is the permittivity $\left(\mathrm{F} \cdot \mathrm{m}^{-1}\right)$ and $\mu$ the viscosity $(\mathrm{Pa} \cdot \mathrm{s})$ of the solution. The zeta potential obtained using the EPM is an effective value across all the suspended particles; the zeta potential of individual particles (and, indeed, between the different faces of a given

210 particle) may differ from the single value interpreted from EPM measurements.

211 The streaming potential method (termed here SPM) used to determine zeta potential is conducted using intact samples of porous materials, packed beds of particles, or surfaces

213 through, or across, which the solution of interest is caused to flow. A pressure difference $\Delta P$

214 is applied across the sample and the resulting electrical potential difference $\Delta V$ is measured.

215 The potential difference is then normalized by the pressure difference to yield the streaming 216 potential coupling coefficient, which is typically treated as an isotropic quantity that can be

217 related to the zeta potential by the Helmholtz-Smoluchowski equation for streaming potential 218 (e.g. $[\underline{17}, \underline{34}, \underline{52}])$ 
$219 C=\frac{\varepsilon \zeta}{\sigma_{s} \mu}$

220 where $\sigma_{S}$ is the electrical conductivity of the solution of interest $\left(\mathrm{S} \cdot \mathrm{m}^{-1}\right)$. When streaming

221 potential measurements are obtained in porous media, it may be necessary to use a version of equation (2) modified to account for the effect of enhanced electrical conductivity through

223 the EDL (often termed surface electrical conductivity; [49])

224

$C=\frac{\varepsilon \zeta}{\sigma_{s S} \mu F}$

225 where $\sigma_{s s}$ is the electrical conductivity of the system saturated with the solution of interest and $F$ is the so-called formation factor (dimensionless) which is defined as the ratio of the solution conductivity $\sigma_{S}$ to the system conductivity $\sigma_{S S}$ when surface electrical conductivity is negligible. The formation factor is typically measured on the system saturated with a concentrated solution with high electrical conductivity (e.g. [포 $\underline{40}, \underline{83}])$.

\section{Development of surface charge on calcite in aqueous solution}

\subsection{Effect of $\mathbf{p H}$}

233 The development of surface charge on calcite in aqueous solution is still not fully understood

$234[\underline{71}, \underline{79}, \underline{85}]$. In most metal oxides, charge development occurs when mineral surfaces sites

235 are hydrated to form amphoteric groups $>\mathrm{MeOH}$ (where Me denotes a metal ion and >

236 denotes the crystal lattice) and these react either with $\mathrm{H}^{+}$or $\mathrm{OH}^{-}$ions according to (e.g. [61,

237 77])

$238>\mathrm{MeOH}^{0}+\mathrm{OH}^{-} \Leftrightarrow>\mathrm{MeO}^{-}+\mathrm{H}_{2} \mathrm{O}$

239

$$
>\mathrm{MeOH}^{0}+\mathrm{H}^{+} \Leftrightarrow>\mathrm{MeOH}_{2}{ }^{+}
$$


240 The relative abundance of negatively and positively charged surface sites depends on the

241 relative concentration of $\mathrm{H}^{+}$and $\mathrm{OH}^{-}$in solution; these ions behave as 'potential determining

242 ions' (PDIs) for the surface. Consequently, the net surface charge depends on the solution

$243 \mathrm{pH}$. It is therefore common to see surface charge and/or zeta potential plotted as a function of

$244 \mathrm{pH}$, with the surface charge and/or zeta potential becoming more negative as the $\mathrm{pH}$ increases

245 and the deprotonation reaction (4) is favoured, and more positive as the $\mathrm{pH}$ decreases and the

246 protonation reaction (5) is favoured (e.g. $[13, \underline{32}])$. When the number of positively and

247 negatively charged surface sites exactly balances, a surface charge of zero is observed and the

248 corresponding $\mathrm{pH}$ is termed the 'point of zero charge' (PZC). A zeta potential of zero may

249 also be observed and the corresponding $\mathrm{pH}$ is termed the 'iso-electric-point' (IEP) (e.g. [34]).

250 The IEP and PZC may not coincide, for reasons discussed in more detail in the next section.

251 The surface of calcite differs from the metal oxides in several important respects. First, the

252 mineral is soluble in aqueous solution and the lattice ions $\mathrm{Ca}^{2+}$ and $\mathrm{CO}_{3}{ }^{2-}$ can be released into

253 solution or deposited on the surface depending upon the solution $\mathrm{pH}[\underline{66}, \underline{75]}$. Second,

254 atmospheric $\mathrm{CO}_{2}$ in open system experiments can dissolve into solution, affecting the $\mathrm{pH}$ and

255 the equilibrium concentrations of $\mathrm{Ca}^{2+}, \mathrm{CO}_{3}{ }^{2-}$ and $\mathrm{HCO}_{3}{ }^{-}$(e.g. [18]). Third, the hydrated

256 calcite surface contains protonated anion surface sites $>\mathrm{CO}_{3} \mathrm{H}^{0}$ as well as hydroxylated cation

257 sites $>\mathrm{CaOH}^{0}$ (e.g. [ [57, 79]). Evidence to support the presence of these sites has been

258 provided by X-ray photoelectron spectroscopic (XPS) and infrared (IR) spectroscopic

259 measurements $[\underline{56}, \underline{72}, \underline{73}]$. The protonation and deprotonation reactions at these surface sites,

260 and therefore the relative abundance of positively and negatively charged sites on the mineral

261 surface, is $\mathrm{pH}$ dependent according to the following reactions (e.g. $[\underline{29}, \underline{57}, \underline{79}])$

$262>\mathrm{CaOH}^{0}+\mathrm{OH}^{-} \Leftrightarrow>\mathrm{CaO}^{-}+\mathrm{H}_{2} \mathrm{O}$

263

$>\mathrm{CO}_{3} \mathrm{H}^{0}+\mathrm{OH}^{-} \Leftrightarrow>\mathrm{CO}_{3}{ }^{-}+\mathrm{H}_{2} \mathrm{O}$ 
265 Thus it would be expected that the surface charge, and hence the zeta potential, of calcite in 266 aqueous solution are both determined by the $\mathrm{pH}$, with $\mathrm{H}^{+}$and $\mathrm{OH}^{-}$behaving as the PDIs.

267 Numerous studies have determined the variation in zeta potential with $\mathrm{pH}$ for a variety of 268 calcite types and solution compositions (e.g. Fig. 2).

269 However, this analysis ignores the contribution of the lattice ions $\mathrm{Ca}^{2+}, \mathrm{CO}_{3}{ }^{2-}$ in solution .

270 Several experimental studies have shown that the zeta potential of calcite is independent of $271 \mathrm{pH}$ if the concentration of calcium (expressed in this paper as $\mathrm{pCa}$, where $\mathrm{p}$ represents the 272 negative logarithm) is kept constant (e.g. [12, 21, $\underline{70]}$; see Fig. 3a). Moreover, other studies

273 have demonstrated a relationship between zeta potential and pCa (e.g. [ㄴ, 12, $\underline{54}, \underline{78}]$; see Fig.

274 4), and a strong dependence between the zeta potential of calcite and the excess of $\mathrm{Ca}^{2+}$ ions 275 at the mineral surface has been observed [33]. These data show that the development of 276 charge on the calcite surface is more complex than the simple protonation and deprotonation 277 reactions that occur at the surface sites of metal oxides (e.g. [71]). Instead, the lattice ions $278 \mathrm{Ca}^{2+}$ and $\mathrm{CO}_{3}{ }^{2-}$ adsorb onto the mineral surfaces through surface complexation reactions such 279 as (e.g. $[\underline{29}, \underline{71}, \underline{79}, \underline{85}])$

$280>\mathrm{CO}_{3} \mathrm{H}^{0}+\mathrm{Ca}^{2+} \Leftrightarrow>\mathrm{CO}_{3} \mathrm{Ca}^{+}+\mathrm{H}^{+}$

281 and, in the presence of $\mathrm{CO}_{2}$, reactions such as

$282>\mathrm{CaOH}^{0}+\mathrm{CO}_{2} \Leftrightarrow>\mathrm{CaCO}_{3}{ }^{-}+\mathrm{H}^{+}$

$>\mathrm{CaOH}^{0}+\mathrm{CO}_{2} \Leftrightarrow>\mathrm{CaHCO}_{3}{ }^{0}$

284 As discussed below, the concentration dependent adsorption of these lattice ions (and other 285 potential determining ions) is the primary control on the zeta potential of calcite. 


\subsection{Potential determining ions}

287 Surface diffraction studies have revealed well-ordered water layers a few $\AA\left(=1 \times 10^{-10} \mathrm{~m}\right)$ 288 above the calcium and carbonate ions on the mineral surface $[\underline{19}, \underline{20}, \underline{24}, \underline{29}, \underline{45}]$. This is the hydrolysis plane of Stipp [71] and the 0-plane invoked in various surface complexation models (SCMs) of the calcite-water interface $([\underline{29}, \underline{85]}$; see also Fig. 1a). Protonation and

291 deprotonation reactions occur in this plane, but it does not contain the lattice ions $\mathrm{Ca}^{2+}$ and

$292 \mathrm{CO}_{3}{ }^{2-}$ or other adsorbed ion complexes. These are confined to the 1- and 2-planes (or the aand b-planes), which here we associate with the inner and outer Helmholtz planes respectively (Fig. 1a). Most SCMs include ordered water layers at the 0-plane, and the pHdependent protonation and deprotonation reactions $(6)-(8)$ that occur at the sites defining the 0-plane $[\underline{29}, \underline{71}, \underline{85}]$. However, the SCM of Heberling et al. [29] predicted that the charge at the 0 -plane is only weakly $\mathrm{pH}$ dependent. The dominant surface species are $>\mathrm{CaOH}^{0}$ and $>\mathrm{CaCO}_{3}{ }^{-}$, causing the 0 -plane to be negatively charged across the $\mathrm{pH}$ range $5.5-11$. Thus, unlike the $>\mathrm{MeOH}$ groups on oxide mineral surfaces, the calcite surface species $>\mathrm{CaOH}^{-}$and $>\mathrm{CaCO}_{3}{ }^{-}$do not determine the $\mathrm{pH}$ dependence of the zeta potential. Rather, the potential at the OHP and, hence, the zeta potential, is instead controlled by adsorption of the potentialdetermining lattice ions $\mathrm{Ca}^{2+}$ or $\mathrm{CO}_{3}{ }^{2-}$ at the 1- or 2-planes. The available evidence suggests that most of the adsorbed lattice PDIs are located at the 2-plane $[\underline{29}, \underline{85}]$.

304 Dissolution of calcite in aqueous solution is described by the following reaction:

$\mathrm{CaCO}_{3}(\mathrm{~s}) \Leftrightarrow \mathrm{Ca}^{2+}(\mathrm{aq})+\mathrm{CO}_{3}{ }^{2-}(\mathrm{aq})$

306 The equilibrium conditions are defined by the $\mathrm{pH}$, the concentration of the ionic species and, 307 in open system conditions, the partial pressure of $\mathrm{CO}_{2}\left(p \mathrm{CO}_{2}\right)$ in solution $[\underline{66}, \underline{68]}$. Moreover,

308 the concentration of lattice ion species available to adsorb onto the calcite surface is controlled by the reactions $[\underline{18}]$ : 
$311 \mathrm{HCO}_{3}^{-}(\mathrm{aq})+\mathrm{H}_{2} \mathrm{O}(\mathrm{l}) \Leftrightarrow \mathrm{H}_{2} \mathrm{CO}_{3}(\mathrm{aq})+\mathrm{OH}^{-}(\mathrm{aq})$

$312 \quad \mathrm{H}_{2} \mathrm{CO}_{3}(\mathrm{aq}) \Leftrightarrow \mathrm{H}_{2} \mathrm{O}(\mathrm{l})+\mathrm{CO}_{2}(\mathrm{~g})$

$313 \mathrm{Ca}^{2+}(\mathrm{aq})+\mathrm{H}_{2} \mathrm{O}(\mathrm{l}) \Leftrightarrow \mathrm{Ca}(\mathrm{OH})^{+}(\mathrm{aq})+\mathrm{H}^{+}(\mathrm{aq})$

$314 \mathrm{Ca}^{2+}(\mathrm{aq})+\mathrm{HCO}_{3}^{-}(\mathrm{aq}) \Leftrightarrow \mathrm{CaHCO}_{3}^{+}(\mathrm{aq})$

315 It can be seen from (12) - (17) that $\mathrm{pH}\left(\right.$ and $p \mathrm{CO}_{2}$ ) determines the $\mathrm{Ca}^{2+}$ and $\mathrm{CO}_{3}{ }^{2-}$

316 concentrations in the solution at equilibrium. Apparent trends between zeta potential and $\mathrm{pH}$

317 therefore reflect the fact that $\mathrm{pH}$ and $\mathrm{pCa}$ are directly related at fixed $p \mathrm{CO}_{2}$ (e.g. [64]). We

318 confirm this experimentally in a later section. Thus, $\mathrm{H}^{+}$is not the key PDI for the calcite

319 surface; rather, it is the lattice ion $\mathrm{Ca}^{2+}[\underline{4}, \underline{12}, \underline{21}, \underline{33}, \underline{51}, \underline{54}]$. Moreover, the PZC and IEP are 320 not closely related. In principle, the $\mathrm{PZC}$ could be defined in terms of $\mathrm{pH}$, as $\mathrm{pH}$ controls the 321 protonation and deprotonation reactions at the 0 -plane, However, in practice, the PZC is not 322 observed over the $\mathrm{pH}$ range 5.5-11 [29]. The IEP must be defined in terms of $\mathrm{pCa}$, or in terms 323 of the concentration of other PDIs for the calcite surface such as $\mathrm{Mg}^{2+}$ as discussed below.

\section{Experimental measurements of zeta potential}

326 Published measurements of zeta potential in calcite and natural carbonates in aqueous

327 solution range from $+29 \mathrm{mV}$ to $-39 \mathrm{mV}$ (Fig. 2). As discussed below, the zeta potential 328 depends on the electrolyte concentration and composition, the nature of the calcite, sample 329 preparation, experimental conditions and measurement method. However, limited reporting 330 of the nature of the samples and experimental method, especially sample history, preparation 331 and cleaning, and experimental conditions (especially $\mathrm{pH}, \mathrm{pCa}$ and $p \mathrm{CO}_{2}$ ), makes it 332 challenging to systematically compare experimental data (see Table 1 for a summary). In this 
section, we review and discuss the data published to date, and summarize the key controls on zeta potential.

\subsection{Electrolyte concentration and composition}

\subsubsection{Effect of $\mathrm{pH}$}

Many studies have reported more negative values of zeta potential with increasing $\mathrm{pH}$ (e.g. $[\underline{12}, \underline{18}, \underline{54}, \underline{78}, \underline{80])}$. For example, Thompson and Pownall [78] reported a close-to-linear relationship between zeta potential and $\mathrm{pH}$ (square data in Fig. 2a) using packed synthetic calcite and $\mathrm{NaCl}$ solution of ionic strength $5 \times 10^{-3} \mathrm{M}$ (filled squares) and $\mathrm{NaCl} / \mathrm{NaHCO}_{3}$ of

341 ionic strength $5 \times 10^{-4} \mathrm{M}$ (open squares). Similarly, Vdovic [80] obtained a linear relationship

342 between zeta potential and $\mathrm{pH}$ using natural carbonate powder samples suspended in $10^{-3} \mathrm{M}$

$343 \mathrm{NaCl}$ electrolyte (filled and open circles in Fig. 2b). However, there are numerous exceptions

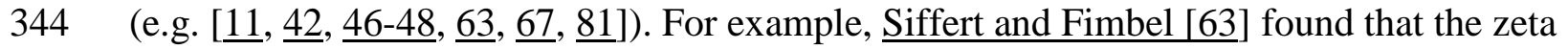
potential of synthetic calcite at equilibrium $\mathrm{pH}$ (9.1; Table 1a) could be either positive or negative, dependent on the dispersed mass. Away from the equilibrium $\mathrm{pH}$, the zeta potential

347 decreased with either increasing or decreasing $\mathrm{pH}$ (open and grey stars in Fig. 2a). Vdović 348 and Bišćan [81] (open circles in Fig. 2a) and Vdovic [80] (solid circles in Fig. 2a) observed

349 similar behaviour. The latter reported zeta potential values that changed polarity with both 350 increasing and decreasing $\mathrm{pH}$, thus apparently defining two IEPs. Mahani et al. [46] [47] reported an increasingly negative zeta potential with increasing $\mathrm{pH}$ (grey triangles, diamonds and squares in Fig. 2a-b), contrary to the trends reported above. However, as discussed in the previous section, SCMs for calcite suggest the electrical potential at the mineral surface is only weakly $\mathrm{pH}$ dependent, and experimental data have shown that the zeta potential is independent of $\mathrm{pH}$ if $\mathrm{pCa}$ is held constant (Fig. 3). These data confirm that zeta potential is 
not directly controlled by $\mathrm{pH}$, but rather by the concentration of lattice ions such as $\mathrm{Ca}^{2+}$ and other PDIs discussed below.

\subsubsection{Effect of $\mathrm{pCa}$ and $\mathrm{pCO}_{3}$}

Many authors have concluded that the principal PDIs for calcite are the lattice ions $\mathrm{Ca}^{2+}$ and $\mathrm{CO}_{3}{ }^{2-}$ (e.g. $[\underline{7}, \underline{12}, \underline{21}, \underline{33}, \underline{48}, \underline{54}, \underline{62}, \underline{63}, \underline{67}, \underline{78}, \underline{80}, \underline{81]})$. Consequently, the effect of $\mathrm{Ca}^{2+}$ on the zeta potential has been the topic of several experimental studies (e.g. [ $\underline{4}, \underline{12}, \underline{33}, \underline{54}, \underline{78}]$; see Fig. 4). The consistent observation in these studies is that decreasing pCa yields more positive zeta potential, consistent with increased adsorption of $\mathrm{Ca}^{2+}$ onto the calcite surface

(Fig. 1). However, significant differences in the magnitude and polarity of the zeta potential, in the gradient of zeta potential vs. $\mathrm{pCa}(\mathrm{d} \zeta / \mathrm{dpCa})$, and in the IEP (expressed as $\mathrm{pCa})$, have been reported (Fig. 4; Table $1 \mathrm{~b}$ ). The zeta potential varies between $+20 \mathrm{mV}$ and $-26 \mathrm{mV}$, depending on calcite type and experimental conditions. Most studies report a linear or closeto-linear relationship between zeta potential and $\mathrm{pCa}$, especially for $\mathrm{pCa}$ values close to the IEP, with the gradient $\mathrm{d} \zeta / \mathrm{dpCa}$ in the range -8 to $-15 \mathrm{mV} /$ decade (Fig. 4). A linear relationship is consistent with Nernstian behaviour of the calcite surface and suggests the electrical double layer can be reasonably described by the simple Gouy-Chapman-Grahame model close to the IEP (e.g. [34]). This model is valid only when ions other than the lattice ions show no specific adsorption at the surface. The relationship between zeta potential and

374 pCa can then be expressed as [21]:

$$
\left.\frac{d \zeta}{d p C a}\right|_{\zeta \rightarrow 0}=\frac{-2.303 \frac{k T}{z e}}{\left(1+\frac{C_{d}}{C_{S}}\right) \exp (\kappa \Delta)}
$$
charge on an electron, $\kappa$ is the Debye-Huckel reciprocal length, $C_{d}$ and $C_{s}$ are the capacitance 
per unit area of the diffuse and Stern layers respectively, $\kappa$ is the Debye-Huckel reciprocal length, and $\Delta$ is the distance of the shear plane from the Stern plane (see Fig. 1).

Zeta potential data obained at low ionic strength using the EPM method show a broadly consistent value of $\mathrm{d} \zeta / \mathrm{dpCa}$ of approximately $-13 \mathrm{mV} / \mathrm{decade}$ (Fig. 4a). Equation (18) can be used to match these data using one value of $C_{s} \sim 0.4 \mathrm{Fm}^{-2}$ and $\Delta=$ zero. For comparison,

383 Heberling et al. [29] fitted their zeta potential data using a more sophisticated SCM with $C_{s}=$ $0.45 \mathrm{Fm}^{-2}$ and $\Delta=0.33 \mathrm{~nm}$. Previous SCMs for calcite used unrealistically high $C_{s}$ values of $10-100 \mathrm{Fm}^{-2}[\underline{57}, \underline{79}]$. However, a number of recent studies have reported non-linear relationships between zeta potential and pCa (e.g. $[\underline{11}, \underline{42}, \underline{88}]$; see Fig 4b). Moreover, a wide range of IEP (expressed as $\mathrm{pCa}$ ) values have been reported (pCa of $1.92-4.5$; Table $1 \mathrm{~b}$ ). As discussed in the following sections, the variability of these results might be attributed to differences in experimental conditions, including $p \mathrm{CO}_{2}$, calcite type, measurement technique and the establishment of equilibrium. The effect of the carbonate ion on the zeta potential has received less attention than the calcium ion. The very limited data suggest that addition of

$392 \mathrm{CO}_{3}{ }^{2-}$ makes the zeta potential more negative, consistent with increased adsorption of $\mathrm{CO}_{3}{ }^{2-}$ onto the calcite surface (e.g. $[\underline{16}, \underline{51}, \underline{64]})$.

\subsubsection{Effect of $\mathrm{pMg}$ and $\mathrm{pSO}_{4}$}

The magnesium ion is also compatible with the calcite crystal structure []. It has a direct influence on geochemical processes involving natural carbonates of mixed mineralogy such as dolomite [50] and is also abundant in natural brines, yet has received much less attention than $\mathrm{Ca}^{2+}$. De Groot and Duyvis [14] suggested that $\mathrm{Ca}^{2+}$ and $\mathrm{Mg}^{2+}$ influence the zeta potential of calcite to a similar extent, but their dataset was very sparse, comprising just five measurements (two for $\mathrm{Mg}^{2+}$ and three for $\mathrm{Ca}^{2+}$ ) at high $\mathrm{pMg}$ (i.e. at very low concentration; compare filled and open triangles in Fig. 5a). Smallwood [64] obtained a similar response 
402 (compare filled and open squares in Fig. 5a) over the same concentration range. More recent

403 studies have found that the zeta potential becomes more positive with decreasing $\mathrm{pMg}([\underline{4}$,

404 11, 87]; see data represented by crosses, circles and diamonds in Fig. 5a). Alroudhan et al. [4]

405 found that $\mathrm{Mg}^{2+}$ behaved identically to $\mathrm{Ca}^{2+}$ within experimental error over a wide range of

$406 \mathrm{pCa}$ and $\mathrm{pMg}(0.4-3$; compare filled and open diamonds). Moreover, they were the first to

407 report an IEP in terms of $\mathrm{pMg}$, which was identical to $\mathrm{pCa}$ IEP within experimental error.

408 However, data showing the effect of pMg on zeta potential are still very scarce, especially at

409 low pMg.

410 A number of studies have also shown that the zeta potential is affected by the concentration

411 of $\mathrm{SO}_{4}{ }^{2-}$, observing that the zeta potential becomes more negative with decreasing $\mathrm{pSO}_{4}([4$,

$412 \underline{64}, \underline{88}$; Fig, 5b). Smallwood [64] argued that $\mathrm{SO}_{4}{ }^{2-}$ is adsorbed onto the calcite mineral

413 surface, similar to the lattice ions $\mathrm{Ca}^{2+}, \mathrm{Mg}^{2+}$ and $\mathrm{CO}_{3}{ }^{2-}$, as indicated by its ability to reverse

414 the polarity of the zeta potential (Fig. 5b). However, no other papers have reported an IEP in

415 terms of $\mathrm{pSO}_{4}$. Zhang and Austad [88] and Alroudhan et al. [4] both observed a linear

416 relationship between zeta potential and $\mathrm{pSO}_{4}$ for chalk and natural carbonate respectively, but

417 the IEP was not encountered over the concentration range investigated (Fig. 5b). Data

418 showing the effect of $\mathrm{pSO}_{4}$ on zeta potential are still scarce and do not conclusively show that

$419 \mathrm{SO}_{4}{ }^{2-}$ is a PDI for the calcite surface.

420 4.1.4. Indifferent ions and total ionic strength

421 Ions other than $\mathrm{Ca}^{2+}, \mathrm{Mg}^{2+}, \mathrm{CO}_{3}{ }^{2-}$ and $\mathrm{SO}_{4}{ }^{2-}$ are generally assumed to be indifferent to the

422 calcite mineral surface; they have little or no tendency to adsorb onto the surface. It is well

423 known that the zeta potential decreases in magnitude with increasing concentration of

424 indifferent ions such as $\mathrm{Na}^{+}, \mathrm{K}^{+}, \mathrm{Cl}^{-}$, reflecting contraction of the electrical double layer

425 (EDL; e.g. [ㅎ6, $\underline{\text { 83] }) . ~ P i e r r e ~ e t ~ a l . ~[54] ~ o b t a i n e d ~ t h e ~ s a m e ~ I E P ~(e x p r e s s e d ~ a s ~ p H) ~ o n ~ n a t u r a l ~}$ 
calcite irrespective of the concentration of $\mathrm{NaCl}\left(0,10^{-3}, 10^{-2} \mathrm{M}\right)$, indicating that $\mathrm{Na}$ and $\mathrm{Cl}$ are indifferent ions. Alroudhan et al. [4] found that the sensitivity of zeta potential to pCa (i.e. $\mathrm{d} \zeta / \mathrm{dpCa}$ ) decreased as $\mathrm{NaCl}$ concentration increased, consistent with contraction of the EDL reducing the absolute magnitude of the zeta potential (Fig. $4 \mathrm{~b}$ and Table 1b). However, they also found that the IEP (as $\mathrm{pCa}$ ) decreased with increasing $\mathrm{NaCl}$ concentration, which is not expected for indifferent ions. They suggested that at the high $\mathrm{NaCl}$ concentrations investigated (up to $2 \mathrm{M}$ ), the ability of $\mathrm{Ca}^{2+}$ ions to interact with calcite surface was reduced due to contraction of the EDL and increasing occupancy of hydrated $\mathrm{Na}^{+}$ions in the diffuse layer. However, data to support this hypothesis are scarce; few studies have obtained zeta potential measurements on calcite at high ionic strength $(>0.1 \mathrm{M})$.

\subsection{Partial pressure of $\mathrm{CO}_{2}$}

Variations in $p \mathrm{CO}_{2}$ across different experiments may be one factor that explains the variation in reported values of IEP. In closed system experiments with controlled $p \mathrm{CO}_{2}$, the very limited data available suggest that the IEP (expressed as $\mathrm{pH}$ ) decreases with increasing $p \mathrm{CO}_{2}$ $[\underline{29}, \underline{51}]$. Moreover, in open system experiments, Somasundaran and Agar [67] postulated that $\mathrm{pH}_{\text {IEP }}$ was a function of mixing time of the sample powder in solution, due to an increase in $\mathrm{CO}_{2}$ concentration in the suspension. They used this mechanism to explain the decrease in

$443 \mathrm{pH}_{\text {IEP }}$ they observed with increased mixing time. The reported $\mathrm{pH}_{\text {IEP }}$ in closed system experiments is generally higher than the value in open system experiments, consistent with reduced access to $\mathrm{CO}_{2}$ (Table 1a). The absence of, or limited access to, $\mathrm{CO}_{2}$ in closed system experiments causes a decrease in carbonic acid formation (equation 16) and in turn increases

$447 \mathrm{pH}_{\mathrm{IEP}}[\underline{66]}$.

448 The effect of $p \mathrm{CO}_{2}$ on the IEP expressed as $\mathrm{pCa}$ or $\mathrm{pMg}$ is less well understood. No studies have varied $p \mathrm{CO}_{2}$ and $\mathrm{pCa}$ or $\mathrm{pMg}$, or measured $\mathrm{pCa}$ or $\mathrm{pMg}$ whilst varying $p \mathrm{CO}_{2}$ and $\mathrm{pH}$. 
450 Studies investigating the effect of $\mathrm{pCa}$ on zeta potential have typically been conducted in 451 simple open or closed system conditions. In open system experiments, measured pCaIEP lies 452 in the range of $4.25-4.5([\underline{21}, \underline{33}, \underline{67]}$; Table $1 \mathrm{~b})$. In closed system experiments, reported 453 pCaIEP values have a wider range of $0.4-4$ and are always lower than the pCaIEP values 454 reported in open system experiments (Table $1 \mathrm{~b}$ ). The broad range of pCaIEP observed in 455 closed system experiments might be attributed to different amounts of $\mathrm{CO}_{2}$ dissolved into solution during preparation (e.g. [78]) or the type of calcite used (synthetic vs. natural; [54]; see also the next section). Recent studies of zeta potential on natural carbonates in closed system experiments consistently show the lowest values of pCaIEP in the range 0.4-0.75 [4,

$459 \underline{11}, \underline{42}$. In closed system experiments, $p \mathrm{CO}_{2}$ is fixed and, as we show later, lower $\mathrm{pCa}$ 460 corresponds to lower $\mathrm{pH}$. Lower $\mathrm{pH}$ is equivalent to higher $p \mathrm{CO}_{2}$ (e.g. [29]; see also reactions 461 14-18).

\subsection{Natural versus synthetic calcite}

The zeta potential has been measured on a wide variety of calcite samples with differing nature and origin which can be broadly subdivided into three types: (1) synthetic calcite (pure precipitated crystalline calcium carbonate), (2) Iceland spar (pure crystalline calcite of natural origin) and (3) natural carbonate (composed mostly of calcite with inorganic material or organic matter). Data for Iceland spar and synthetic calcite show both positive and negative values for a given value of pH (Fig. 2; Table 1a) and pCa (Fig. 4a, Table 1b). The broad range of zeta potential values observed for a given $\mathrm{pH}$ may reflect differences in the concentrations of PDIs such as $\mathrm{Ca}^{2+}$ and $\mathrm{Mg}^{2+}$ that were not measured in the experiments;

471 they may also reflect differences in $p \mathrm{CO}_{2}$ or, as discussed below, the equilibration method.

472 The range of values observed for a given $\mathrm{pCa}$ is more difficult to explain, but most likely 
473 reflects differences in $p \mathrm{CO}_{2}$ or the equilibration method; it may also reflect differences in the concentrations of other PDIs such as $\mathrm{Mg}^{2+}$ and $\mathrm{SO}_{4}{ }^{2-}$.

475 Data for natural calcite and carbonate rocks show less variability, with most studies returning negative values of zeta potential irrespective of $\mathrm{pH}$; the few positive values in Fig. 2 were mostly obtained using natural brines rich in $\mathrm{Ca}^{2+}$ where, as we show later, positive zeta potential is expected. Berlin and Khabakov [7] reported negative zeta potentials on 115 natural carbonate samples irrespective of $\mathrm{pH}$. Likewise, with relatively few exceptions, the zeta potential on natural samples has been found to be negative at high $\mathrm{pCa}$ and positive at low pCa, although there is some variability in $\mathrm{pCa}_{\mathrm{IEP}}$ as discussed above (Fig. 4b). It has been suggested that the more negative zeta potentials typically observed in natural carbonates are due to the presence of organic matter incorporated in their structure during formation [ $\underline{80}$,

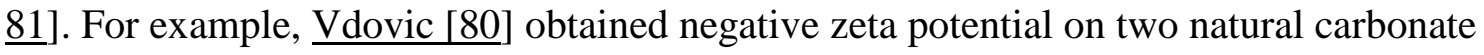
samples over the whole $\mathrm{pH}$ range (filled and open circles in Fig. 2b); however, they obtained a positive zeta potential on synthetic calcite (filled circles in Fig. 2a). Likewise, Cicerone et al. [12] found that natural (biogenetic) calcite (open triangles in Fig. 2b) bore a more negative zeta potential than pure calcite (filled triangles in Fig. 2a). However, the role of organic material in controlling the zeta potential of natural carbonates remains poorly understood.

\subsection{Measurement technique}

Measurements of zeta potential generally use either the electrophoretic mobility (EPM) method or the streaming potential method (SPM) introduced earlier. There appears to be no systematic difference in the reported IEP and both techniques have yielded a linear Nernstian

494 relationship between zeta potential and pCa (Table 1; Fig. 4). However, only Alroudhan et al.

495 [4] have compared the two techniques on the same (natural) calcite samples and electrolytes.

496 Using the EPM method and natural (powdered) carbonate suspended in $0.05 \mathrm{M} \mathrm{NaCl}$ 
497 electrolyte, they obtained a linear regression between zeta potential and pCa with a gradient 498 of $-10.45 \mathrm{mV} / \mathrm{decade}$, which they fitted using equation (18) and values of $C_{s}=1.13 \mathrm{Fm}^{-2}$ and

$499 \Delta=0$. Note that this gradient is lower than obtained in previous studies on similar samples

500 (as discussed above; see also Fig. 4a) and the value of $C_{s}$ used to obtain a match is higher.

501 However, Alroudhan et al. [4] investigated electrolytes of higher total ionic strength than previous studies and their results suggest that $C_{s}$ increases with increasing total ionic strength.

503 Using the SPM method and the same natural (intact) carbonates and electrolytes, $\underline{\text { Alroudhan }}$

504 et al. [4] obtained the same IEP (expressed as pCa) within experimental error, but the 505 gradient of a linear regression through the data was approximately two times smaller at -5.10 $\mathrm{mV} / \mathrm{decade}$. They argued that the shear plane is further away from the mineral surface in

507 intact natural samples as opposed to powdered samples owing to the complex topology of the 508 pore-space (see also Vernhet et al. [82] for similar comparisons on other materials), and fitted 509 the SPM data using equation (18) with the same value of $C_{s}$ but a higher value of

$510 \Delta=0.245 \mathrm{~nm}$. Thus differences in the observed sensitivity of zeta potential to pCa (or the

511 concentration of other PDIs) may reflect differences in the measurement technique and/or the 512 nature of the sample (intact versus powdered).

\section{4.5. Establishment of equilibrium between sample and electrolyte}

514 Most studies equilibrate the calcite-electrolyte systems of interest for 48 hours or less prior to

515 measuring the zeta potential (Table 1). Only a few studies have investigated longer

516 equilibration times (e.g. $[\underline{4}, \underline{12}, \underline{29}, \underline{33}, \underline{67]})$. Some studies have reported equilibration times

517 of an hour or less (e.g. $[\underline{11}, \underline{18}, \underline{48}, \underline{58}, \underline{60]})$. Heberling et al. [29] investigated the difference

518 between equilibrium and non-equilibrium measurements. In a study using natural intact

519 limestone, Alroudhan et al. [4] found that the equilibrium $\mathrm{pH}$ in open system conditions was 520 reached after 100 hours and sometimes more, and that it could take a factor of 2-3 times 
521 longer to reach the equilibrium pCa (e.g. Fig. 6). Thus there is the risk that short equilibration times may not yield a stable equilibrium in $\mathrm{pH}$ and/or $\mathrm{pCa}$, which will affect the measured zeta potential. Moreover, the equilibrium $\mathrm{pH}$ may be achieved before the equilibrium $\mathrm{pCa}$, so assessing equilibration based on $\mathrm{pH}$ measurements alone may not be sufficient. As discussed above, values of the zeta potential on calcite are primarily controlled by $\mathrm{pCa}$ and the concentration of other PDIs such as $\mathrm{Mg}^{2+}$, rather than $\mathrm{pH}$. Therefore, it is important to ensure that equilibrium in the concentration of these PDIs has been reached prior to taking measurements. Inconsistent values of zeta potential obtained in some studies may reflect a lack of equilibration.

\subsection{Summary of published zeta potential data on calcite}

531 Published measurements to date have typically observed linear, Nernstian relationships

532 between zeta potential and $\mathrm{pH}$, and between zeta potential and $\mathrm{pCa}$, especially for values of

$533 \mathrm{pH}$ and $\mathrm{pCa}$ close to the IEP. However, despite the clear relationship between zeta potential and $\mathrm{pH}$ obtained in such studies, the proton is not a PDI for calcite, as varying $\mathrm{pH}$ whilst holding pCa constant yields constant zeta potential within experimental error. Moreover, surface complexation models suggest that the calcite surface remains negatively charged over

537 the $\mathrm{pH}$ range 5.5-11, and the surface charge is only weakly dependent on $\mathrm{pH}$. The zeta

538 potential is controlled instead by the concentration-dependent adsorption of lattice ions $\mathrm{Ca}^{2+}$ 539 and $\mathrm{CO}_{3}{ }^{2-}$ in the Stern layer, and also by the adsorption of $\mathrm{Mg}^{2+}$ ions, although experimental

540 data testing the effect of $\mathrm{pMg}$ are scarce. The few data available suggests that $\mathrm{Mg}^{2+}$ behaves

541 identically to $\mathrm{Ca}^{2+}$ within experimental error. The $\mathrm{SO}_{4}{ }^{2-}$ ion has also been suggested as a PDI

542 for the calcite surface, but the evidence is not conclusive.

543 A wide range of values of IEP (expressed as pCa) have been observed, depending upon

544 whether the sample is natural or artificial, whether the experiments are open or closed to 
atmospheric $\mathrm{CO}_{2}$, and the approach taken to equilibrate the sample and electrolyte prior to obtaining data. In open system experiments, measured pCaIEP lies in the range of $4.25-4.5$,

547 but in closed system experiments, pCaIEP has a wider range of 0.4 - 4 and is always lower

548 than values reported in open system experiments. Natural samples generally show more

549 negative values of zeta potential than artificial samples for a given value of $\mathrm{pCa}$, and

550 therefore yield lower values of $\mathrm{pCa}_{\mathrm{IEP}}$. Recent studies of zeta potential on natural carbonates

551 in closed system experiments consistently show the lowest values of pCaIEP in the range 0.45520.75.

5. Measurements of zeta potential on natural limestone rock samples: Impact of rock type, PDI concentration and ionic strength

556

557

558

559

560

561

562

563

564

As outlined in the previous section, few studies have reported measurements of zeta potential in carbonates at conditions relevant to natural subsurface systems. Most have explored synthetic calcite and dilute electrolytes with much lower total ionic strength and PDI concentration than subsurface brines. Moreover, most did not employ an experimental method that established equilibrium conditions of $\mathrm{pH}, p \mathrm{CO}_{2}$ and $\mathrm{PDI}$ concentration relevant to subsurface carbonates. The aim of this section is to report new measurements of zeta potential relevant to natural systems, with a particular emphasis on determining (i) the relationship between $\mathrm{pH}$ and pPDI $\left(\mathrm{Ca}^{2+}\right.$ and $\left.\mathrm{Mg}^{2+}\right)$ in equilibrated calcite-electrolyte systems, given that no studies have measured $\mathrm{pPDI}$ whilst varying $\mathrm{pH}$, or reported $\mathrm{pH}$ whilst varying pPDI, (ii) the effect of high concentrations of indifferent ions such as $\mathrm{NaCl}$ on the sensitivity of the zeta potential to pPDI, (iii) whether $\mathrm{SO}_{4}{ }^{2-}$ is a PDI for the calcite mineral, and (iv) how the zeta potential is affected by pPDI over the concentration range found in natural brines. Only Alroudhan et al. [4] have probed this parameter space, and they used 
only a single rock type. Here we investigate two further natural carbonates to determine whether the results are rock-type specific.

571 We used the SPM described by Jackson and co-workers $[\underline{4}, \underline{35}, \underline{38}, \underline{39}, \underline{83}]$ to measure the 572 zeta potential. The SPM is applicable to intact natural samples, can be used to measure zeta 573 potential at high ionic strength (> $2 \mathrm{M})$, and can also be used during multiphase flow and at 574 elevated temperature $[\underline{1}, \underline{2}, \underline{4}, \underline{35}, \underline{37}, \underline{38}, \underline{83}, \underline{84}]$. The SPM measurements were complemented by chemical analysis of the effluent electrolyte, to monitor adsorption/desorption of ionic species during the experiments. The results have broad application to earth engineering processes such as hydrocarbon production and geological

$578 \mathrm{CO}_{2}$ storage, and we use them here to investigate the mechanisms that underpin the use of controlled injection brine compositions during waterflooding of hydrocarbon reservoirs [41, $\underline{74}, \underline{86}, \underline{87]}$.

\subsection{Materials and Experimental Method}

We used two intact natural carbonate core samples that in x-ray diffraction (XRD) analysis appear to be identical pure limestone that differ only in age and permeability (Table 2). Also shown in Table 2 are the properties of the Portland Limestone samples investigated by Alroudhan et al. [4], which we compare to the new results presented here when possible. Samples were cleaned using the enhanced method reported in Alroudhan et al. [4]. The brines used were synthetic solutions of reagent-grade $\mathrm{NaCl}, \mathrm{CaCl}_{2} .2 \mathrm{H}_{2} \mathrm{O}, \mathrm{Na}_{2} \mathrm{SO}_{4}$ and $\mathrm{MgCl}_{2} .6 \mathrm{H}_{2} \mathrm{O}$ salts (Sigma Aldrich, UK) in deionized water (DIW) from a filtered system with electrical conductivity below $1 \mu \mathrm{S} / \mathrm{cm}$.

The equilibrium condition of carbonate/electrolyte/ $\mathrm{CO}_{2}$ discussed previously (see Fig. 6) was

591 replicated following the approach of Alroudhan et al. [4]. $\mathrm{NaCl}$ electrolytes of varying

592 concentrations $(0.05-5 \mathrm{M})$ were equilibrated by leaving offcuts of the tested carbonate 
samples in a closed beaker containing an air gap to allow $\mathrm{CO}_{2}$ to dissolve into solution, replicating the open-system conditions of carbonate deposition [ㄷ]. The $\mathrm{pH}$ of the $\mathrm{NaCl}$ electrolyte (measured using a Five-Go Mettler-Toledo $\mathrm{pH}$ meter with their 3-in-1 pH electrode LE438, implementing where necessary the manufacturer's recommended calibration and correction procedures at high ionic strength) and $\mathrm{Ca}^{2+}$ concentration (measured using Inductively Coupled Plasma Atomic Emission Spectroscopy, ICP-AES) were monitored until both reached constant value within experimental error. The equilibrium $\mathrm{pH}$ was found to be $8.3 \pm 0.1$ for both Ketton and Estaillades, in agreement with $\underline{\text { Alroudhan et }}$ al. [4], and the equilibrium pCa was found to be $2.8 \pm 0.1$ and $3.1 \pm 0.1$, respectively. The equilibrated $\mathrm{NaCl}$ solutions were termed $\mathrm{NaCl}-\mathrm{EQ}$ and were then used directly in zeta potential measurements, or were modified by addition of $\mathrm{Ca}^{2+}, \mathrm{Mg}^{2+}$ and/or $\mathrm{SO}_{4}{ }^{2-}$.

604 The apparatus used to measure zeta potential in our SPM is closed to the atmosphere, and the second stage of equilibration prior to measuring the zeta potential was to ensure equilibrium between the electrolyte of interest (NaCl-EQ with or without the addition of $\mathrm{Ca}^{2+}, \mathrm{Mg}^{2+}$ or

$607 \mathrm{SO}_{4}{ }^{2-}$ ) and the rock sample at the closed-system conditions pertaining to a rock-brine system 608 at depth. The rock sample was pre-saturated with the selected electrolyte at open-system conditions and then confined in the core holder at closed-system conditions, and the electrolyte was pumped through the sample from the (closed) inlet reservoir to the (closed)

611 outlet reservoir and back again. The repeated flow of the electrolyte through the sample at 612 closed system conditions mimics migration of the electrolyte into the carbonate rock at depth.

613 At regular intervals, the electrical conductivity and $\mathrm{pH}$ of the electrolyte in the reservoirs was 614 measured, and equilibrium was assumed to have been reached when the conductivity and $\mathrm{pH}$ 615 of the electrolyte in each reservoir differed by $<5 \%$.

616 Electrolyte samples were analysed before and after the SPM experiments for key ions $\left(\mathrm{Na}^{+}\right.$, $617 \mathrm{Ca}^{2+}, \mathrm{Mg}^{2+}$ and $\mathrm{SO}_{4}{ }^{2-}$ ). We used ICP-AES for cations and Ion Chromatography (IC) for 
anions with appropriate dilution where necessary. The ICP-EAS analysis was carried out in

619 the Analytical Chemistry Laboratory at the Natural History Museum London; the IC analysis

620 was carried out in the TOTAL Laboratory for Reservoir Physics at Imperial College London.

621 Instrument error was determined by using certified solutions containing $\mathrm{Na}^{+}, \mathrm{Ca}^{2+}, \mathrm{Mg}^{2+}$ and

$622 \mathrm{SO}_{4}{ }^{2-}$ and the error calculated from the standard deviation of five repeat measurements of

623 each solution.

\section{5.2. Design of experiments}

625 We conducted two sets of experiments. In the first, the sensitivity of zeta potential to variations in $\mathrm{NaCl}$ concentration was tested using the equilibrated $\mathrm{NaCl}-\mathrm{EQ}$ solutions described above. In these experiments, the concentration of $\mathrm{Ca}^{2+}, \mathrm{Mg}^{2+}$ and $\mathrm{SO}_{4}{ }^{2-}$ was dictated by the equilibration process; no additional salts containing these ionic species were added to the NaCl-EQ solutions. In the second, the sensitivity of the zeta potential to

630 variations in $\mathrm{Ca}^{2+}, \mathrm{Mg}^{2+}$ and $\mathrm{SO}_{4}{ }^{2-}$ concentration was tested by adding salts containing these ionic species over the range found in natural brines $\left(0.007-0.42 \mathrm{M}\right.$ for $\mathrm{Ca}^{2+}$ and $\mathrm{Mg}^{2+} ; 0.002$ $-0.096 \mathrm{M}$ for $\left.\mathrm{SO}_{4}{ }^{2-}\right)$ to $\mathrm{NaCl}-\mathrm{EQ}$ solutions of two different ionic strengths $(0.5 \mathrm{M}$ and $2 \mathrm{M})$. The $0.5 \mathrm{M} \mathrm{NaCl}$ concentration represents seawater and is similar to the ' $\mathrm{ZP}$ brine' of $\underline{\mathrm{Zhang}}$ and Austad [88] and Zhang et al. [87], allowing direct comparison of results. The $2 \mathrm{M} \mathrm{NaCl}$ concentration represents the saline brines found in many saline aquifers and hydrocarbon reservoirs (e.g. [59]). In the second set of experiments, we investigated for the first time the relationship between $\mathrm{pCa}$ (or $\mathrm{pMg}$ ) and $\mathrm{pH}$. Note that in the experiments reported here, precipitation of salts such as $\mathrm{CaSO}_{4}$ and $\mathrm{MgCO}_{3}$ in the pore-space was prevented because each ion of interest $\left(\mathrm{Ca}^{2+}, \mathrm{Mg}^{2+}\right.$ or $\left.\mathrm{SO}_{4}{ }^{2-}\right)$ was added to $\mathrm{NaCl}-\mathrm{EQ}$ electrolyte containing only trace or zero concentration of cations or anions other than $\mathrm{Na}^{+}$and $\mathrm{Cl}^{-}$. 
642 Streaming potentials were measured using the paired-stabilization method of Vinogradov et

643 al. [83] and typical raw results are shown in Fig. 7b,c. The stabilized voltage was plotted

644 against the stabilized pressure difference across the sample for four different flow rates and a

645 linear regression through the data yielded the streaming potential coupling coefficient and,

646 via equation (3), the zeta potential. The uncertainty in the streaming potential coupling

647 coefficient arising from the range of linear regressions that can be forced through the

648 stabilized voltage and pressure data was used to determine the associated experimental error

649 in zeta potential reported in the following sections.

650 5.3.1. Impact of $\mathrm{Na}^{+}$concentration on zeta potential

651 We begin by reporting the effect of $\mathrm{NaCl}$ concentration on zeta potential. When possible, we

652 compare results from the Ketton and Estaillades samples investigated here against the

653 Portland sample studied by Alroudhan et al. [4]. Fig. 7a shows the zeta potential as a function

654 of $\mathrm{NaCl}$ concentration (in $\mathrm{M}$ ) on a log-log scale for all three natural carbonate samples. A

655 linear regression can be fitted to the data from each rock type (with $R^{2}>0.97$ ) but the

656 gradient of the regression differs between samples. The Estaillades sample (filled triangles)

657 shows the highest gradient $(-8.08 \pm 0.52 \mathrm{mV} / \mathrm{M})$ and the Portland sample (filled grey

658 diamonds) the lowest gradient $(-5.08 \pm 0.47 \mathrm{mV} / \mathrm{M})$ with the Ketton sample (filled squares)

659 in between $(-6.11 \pm 0.49 \mathrm{mV} / \mathrm{M})$.

660 At low $\mathrm{NaCl}$ concentration $(<0.1 \mathrm{M})$ the zeta potential is negative and identical (within

661 experimental error) for all three samples. However, as $\mathrm{NaCl}$ concentration increases, the zeta

662 potentials diverge with $\left|\zeta_{\text {Portland }}\right|>\left|\zeta_{\text {Ketton }}\right|>\left|\zeta_{\text {Estaillades }}\right|$. Moreover, the zeta potential of the

663 Estaillades samples becomes positive at $\mathrm{NaCl}$ concentration $>1.9 \mathrm{M}$, whereas the other two

664 samples yield negative zeta potential over the entire concentration range investigated. The 
665 inset plots $7 \mathrm{~b}$ and $7 \mathrm{c}$ show there is no ambiguity in the polarity of the zeta potential: for a

$666 \mathrm{NaCl}$ concentration of $1.8 \mathrm{M}$ the streaming potential, and hence zeta potential, of the

667 Estaillades sample is clearly negative $(-0.56 \mathrm{mV} \pm 0.33)$ and becomes positive $(0.72 \mathrm{mV} \pm$

6680.33 ) for a $\mathrm{NaCl}$ concentration of $2 \mathrm{M}$. As discussed above, $\mathrm{Na}^{+}$and $\mathrm{Cl}^{-}$are believed to be

669 indifferent ions to the calcite mineral surface and their presence is expected to affect the

670 magnitude, but not the polarity, of the zeta potential (e.g. [23$, \underline{34}, \underline{54]})$.

671 5.3.2. Impact of $\mathrm{pCa}^{2+}, \mathrm{pMg}^{2+}$ and $\mathrm{pSO}_{4}{ }^{2-}$ on zeta potential

672 We next investigate the impact of the concentration of the confirmed and suggested PDIs

$673 \mathrm{Ca}^{2+}, \mathrm{Mg}^{2+}$ and $\mathrm{SO}_{4}{ }^{2-}$ on the zeta potential. We plot concentration as pPDI and, in all cases,

674 the highest pPDI values reported correspond to the equilibrium concentrations in the $\mathrm{NaCl}-$

675 EQ electrolytes. Fig. 8a shows the impact of $\mathrm{pCa}$ and $\mathrm{pMg}$ on the zeta potential of

676 Estaillades, and the impact of $\mathrm{pCa}$ on the zeta potential of Ketton, for two different $\mathrm{NaCl}$

677 concentrations $(0.5 \mathrm{M}$ and $2 \mathrm{M})$ typical of subsurface brines; also shown for comparison are

678 the data from Portland obtained by Alroudhan et al. [4]. We find that the zeta potential

679 consistently becomes more positive with decreasing $\mathrm{pCa}$ or $\mathrm{pMg}$. Moreover, the response to

$680 \mathrm{pCa}$ and $\mathrm{pMg}$ is identical within experimental error for the Estaillades carbonate, irrespective

681 of $\mathrm{NaCl}$ concentration. Alroudhan et al. [4] also found that $\mathrm{pCa}$ and $\mathrm{pMg}$ behaved identically

682 for the Portland carbonate, although they investigated a lower $\mathrm{NaCl}$ concentration of $0.05 \mathrm{M}$

683 and their data are not shown here.

684 The response of the zeta potential to $\mathrm{pCa}$ or $\mathrm{pMg}$ is generally sample specific and depends on 685 the $\mathrm{NaCl}$ concentration. At the lower $(0.5 \mathrm{M}) \mathrm{NaCl}$ concentration investigated here, Ketton 686 and Portland exhibit identical behaviour over the entire pCa range investigated: a linear

687 regression provides an excellent fit to the data $\left(R^{2}>0.98\right)$ with a gradient of $-4.5 \pm 0.25$

$688 \mathrm{mV} /$ decade and an $\mathrm{pCa}$ IEP of $0.5 \pm 0.03$. A linear regression with the same gradient also 
provides an excellent fit to the Estaillades data at the lower $\mathrm{NaCl}$ concentration investigated; however, $\mathrm{pCa}$ IEP is much higher at $1.7 \pm 0.03$. Nernstian (linear) behaviour is therefore always observed at the lower $\mathrm{NaCl}$ concentration over the entire $\mathrm{pCa}$ and $\mathrm{pMg}$ range investigated,

692 but the IEP is different for the Estaillades sample. Fitting the Gouy-Chapman-Grahame

693 model (equation 18) to these data yields $C_{s}=1 \mathrm{Fm}^{-2}$ and $\Delta=0.245 \mathrm{~nm}$, similar to the values

694 obtained for Portland carbonate by Alroudhan et al. [4] and within the range used by

695 Heberling et al. [29].

696 At the higher $(2 \mathrm{M}) \mathrm{NaCl}$ concentration investigated here, the Ketton carbonate continues to 697 show linear, Nernstian behaviour close to the IEP with a gradient and IEP identical to that obtained using $0.5 \mathrm{M} \mathrm{NaCl}$ within experimental error, but the behaviour becomes non-linear (non-Nernstian) away from the IEP at high pCa. The Portland sample shows linear, Nernstian behaviour over the entire $\mathrm{pCa}$ range investigated with an identical IEP within experimental error but a lower gradient of $-2.86 \pm 0.25 \mathrm{mV} /$ decade. The Estaillades carbonate exhibits notably different behaviour, with the zeta potential remaining positive over the entire $\mathrm{pCa} / \mathrm{pMg}$ range investigated, and non-Nernstian behaviour at high pCa. Cicerone et al. [12] also observed non-Nernstian behavior far from IEP and related that to variations in the Stern layer capacitance or to breakdown of the Gouy-Chapman-Grahame model.

Increasing $\mathrm{pSO}_{4}$ consistently yields more positive zeta potential, although the sensitivity is much less than that observed when varying pCa or pMg (Fig. 8b). A linear regression yields a good fit to the data at the lower $\mathrm{NaCl}$ concentration investigated here $\left(\mathrm{R}^{2}>0.92\right)$ with a consistent gradient of $0.84 \pm 0.2 \mathrm{mV} /$ decade for both the Estaillades and Portland carbonates.

710 A key feature is that an apparent IEP of $\mathrm{pSO}_{4}=1.59 \pm 0.2$ is observed for the Estaillades sample in $2 \mathrm{M} \mathrm{NaCl}$ electrolyte. It is also notable that the difference in absolute zeta potential between the different carbonate samples observed in Fig. 7 persists in Fig. 8, with $\left|\zeta_{\text {Portland }}\right|>$ 
715 Fig. 9a shows the relationship between the equilibrium $\mathrm{pH}$ and $\mathrm{pCa}$ or $\mathrm{pMg}$ obtained across all of the experiments reported here. A linear regression provides an excellent fit to the data

$717\left(\mathrm{R}^{2}>0.98\right)$ with a gradient of 0.81 , irrespective of $\mathrm{NaCl}$ concentration, rock sample or PDI

718 varied, although the value of $\mathrm{pH}$ is consistently higher in the experiments varying $\mathrm{pMg}$ as

719 compared to those varying $\mathrm{pCa}$. These experimental data confirm that equilibrium $\mathrm{pH}$ and

720 pPDI are related at fixed $p \mathrm{CO}_{2}$ via equations (14) - (18). It is possible to plot the data obtained here against $\mathrm{pH}$ and obtain an apparently strong correlation (Fig. 9b) even though $\mathrm{pCa}$ and $\mathrm{pMg}$ were the controlled parameters. The relation between $\mathrm{pH}$ and $\mathrm{pCa}$ or $\mathrm{pMg}$ obtained here is consistent with model predictions (e.g. PHREEQC; [55]). However, it has not previously been demonstrated in properly equilibrated experiments where zeta potential was also measured, or over such a wide range of $\mathrm{pCa}$.

\subsection{Discussion}

\subsubsection{Impact of indifferent ions}

728 The results presented here show a clear relationship between the concentration of indifferent ions $\mathrm{Na}^{+}$and $\mathrm{Cl}^{-}$and the zeta potential on natural carbonate (Fig. 7). Such a relationship is expected owing to collapse of the double layer with increasing ionic strength, but if double layer collapse is the only control on zeta potential, then the zeta potential should be proportional to the logarithm of $\mathrm{NaCl}$ concentration (as a proxy for ionic strength; e.g. [27]). Consequently, the dependence of zeta potential on $\mathrm{NaCl}$ concentration observed in Fig. 7 cannot result only from double layer collapse. Fig. 10 shows the equilibrium $\mathrm{pCa}$ and $\mathrm{pSO}_{4}$ as a function of $\mathrm{NaCl}$ concentration, corresponding to the zeta potential data shown in Fig. 7.

736 Note that $\mathrm{pMg}$ remained large and approximately constant at $4.19 \pm 0.03$ for all samples 
737

738

739

740

741

742

743

744

745

746

747

748

749

750

751

752

753

754

755

756

757

758

759

760

irrespective of $\mathrm{NaCl}$ concentration (i.e. the $\mathrm{Mg}^{2+}$ concentration is small). pCa generally decreases with increasing $\mathrm{NaCl}$ concentration (Fig. 10a); hence, given that zeta potential becomes more positive with decreasing $\mathrm{pCa}$, these data are consistent with the more positive zeta potential observed with increasing $\mathrm{NaCl}$ concentration in Fig. 7. However, the sensitivity decreases at high $\mathrm{NaCl}$ concentration, moreover, these data do not explain the polarity change of the zeta potential observed for the Estaillades carbonate. This remains a curious feature of the new data obtained here and may suggest that $\mathrm{Na}^{+}$is not in fact an indifferent ion to the calcite surface in some circumstances, as suggested by $[\underline{29}, \underline{44}]$.

\subsubsection{Impact of carbonate type}

The results obtained here also show that natural carbonate samples that appear identical in XRD display different zeta potential behaviour. The Estaillades carbonate, in particular, behaves differently to the Ketton and Portland carbonates, showing inversion of the zeta potential with increasing $\mathrm{NaCl}$ concentration (Fig. 7), higher values of $\mathrm{pCa} \mathrm{IIEP}_{\mathrm{I}} / \mathrm{pMg}_{\mathrm{IEP}}$ compared to Ketton and Portland (Fig. 8a), and also an apparent IEP expressed as $\mathrm{pSO}_{4}$ (Fig. 8b). The Estaillades carbonate released the least $\mathrm{SO}_{4}{ }^{2-}$ during equilibration with the $\mathrm{NaCl}$ solutions, while the Portland sample released the most $\mathrm{SO}_{4}{ }^{2-}$ (Fig. 10b), consistent with the observed differences in zeta potential $\left(\zeta_{\text {Portland }}>\zeta_{\text {Ketton }}>\zeta_{\text {Estaillades }}\right)$ in Figs. 7 and 8 . We hypothesize that Ketton and Portland contain undetected sources of $\mathrm{SO}_{4}{ }^{2-}$ which affects the pristine zeta potential, yielding more negative values and lower $\mathrm{pCa}_{\mathrm{IEP}}$ than Estaillades. Natural carbonates can incorporate a number of different minerals, including clays, organic matter, apatite, anhydrite or quartz, that yield a more negative zeta potential than pure calcite $[\underline{12}, \underline{65}, \underline{66}]$. Our data therefore suggest that the behaviour of the natural Ketton and Portland carbonate samples investigated here is affected by the presence of impurities such as anhydrite. In contrast, the behaviour of the Estaillades sample is consistent with the ionic 
strength effect as calculated with a Pitzer model for a calcite-atmospheric $\mathrm{CO}_{2}$ equilibrium solution [55].

763 The contrasting behaviour of Estaillades carbonate may also reflect differences in the affinity

764 of $\mathrm{Ca}^{2+}$ and $\mathrm{CO}_{3}{ }^{2-}$ for the mineral surface. Pierre et al. [54] suggested that the IEP is governed 765 by the relative magnitude of the equilibrium constants $K_{\mathrm{Ca}}$ and $K_{\mathrm{CO} 3}$ governing the adsorption of $\mathrm{Ca}^{2+}$ and $\mathrm{CO}_{3}{ }^{2-}$ ions on the calcite mineral surface. The IEP shifts to lower pCa if $K_{\mathrm{CO} 3}>$ $K_{\mathrm{Ca}}$; that is, if the calcite surfaces show greater affinity for $\mathrm{CO}_{3}{ }^{2-}$ than $\mathrm{Ca}^{2+}$. Pierre et al. [54] found the IEP differed for synthetic and natural calcite and argued that this reflected the differing affinity for $\mathrm{Ca}$ and $\mathrm{CO}_{3}$. The Pierre et al. model suggests that the Estaillades carbonate investigated here has a much lower affinity to $\mathrm{CO}_{3}{ }^{2-}$ (and greater affinity to $\mathrm{Ca}^{2+}$ ) than the Ketton and Portland carbonates at equilibrium conditions.

\subsection{3. $\mathrm{SO}_{4}$ as a PDI for calcite}

773 Several studies have suggested that the $\mathrm{SO}_{4}{ }^{2-}$ ion is a PDI for calcite (e.g. [ $\left.[\underline{64}, \underline{88}]\right)$. However,

774 these studies did not measure changes in $\mathrm{pCa}$ or $\mathrm{pMg}$ in response to changing $\mathrm{pSO}_{4}$. Here, we 775 find that $\mathrm{SO}_{4}{ }^{2-}$ has only a minor influence on the zeta potential of natural carbonate (Fig. $8 \mathrm{~b}$ ). 776 At low ionic strength $(0.5 \mathrm{M} \mathrm{NaCl})$, the change in $\mathrm{pSO}_{4}$ correlates to a change in $\mathrm{pCa}$ (Fig.

777 11a) which can explain the change in zeta potential (Fig. 11b). We observe a linear

778 relationship between zeta potential and $\mathrm{pCa}$ with a similar gradient $\left(5.1 \mathrm{mV} / \mathrm{decade} ; \mathrm{R}^{2}>0.85\right)$

779 to that obtained in the experiments where $\mathrm{pCa}$ was varied $(4.5 \mathrm{mV} /$ decade). However, at high 780 ionic strength $(2 \mathrm{M} \mathrm{NaCl}), \mathrm{pCa}$ is relatively insensitive to $\mathrm{pSO}_{4}$ (Fig. 11a), yet the zeta 781 potential still varies in response to changing $\mathrm{pSO}_{4}$ and changes polarity from positive to negative. Moreover, there is not a clear correlation between pCa and zeta potential (Fig. 11b).

783 It may be that small changes in $\mathrm{pCa}, \mathrm{pMg}$ and even $\mathrm{pNa}$ within experimental error all

784 contribute to the observed change in zeta potential, as it is only c. $1 \mathrm{mV}$ in magnitude and 
785 close to the IEP. Geochemical modelling beyond the scope of the paper is required to test this hypothesis.

788 5.1.4. Implications for wettability alteration and hydrocarbon recovery in carbonate reservoirs

790

In carbonate rock formations with positively charged mineral surfaces, an attractive electrostatic force will act between the mineral surfaces and the negatively charged oil-brine interface, promoting wettability alteration to oil-wet conditions (e.g. $[10, \underline{11}])$. Several studies have suggested that carbonate rocks saturated with natural brines rich in $\mathrm{Ca}^{2+}$ and $\mathrm{Mg}^{2+}$ ions have positively charged mineral surfaces so are likely to be oil-wet (e.g. $[\underline{4}, \underline{11}, \underline{38}, \underline{46}, \underline{47]})$. The wettability of a reservoir plays a key role in the efficiency with which the oil can be produced. However, we find here considerable variability in the IEP expressed as $\mathrm{pCa}$, suggesting that some carbonates will be positively charged in contact with natural brines, and others will not. The SPM used here is a suitable technique to determine the zeta potential of intact reservoir rock samples saturated with natural brine (e.g. [38]).

800 In many reservoirs, water is injected to maintain the pressure and displace oil towards

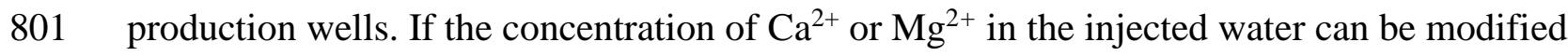

802 to fall below the IEP, either selectively or by bulk dilution in a process termed 'controlled

803 salinity waterflooding' (CSW), the zeta potential will change polarity from positive to

804 negative. The polarity change leads to electrostatic repulsion between the mineral surfaces

805 and the negatively charged oil-brine interface. This may promote wettability alteration to 806 water-wet conditions, releasing previously adsorbed oil from the calcite mineral surfaces and 807 therefore improving oil recovery (e.g. [47]). 

reduction in Ca concentration is required to change the polarity of calcite (Table 1). However, our results suggest that far less dilution may be required in some natural carbonates (e.g.

811 Ketton and Portland); in others, the IEP may never be encountered and the mineral surfaces

812 may remain positively charged (e.g. Estaillades). The carbonate-rock-specific relationship

813 between zeta potential and PDI concentration observed here may explain why CSW in some

814 cases yields increased recovery and in other cases does not (e.g. [프 59]). Future work

815 relevant to CSW should focus on testing the link between brine composition, zeta potential

816 and increased oil recovery using integrated experiments with consistent materials and

817 experimental conditions (e.g. [37]).

\section{Conclusions}

820 Experimental studies of the zeta potential of calcite and carbonate have reported a broad

821 range of values with numerous inconsistent results. Yet the primary data source to understand

822 calcite surface charge comprises measurements of zeta potential, so it is important to

823 understand the key controls on zeta potential and why studies have reported apparently

824 contradictory values. A comprehensive review of the literature, supplemented by experimental data new to this study, suggests that:

1. The potential determining ions (PDIs) for the carbonate mineral surface are the lattice ions

$827 \mathrm{Ca}^{2+}, \mathrm{Mg}^{2+}$ and $\mathrm{CO}_{3}{ }^{2-}$. The zeta potential is controlled by the concentration-dependent

828 adsorption of these ions within the Stern layer, primarily at the Outer Helmholtz Plane $829 \quad(\mathrm{OHP})$

830 2. Given (1), the Iso-Electric Point (IEP) at which the zeta potential is zero should be 831 expressed as $\mathrm{pCa}$ (or $\mathrm{pMg}$ ). It should not be reported as $\mathrm{pH}$, similar to most metal oxides. 
832 3. The $\mathrm{pH}$ does not directly control the zeta potential. Varying the $\mathrm{pH}$ whilst holding $\mathrm{pCa}$

833 constant yields constant zeta potential. The $\mathrm{pH}$ affects the zeta potential only by

834 moderating the equilibrium pCa for a given $\mathrm{CO}_{2}$ partial pressure $\left(p \mathrm{CO}_{2}\right)$.

835 4. Experimental studies that appear to yield a systematic relationship between $\mathrm{pH}$ and zeta

836 potential are most likely observing the relationship between pCa and zeta potential, with

837 pCa responding to the change in $\mathrm{pH}$. New experimental data presented here show a

838 consistent linear relationship between equilibrium $\mathrm{pH}$ and equilibrium $\mathrm{pCa}$ or $\mathrm{pMg}$

839 irrespective of sample or solution ionic strength.

840 5. The surface charge is weakly dependent on $\mathrm{pH}$ through protonation and deprotonation

841 reactions that occur within a hydrolysis layer immediately adjacent to the mineral surface.

842 The Point of Zero Charge (PZC) at which the surface charge is zero could be expressed as

$843 \mathrm{pH}$, but surface complexation models suggest the surface is negatively charged over the

$844 \quad$ pH range 5.5-11.

845 6. Several studies have suggested that $\mathrm{SO}_{4}{ }^{2-}$ is also a PDI for the calcite surface, but new

846 experimental data presented here indicate that the value of $\mathrm{pSO}_{4}$ may affect zeta potential

847 only by moderating the equilibrium $\mathrm{pCa}$. Modelling will be required to provide a more

848 thorough interpretation of the new data.

849 7. Natural carbonate typically yields a more negative zeta potential than synthetic calcite,

850 most likely due to the presence of impurities including clays, organic matter, apatite,

851 anhydrite or quartz, that yield a more negative zeta potential than pure calcite. New data

852 presented here show that apparently identical natural carbonates display differing zeta

853 potential behavior, most likely due to the presence of small volumes of these impurities.

854 8. It is important to ensure that equilibrium, defined in terms of the concentration of PDIs,

855 has been reached prior to taking measurements. Inconsistent values of zeta potential

856 obtained in some studies may reflect a lack of equilibration. 
857 9. The data collated and reported here have broad application in engineering processes

858 including the manufacture of paper and cement, the geologic storage of nuclear waste and $859 \mathrm{CO}_{2}$, and the production of oil and gas.

\section{Acknowledgments}

861 TOTAL are thanked for partially funding Jackson under the TOTAL Chairs programme at

862 Imperial College London, and for supporting Vinogradov through the TOTAL Laboratory for

863 Reservoir Physics where the experiments reported were undertaken. Petroleum Development 864 Oman are thanked for supporting Al Mahrouqi. 
866 [1] Al Mahrouqi D, Vinogradov J, Jackson M. Understanding controlled salinity waterflooding in 867 carbonates using streaming potential measurements. Proceedings of the SPE Latin American and 868 Caribbean Petroleum Engineering Conference, 18-20 November, Quito, Ecuador SPE-177242869 MS2015.

870 [2] Al Mahrouqi D, Vinogradov J, Jackson MD. Temperature dependence of the zeta potential in 871 intact natural carbonates. Geophysical Research Letters. 2016.

872 [3] Alotaibi MB, Azmy R, Nasr-El-Din HA. Wettability challenges in carbonate reservoirs. Proceedings 873 of the SPE Improved Oil Recovery Symposium, 24-28 April, Tulsa, Oklahoma, USA SPE-129972874 MS2010.

875 [4] Alroudhan A, Vinogradov J, Jackson M. Zeta potential of intact natural limestone: Impact of 876 potential-determining ions $\mathrm{Ca}, \mathrm{Mg}$ and $\mathrm{SO}_{4}$. Colloids and Surfaces A: Physicochemical and 877 Engineering Aspects. 2016.

878 [5] Bapat JD. Mineral admixtures in cement and concrete: CRC Press, Taylor \& Francis, New York 8792012.

880 [6] Bard AJ, Faulkner LR, Leddy J, Zoski CG. Electrochemical methods: Fundamentals and 881 applications: Wiley, New York; 1980.

882 [7] Berlin TS, Khabakov AV. Difference in the electrokinetic potentials of carbonate sedimentary 883 rocks of different origin and composition. Geochemistry. 1961:217-30.

884 [8] Bragg WL. Atomic structure of minerals: Cornell University Press, New York; 1950.

885 [9] Buckley J, Liu Y, Monsterleet S. Mechanisms of wetting alteration by crude oils. SPE Journal. 886 1998;3:54-61.

887 [10] Buckley J, Takamura K, Morrow N. Influence of electrical surface charges on the wetting 888 properties of crude oils. SPE Reservoir Engineering. 1989;4:332-40.

889 [11] Chen L, Zhang G, Wang L, Wu W, Ge J. Zeta potential of limestone in a large range of salinity. 890 Colloids and Surfaces A: Physicochemical and Engineering Aspects. 2014;450:1-8.

891 [12] Cicerone DS, Regazzoni AE, Blesa MA. Electrokinetic properties of the calcite water interface in 892 the presence of magnesium and organic-matter. Journal of Colloid and Interface Science.

893 1992;154:423-33.

894 [13] Davis JA, Kent D. Surface complexation modeling in aqueous geochemistry. Reviews in 895 Mineralogy and Geochemistry. 1990;23:177-260.

896 [14] De Groot K, Duyvis E. Crystal form of precipitated calcium carbonate as influenced by adsorbed 897 magnesium ions. Nature. 1966;212:183-4.

898 [15] Delgado AV, Gonzalez-Caballero F, Hunter RJ, Koopal LK, Lyklema J. Measurement and 899 interpretation of electrokinetic phenomena. Journal of Colloid and Interface Science. 2007;309:194900224.

901 [16] Douglas H, Walker R. The electrokinetic behaviour of Iceland Spar against aqueous electrolyte 902 solutions. Transactions of the Faraday Society. 1950;46:559-68.

903 [17] Dukhin SS, Deriaguine BV. Surface and colloid science: Electrokinetic phenomena: John Wiley \& 904 Sons, New York; 1974. 
905 [18] Eriksson R, Merta J, Rosenholm JB. The calcite/water interface: Surface charge in indifferent 906 electrolyte media and the influence of low-molecular-weight polyelectrolyte. Journal of Colloid and 907 Interface Science. 2007;313:184-93.

908 [19] Fenter P, Geissbühler P, DiMasi E, Srajer G, Sorensen LB, Sturchio NC. Surface speciation of 909 calcite observed in situ by high-resolution X-ray reflectivity. Geochimica et Cosmochimica Acta. $910 \quad 2000 ; 64: 1221-8$.

911 [20] Fenter P, Sturchio NC. Mineral-water interfacial structures revealed by synchrotron X-ray 912 scattering. Progress in Surface Science. 2004;77:171-258.

913 [21] Foxall T, Peterson GC, Rendall HM, Smith AL. Charge determination at calcium salt/aqueous 914 solution interface. Journal of the Chemical Society, Faraday Transactions 1: Physical Chemistry in 915 Condensed Phases. 1979;75:1034-9.

916 [22] Fuerstenau MC, Gutierrez G, Elgillani DA. The influence of sodium silicate in non metallic 917 flotation systems. Transactions of the AIME. 1968;241:319.

918 [23] Garrels RM, Christ CL. Solutions, minerals, and equilibria: Harper \& Row; 1965.

919 [24] Geissbühler P, Fenter P, DiMasi E, Srajer G, Sorensen L, Sturchio N. Three-dimensional structure 920 of the calcite-water interface by surface X-ray scattering. Surface Science. 2004;573:191-203.

921 [25] Glover P. Comment on "Examination of a Theoretical Model of Streaming Potential Coupling 922 Coefficient". International Journal of Geophysics. 2015;2015.

923 [26] Glover PW, Jackson MD. Borehole electrokinetics. The Leading Edge. 2010;29:724-8.

924 [27] Glover PWJ, Walker E, Jackson MD. Streaming-potential coefficient of reservoir rock: A 925 theoretical model. Geophysics. 2012;77:D17-D43.

926 [28] Gomari KR, Hamouda A, Denoyel R. Influence of sulfate ions on the interaction between fatty 927 acids and calcite surface. Colloids and Surfaces A: Physicochemical and Engineering Aspects.

928 2006;287:29-35.

929 [29] Heberling F, Trainor TP, Lützenkirchen J, Eng P, Denecke MA, Bosbach D. Structure and reactivity 930 of the calcite-water interface. Journal of Colloid and Interface Science. 2011;354:843-57.

931 [30] Hester RE, Harrison RM. Carbon capture: Sequestration and storage: Royal Society of Chemistry, 932 London; 2010.

933 [31] Hiorth A, Cathles LM, Madland MV. The impact of pore water chemistry on carbonate surface 934 charge and oil wettability. Transport in Porous Media. 2010;85:1-21.

935 [32] Hohl H, Sigg L, Stumm W. Characterization of surface chemical properties of oxides in natural 936 waters: The role of specific adsorption in determining the surface charge. In: K. MC, L. JO, (editors). 937 Particulates in Water. Vol. 189: Advances in Chemistry; American Chemical Society: Washington, DC; 938 1980. Chapter 1. p. 1-31.

939 [33] Huang YC, Fowkes FM, Lloyd TB, Sanders ND. Adsorption of calcium ions from calcium chloride 940 solutions onto calcium carbonate particles. Langmuir. 1991;7:1742-8.

941 [34] Hunter RJ. Zeta potential in colloid science : Principles and applications: Academic Press, New 942 Yotk; 1981.

943 [35] Jaafar MZ, Vinogradov J, Jackson MD. Measurement of streaming potential coupling coefficient 944 in sandstones saturated with high salinity NaCl brine. Geophysical Research Letters. 2009;36.

945 [36] Jackson MD. Self-potential: Tools and techniques, in Treatise on Geophysics, vol. 11, 2nd ed., 946 edited by G. Schubert, chap. 9, Elsevier,Oxford. 2015. 
947 [37] Jackson MD, Al-Mahrouqi D, Vinogradov J. Zeta potential in oil-water-carbonate systems and its 948 impact on oil recovery during controlled salinity water-flooding. Scientific Reports. 2016;6:37363.

949 [38] Jackson MD, Vinogradov J. Impact of wettability on laboratory measurements of streaming 950 potential in carbonates. Colloids and Surfaces A-Physicochemical and Engineering Aspects.

951 2012;393:86-95.

952 [39] Jackson MD, Vinogradov J, Saunders JH, Jaafar MZ. Laboratory measurements and numerical 953 modeling of streaming potential for downhole monitoring in intelligent wells. SPE Journal.

954 2011;16:625-36.

955 [40] Jouniaux L, Pozzi JP. Streaming potential and permeability of saturated sandstones under triaxial 956 stress: Consequences for electrotelluric anomalies prior to earthquakes. Journal of Geophysical 957 Research: Solid Earth. 1995;100:10197-209.

958 [41] Karoussi O, Hamouda AA. Imbibition of sulfate and magnesium ions into carbonate rocks at 959 elevated temperatures and their influence on wettability alteration and recovery. Energy \& Fuels. 960 2007;21:2138-46.

961 [42] Kasha A, Al-Hashim H, Abdallah W, Taherian R, Sauerer B. Effect of $\mathrm{Ca}^{2+}, \mathrm{Mg}^{2+}$ and $\mathrm{SO}_{4}{ }^{2-}$ ions on 962 the zeta potential of calcite and dolomite particles aged with stearic acid. Colloids and Surfaces A: 963 Physicochemical and Engineering Aspects. 2015;482:290-9.

964 [43] Kruyt H, Overbeek J. An introduction to physical chemistry for biologists and medical students: 965 Holt, Rinehart and Winston, New York; 1960.

966 [44] Lee SS, Heberling F, Sturchio NC, Eng PJ, Fenter P. Surface charge of the calcite (104) terrace 967 Mmeasured by $\mathrm{Rb}^{+}$adsorption in aqueous solutions using resonant anomalous $\mathrm{X}$-ray reflectivity. The 968 Journal of Physical Chemistry C. 2016;120:15216-23.

969 [45] Magdans U, Torrelles X, Angermund K, Gies H, Rius J. Crystalline order of a water/glycine film 970 coadsorbed on the (104) calcite surface. Langmuir. 2007;23:4999-5004.

971 [46] Mahani H, Keya AL, Berg S, Bartels W-B, Nasralla R, Rossen WR. Insights into the mechanism of 972 wettability alteration by low-salinity flooding (LSF) in carbonates. Energy \& Fuels. 2015;29:1352-67.

973 [47] Mahani H, Keya AL, Berg S, Nasralla R. Electrokinetics of carbonate/brine interface in low974 salinity waterflooding: Effect of brine salinity, composition, rock type, and $\mathrm{pH}$ on $\zeta$-potential and a 975 surface-complexation model. SPE Journal. 2016.

976 [48] Mishra S. The electrokinetics of apatite and calcite in inorganic electrolyte environment. 977 International Journal of Mineral Processing. 1978;05:69-83.

978 [49] Morgan F, Williams E, Madden T. Streaming potential properties of westerly granite with 979 applications. Journal of Geophysical Research: Solid Earth. 1989;94:12449-61.

980 [50] Morse JW. The surface chemistry of calcium carbonate minerals in natural waters: An overview. 981 Marine Chemistry. 1986;20:91-112.

982 [51] Moulin P, Roques H. Zeta potential measurement of calcium carbonate. Journal of Colloid and 983 Interface Science. 2003;261:115-26.

984 [52] Overbeek JTG. Electrochemistry of the double layer. In: Kruyt HR, (editor). Colloid Science. Vol. 985 1: Elsevier, Amsterdam-Huston-New York-London; 1952. p. 115-93.

986 [53] Patil M, Shivakumar K, Prakash S, Rao RB. Effect of organic reagents on the zeta potentials of 987 graphite, quartz and calcite minerals. Journal of Surface Science and Technology. 1998;14:280-5.

988 [54] Pierre A, Lamarche J, Mercier R, Foissy A, Persello J. Calcium as potential determining ion in 989 aqueous calcite suspensions. Journal of Dispersion Science and Technology. 1990;11:611-35. 
990 [55] Plummer LN, Busenberg E. The solubilities of calcite, aragonite and vaterite in $\mathrm{CO}_{2}-\mathrm{H}_{2} \mathrm{O}$ solutions 991 between 0 and $90^{\circ} \mathrm{C}$, and an evaluation of the aqueous model for the system $\mathrm{CaCO}_{3}-\mathrm{CO}_{2}-\mathrm{H}_{2} \mathrm{O}$.

992 Geochimica et Cosmochimica Acta. 1982;46:1011-40.

993 [56] Pokrovsky O, Mielczarski J, Barres O, Schott J. Surface speciation models of calcite and 994 dolomite/aqueous solution interfaces and their spectroscopic evaluation. Langmuir. 2000;16:267799588.

996 [57] Pokrovsky O, Schott J. Surface chemistry and dissolution kinetics of divalent metal carbonates. 997 Environmental Science \& Technology. 2002;36:426-32.

998 [58] Rao KH, Antti B-M, Forssberg E. Mechanism of oleate interaction on salt-type minerals part I. 999 Adsorption and electrokinetic studies of calcite in the presence of sodium oleate and sodium 1000 metasilicate. Colloids and Surfaces. 1989;34:227-39.

1001 [59] Romanuka J, Hofman J, Ligthelm DJ, Suijkerbuijk BMJM, Marcelis AHM, Oedai S, et al. Low 1002 salinity EOR in carbonate Proceedings of the SPE Improved Oil Recovery Symposium, 14-18 April, 1003 Tulsa, Oklahoma, USA SPE-153869-MS2012.

1004 [60] Sampat Kumar VY, Mohan N, Biswas AK. Fundamental studies on the role of carbon dioxide in a 1005 calcite flotation system. Transactions of the AIME. 1971;250:182-6.

1006 [61] Schindler PW, Stumm W. The surface chemistry of oxides, hydroxides, and oxide minerals. In: 1007 Stumm W, (editor). Aquatic Surface Chemistry: Chemical Processes at the Particle-Water Interface: 1008 John Wiley \& Sons, New York; 1987. p. 83-110.

1009 [62] Schramm LL, Mannhardt K, Novosad JJ. Electrokinetic properties of reservoir rock particles. 1010 Colloids and Surfaces. 1991;55:309-31.

1011 [63] Siffert D, Fimbel P. Parameters affecting the sign and magnitude of the eletrokinetic potential of 1012 calcite. Colloids and Surfaces. 1984;11:377-89.

1013 [64] Smallwood P. Some aspects of the surface chemistry of calcite and aragonite Part I: An 1014 electrokinetic study. Colloid and Polymer Science. 1977;255:881-6.

1015 [65] Smani M, Blazy P, Cases J. Beneficiation of sedimentary Moroccan phosphate ores. Transactions 1016 of the AIME. 1975;258:168-82.

1017 [66] Somasundaran P. Encyclopedia of surface and colloid science: CRC press Taylor \& Francis, New 1018 York; 2006.

1019 [67] Somasundaran P, Agar G. The zero point of charge of calcite. Journal of Colloid and Interface 1020 Science. 1967;24:433-40.

1021 [68] Somasundaran P, Amankonah JO, Ananthapadmabhan K. Mineral-solution equilibria in sparingly 1022 soluble mineral systems. Colloids and Surfaces. 1985;15:309-33.

1023 [69] Somasundaran P, Deo, Namita D, Puspendu Natarajan KA. Role of biopolymers on bacterial 1024 adhesion and mineral beneficiation. Minerals and Metallurgical Processing. 2005;22:1-11.

1025 [70] Sondi I, Bišćan J, Vdović N, Škapin SD. The electrokinetic properties of carbonates in aqueous 1026 media revisited. Colloids and Surfaces A: Physicochemical and Engineering Aspects. 2009;342:84-91.

1027 [71] Stipp S. Toward a conceptual model of the calcite surface: Hydration, hydrolysis, and surface 1028 potential. Geochimica et Cosmochimica Acta. 1999;63:3121-31.

1029 [72] Stipp S, Eggleston C, Nielsen B. Calcite surface structure observed at microtopographic and 1030 molecular scales with atomic force microscopy (AFM). Geochimica et Cosmochimica Acta. 1031 1994;58:3023-33. 
1032 [73] Stipp SL, Hochella MF. Structure and bonding environments at the calcite surface as observed 1033 with X-ray photoelectron spectroscopy (XPS) and low energy electron diffraction (LEED). Geochimica 1034 et Cosmochimica Acta. 1991;55:1723-36.

1035 [74] Strand S, Hognesen EJ, Austad T. Wettability alteration of carbonates - Effects of potential 1036 determining ions $\left(\mathrm{Ca}^{2+}\right.$ and $\left.\mathrm{SO}_{4}{ }^{2-}\right)$ and temperature. Colloids and Surfaces A: Physicochemical and 1037 Engineering Aspects. 2006;275:1-10.

1038 [75] Stumm W. Chemistry of the solid-water interface: Processes at the mineral-water and particle1039 water interface in natural systems: John Wiley \& Sons, New Yotk; 1992.

1040 [76] Stumm W, Morgan JJ. Aquatic chemistry: chemical equilibria and rates in natural waters: John 1041 Wiley \& Sons, New York; 2012.

1042 [77] Stumm W, Wehrli B, Wieland E. Surface complexation and its impact on geochemical kinetics. 1043 Croat Chem Acta. 1987;60:429.

1044 [78] Thompson DW, Pownall PG. Surface electrical-properties of calcite. Journal of Colloid and 1045 Interface Science. 1989;131:74-82.

1046 [79] Van Cappellen P, Charlet L, Stumm W, Wersin P. A surface complexation model of the carbonate 1047 mineral-aqueous solution interface. Geochimica et Cosmochimica Acta. 1993;57:3505-18.

1048 [80] Vdovic N. Electrokinetic behaviour of calcite - The relationship with other calcite properties. 1049 Chemical Geology. 2001;177:241-8.

1050 [81] Vdović N, Bišćan J. Electrokinetics of natural and synthetic calcite suspensions. Colloids and 1051 Surfaces A: Physicochemical and Engineering Aspects. 1998;137:7-14.

1052 [82] Vernhet A, Bellon-Fontaine M, Doren A. Comparison of three electrokinetic methods to 1053 determine the zeta potential of solid surfaces. Journal de Chimie Physique. 1994;91:1728-47.

1054 [83] Vinogradov J, Jaafar MZ, Jackson MD. Measurement of streaming potential coupling coefficient 1055 in sandstones saturated with natural and artificial brines at high salinity. Journal of Geophysical 1056 Research-Solid Earth. 2010;115:B12204.

1057 [84] Vinogradov J, Jackson MD. Multiphase streaming potential in sandstones saturated with 1058 gas/brine and oil/brine during drainage and imbibition. Geophysical Research Letters.

1059 2011;38:L01301.

1060 [85] Wolthers M, Charlet L, Van Cappellen P. The surface chemistry of divalent metal carbonate 1061 minerals; a critical assessment of surface charge and potential data using the charge distribution 1062 multi-site ion complexation model. American Journal of Science. 2008;308:905-41.

1063 [86] Yousef AA, Al-Saleh SH, Al-Kaabi A, Al-Jawfi MS. Laboratory investigation of the impact of 1064 injection-water salinity and ionic content on oil recovery from carbonate reservoirs. SPE Reservoir 1065 Evaluation \& Engineering. 2011;14:578-93.

1066 [87] Zhang P, Tweheyo MT, Austad T. Wettability alteration and improved oil recovery by 1067 spontaneous imbibition of seawater into chalk: Impact of the potential determining ions $\mathrm{Ca}^{2+}, \mathrm{Mg}^{2+}$, 1068 and $\mathrm{SO}_{4}{ }^{2-}$. Colloids and Surfaces A: Physicochemical and Engineering Aspects. 2007;301:199-208.

1069 [88] Zhang PM, Austad T. Wettability and oil recovery from carbonates: Effects of temperature and 1070 potential determining ions. Colloids and Surfaces A: Physicochemical and Engineering Aspects.

1071 2006;279:179-87.

1072 
1075 Table 1: Summary of published zeta potential of calcite and carbonate. Table 1a reports studies focusing on the effect 1076 of varying $\mathrm{pH}$. Table $1 \mathrm{~b}$ reports studies focusing on the effect of varying pCa.

1077

Table 1a

\begin{tabular}{|c|c|c|c|c|c|c|c|c|c|c|}
\hline Material & Method & $\begin{array}{c}\text { Background } \\
\text { electrolyte }\end{array}$ & $\begin{array}{c}\text { Equilibrium } \\
\text { condition }\end{array}$ & $\begin{array}{c}\text { Equilibration } \\
\text { time (hr) }\end{array}$ & $\begin{array}{c}\text { Equilibrium } \\
\text { pH }\left(\mathbf{p H}_{\mathrm{EQ}}\right)\end{array}$ & $\begin{array}{c}\text { Open vs. } \\
\text { closed system }\end{array}$ & $\begin{array}{c}\text { Zeta } \\
\text { potential } \\
\text { at EQ. }\end{array}$ & pHIEP & $\begin{array}{c}\text { IEP } \\
\text { determination }\end{array}$ & Reference \\
\hline Iceland spar & SPM & $\begin{array}{c}\text { Deionized water } \\
\left(\mathrm{HNO}_{3} / \mathrm{NaOH}\right)\end{array}$ & $\begin{array}{c}\text { Calcite/water } \\
\text { /air }\end{array}$ & 1440 & 8.2 & Open & Positive & 8.2 & Extrapolated & [67] \\
\hline Iceland spar & SPM & $\mathrm{SiO}_{2} / \mathrm{Na}_{2} \mathrm{O}$ & Calcite/water & N/A & 9.8 & Closed & Positive & 10.8 & Direct & {$[\underline{22}]$} \\
\hline \multirow[t]{2}{*}{ Iceland spar } & \multirow[t]{2}{*}{ SPM } & \multirow[t]{2}{*}{ Deionized water } & \multirow{2}{*}{$\begin{array}{c}\text { Calcite/water } \\
/ \mathrm{CO}_{2}\end{array}$} & \multirow[t]{2}{*}{ N/A } & 6.55 & $\mathrm{pCO}_{2}=0.23$ & Negative & 6.55 & \multirow[t]{2}{*}{ Direct } & \multirow[t]{2}{*}{ [51] } \\
\hline & & & & & 7.05 & $\mathrm{pCO}_{2}=0.023$ & Negative & 7.05 & & \\
\hline \multirow[t]{3}{*}{ Iceland spar } & \multirow[t]{3}{*}{ SPM } & \multirow[t]{3}{*}{ Deionized water } & \multirow{3}{*}{$\begin{array}{c}\text { Calcite/water } \\
/ \mathrm{CO}_{2}\end{array}$} & \multirow[t]{3}{*}{$24-720$} & 5.8 & $\mathrm{pCO}_{2}=1$ & Negative & 6.5 & \multirow[t]{3}{*}{ Direct } & \multirow[t]{3}{*}{ [29] } \\
\hline & & & & & 7.5 & $\mathrm{pCO}_{2}=10^{-3.44}$ & Negative & 8.8 & & \\
\hline & & & & & 8.3 & $\mathrm{pCO}_{2}=10^{-5.2}$ & Negative & 9.4 & & \\
\hline Iceland spar & EPM & Deionized water & Calcite/water & 24 & N/A & Closed & Negative & 5.4 & Extrapolated & [42] \\
\hline Iceland spar & EPM & Deionized water & $\begin{array}{c}\text { Calcite/water } \\
/ \mathrm{CO}_{2}\end{array}$ & $1-2$ & N/A & Open & Negative & $\begin{array}{l}7.2- \\
7.8\end{array}$ & Extrapolated & [으] \\
\hline \multirow[t]{3}{*}{ Iceland spar } & \multirow[t]{2}{*}{ EPM } & Formation water & \multirow[t]{2}{*}{ Calcite/water } & \multirow[t]{2}{*}{24} & N/A & \multirow[t]{2}{*}{ Closed } & Positive & N/A & Direct & \multirow[t]{2}{*}{ [47] } \\
\hline & & Seawater (SW) & & & N/A & & Negative & 7.5 & & \\
\hline & & 25 times diluted SW & & & 9.2 & & Negative & 8.5 & & \\
\hline \multirow[t]{2}{*}{$\begin{array}{l}\text { Synthetic } \\
\text { calcite }\end{array}$} & \multirow[t]{2}{*}{ EPM } & $\begin{array}{l}1 \times 10^{-2} \\
5 \times 10^{-2}\end{array}$ & \multirow[t]{2}{*}{$\begin{array}{c}\text { Calcite/water } \\
\text { /air }\end{array}$} & \multirow[t]{2}{*}{ N/A } & \multirow[t]{2}{*}{ N/A } & \multirow[t]{2}{*}{ Open } & \multirow[t]{2}{*}{ Positive } & \multirow[t]{2}{*}{ N/A } & \multirow[t]{2}{*}{ N/A } & \multirow[t]{2}{*}{ [21] } \\
\hline & & $1.5 \times 10^{-1} \mathrm{M} \mathrm{NaCl}$ & & & & & & & & \\
\hline $\begin{array}{l}\text { Synthetic } \\
\text { calcite }\end{array}$ & EPM & $10^{-2} \mathrm{M} \mathrm{NaCl}$ & Calcite/water & 10 & 9.1 & Closed & Pos - Neg & $10-11$ & N/A & {$[\underline{63}]$} \\
\hline $\begin{array}{l}\text { Synthetic } \\
\text { calcite }\end{array}$ & SPM & $5 \times 10^{-3} \mathrm{M} \mathrm{NaCl}$ & Calcite/water & 48 & $9.11-9.87$ & Closed & Negative & N/A & N/A & [78] \\
\hline $\begin{array}{l}\text { Synthetic } \\
\text { calcite }\end{array}$ & SPM & $\begin{array}{l}5 \times 10^{-3} \mathrm{M} \mathrm{NaCl} \\
10^{-3} \mathrm{M} \mathrm{NaHCO}_{3}\end{array}$ & Calcite/water & 48 & $9.11-9.87$ & Closed & Negative & N/A & N/A & [묘 \\
\hline $\begin{array}{l}\text { Synthetic } \\
\text { calcite }\end{array}$ & SPM & $\begin{array}{c}5 \times 10^{-3} \mathrm{M} \mathrm{NaCl} / \\
10^{-3} \mathrm{M} \\
\mathrm{NaHCO}_{3} / \mathrm{H}_{2} \mathrm{CO}_{3} / \mathrm{Ca} \\
(\mathrm{OH})_{2}\end{array}$ & Calcite/water & 48 & $9.11-9.87$ & Closed & Negative & 8.9 & Extrapolated & [78] \\
\hline $\begin{array}{l}\text { Synthetic } \\
\text { calcite }\end{array}$ & SPM & $5 \times 10^{-4} \mathrm{M} \mathrm{CaCl}_{2}$ & Calcite/water & 48 & $9.11-9.87$ & Closed & Positive & N/A & N/A & [78] \\
\hline $\begin{array}{l}\text { Synthetic } \\
\text { calcite }\end{array}$ & EPM & $10^{-2} \mathrm{M} \mathrm{NaCl}$ & Calcite/water & 24 & 10 & Closed & Positive & 9.6 & Direct & [54] \\
\hline $\begin{array}{l}\text { Synthetic } \\
\text { calcite }\end{array}$ & EPM & $10^{-3} \mathrm{M} \mathrm{KCl}$ & Calcite/water & 168 & $9.8-10$ & Closed & Negative & N/A & N/A & {$[\underline{12}]$} \\
\hline $\begin{array}{l}\text { Synthetic } \\
\text { calcite }\end{array}$ & EPM & $\begin{array}{c}10^{-3} \mathrm{M} \mathrm{KCl} / 10^{-3} \mathrm{M} \\
\mathrm{CaCl}_{2}\end{array}$ & Calcite/water & 168 & $9.8-10$ & Closed & Negative & N/A & N/A & [12] \\
\hline $\begin{array}{l}\text { Synthetic } \\
\text { calcite }\end{array}$ & EPM & $\begin{array}{c}10^{-3} \mathrm{M} \mathrm{KCl} / 10^{-2} \mathrm{M} \\
\mathrm{CaCl}_{2}\end{array}$ & Calcite/water & 168 & $9.8-10$ & Closed & Positive & N/A & N/A & [12] \\
\hline $\begin{array}{l}\text { Synthetic } \\
\text { calcite }\end{array}$ & EPM & $10^{-3} \mathrm{M} \mathrm{NaCl}$ & $\begin{array}{c}\text { Calcite/water } \\
\text { /air }\end{array}$ & Few & 8.6 & Closed & Positive & 9.8 & Direct & {$[\underline{81}]$} \\
\hline $\begin{array}{l}\text { Synthetic } \\
\text { calcite }\end{array}$ & EPM & $10^{-3} \mathrm{M} \mathrm{NaCl}$ & $\begin{array}{c}\text { Calcite/water } \\
\text { /air }\end{array}$ & Few & 8.4 & Closed & Positive & 9.8 & Direct & {$[\underline{80}]$} \\
\hline $\begin{array}{l}\text { Synthetic } \\
\text { calcite }\end{array}$ & EPM & $5.56 \times 10^{-3} \mathrm{M} \mathrm{NaCl}$ & $\begin{array}{c}\text { Calcite/water } \\
/ \mathrm{CO}_{2}\end{array}$ & 1 & $8-8.5$ & Open & Positive & N/A & N/A & {$[\underline{18}]$} \\
\hline $\begin{array}{l}\text { Synthetic } \\
\text { calcite }\end{array}$ & EPM & $10^{-3} \mathrm{M} \mathrm{NaCl}$ & $\begin{array}{c}\text { Calcite/water } \\
\text { /air }\end{array}$ & Few & 8.3 & Closed & Negative & N/A & N/A & {$[\underline{70}]$} \\
\hline
\end{tabular}


Table 1a. (continued)

\begin{tabular}{|c|c|c|c|c|c|c|c|c|c|c|}
\hline Material & Method & $\begin{array}{l}\text { Background } \\
\text { electrolyte }\end{array}$ & $\begin{array}{c}\text { Equilibrium } \\
\text { condition }\end{array}$ & $\begin{array}{c}\text { Equilibration } \\
\text { time (hr) }\end{array}$ & $\begin{array}{c}\text { Equilibrium } \\
\text { pH }\left(\mathbf{p H}_{\mathrm{EQ}}\right)\end{array}$ & $\begin{array}{c}\text { Open vs. } \\
\text { closed } \\
\text { system }\end{array}$ & $\begin{array}{c}\text { Zeta } \\
\text { potential at } \\
\text { EQ. }\end{array}$ & pH IEP & $\begin{array}{c}\text { IEP } \\
\text { determination }\end{array}$ & Reference \\
\hline $\begin{array}{l}\text { Natural } \\
\text { calcite }\end{array}$ & EPM & $2 \times 10^{-3} \mathrm{M} \mathrm{NaCIO}_{4}$ & Calcite/water & 0.5 & $9-10$ & Closed & Negative & N/A & N/A & [58] \\
\hline $\begin{array}{l}\text { Natural } \\
\text { calcite }\end{array}$ & EPM & $2 \times 10^{-2} \mathrm{M} \mathrm{NaClO}_{4}$ & $\begin{array}{c}\text { Calcite/water } \\
\text { /air }\end{array}$ & 0.5 & 8.2 & Open & Negative & 8.2 & Extrapolated & [묘] \\
\hline $\begin{array}{l}\text { Natural } \\
\text { calcite }\end{array}$ & EPM & $10^{-2} \mathrm{M} \mathrm{NaCl}$ & Calcite/water & 24 & 10 & Closed & Negative & 9.4 & Direct & [54] \\
\hline $\begin{array}{c}\text { Natural } \\
\text { (biogenetic) } \\
\text { calcite }\end{array}$ & EPM & $10^{-3} \mathrm{M} \mathrm{KCl}$ & Calcite/water & 168 & $9.8-10$ & Closed & Negative & N/A & N/A & [12] \\
\hline $\begin{array}{l}\text { Natural } \\
\text { calcite }\end{array}$ & EPM & $10^{-3} \mathrm{M} \mathrm{NaCl}$ & $\begin{array}{c}\text { Calcite/water } \\
\text { /air }\end{array}$ & Few & 8.6 & Closed & Negative & N/A & N/A & [1] \\
\hline $\begin{array}{l}\text { Natural } \\
\text { calcite }\end{array}$ & EPM & $2 \times 10^{-3} \mathrm{M} \mathrm{NaNO}_{3}$ & $\begin{array}{c}\text { Calcite/water } \\
\text { /air }\end{array}$ & 2.2 & 8.3 & Open & Negative & 7.8 & Extrapolated & [프] \\
\hline $\begin{array}{l}\text { Natural } \\
\text { calcite }\end{array}$ & EPM & $10^{-3} \mathrm{M} \mathrm{NaCl}$ & $\begin{array}{c}\text { Calcite/water } \\
\text { /air }\end{array}$ & Few & 8.4 & Closed & Negative & N/A & N/A & [요 \\
\hline $\begin{array}{l}\text { Natural } \\
\text { calcite }\end{array}$ & EPM & $10^{-3} \mathrm{M} \mathrm{KNO}_{3}$ & $\begin{array}{c}\text { Calcite/water } \\
\text { /air }\end{array}$ & 1 & N/A & Open & Negative & N/A & N/A & [69] \\
\hline $\begin{array}{c}\text { Natural } \\
\text { carbonate }\end{array}$ & EPM & Deionized water & Calcite/water & 1 & N/A & Closed & Negative & $\begin{array}{l}5.2- \\
5.8\end{array}$ & Extrapolated & [11] \\
\hline \multirow{3}{*}{$\begin{array}{c}\text { Natural } \\
\text { carbonate }\end{array}$} & EPM & Formation water & Calcite/water & 24 & N/A & Closed & Positive & N/A & Direct & [47] \\
\hline & & Seawater (SW) & & & N/A & & Negative & 9.25 & & \\
\hline & & 25 times diluted SW & & & 9.2 & & Negative & 10.25 & & \\
\hline
\end{tabular}


Table 1b.

\begin{tabular}{|c|c|c|c|c|c|c|c|c|c|c|}
\hline $\begin{array}{c}\text { Material } \\
\text { Type }\end{array}$ & Method & $\begin{array}{c}\text { Background } \\
\text { electrolyte }\end{array}$ & $\begin{array}{c}\text { Equilibrium } \\
\text { condition }\end{array}$ & $\begin{array}{l}\text { Equilibration } \\
\text { time (hr) }\end{array}$ & $\begin{array}{c}\text { Equilibrium } \\
\text { pH }\left(\mathbf{p H}_{\mathrm{EQ}}\right)\end{array}$ & $\begin{array}{l}\text { Open vs. } \\
\text { closed system }\end{array}$ & $\mathrm{d} \zeta / \mathrm{dpCa}$ & pCaIEP & $\begin{array}{c}\text { IEP } \\
\text { determination }\end{array}$ & Reference \\
\hline Iceland spar & $\begin{array}{c}\text { Electro } \\
\text { osmosis }\end{array}$ & $\mathrm{NaCl} / \mathrm{Na}_{2} \mathrm{CO}_{3} / \mathrm{CaCl}_{2}$ & Calcite/water & 2 & 9 & Closed & N/A & 3.33 & Extrapolated & [16] \\
\hline Iceland spar & $\begin{array}{c}\text { SPM on } \\
\text { packed } \\
\text { particles }\end{array}$ & $\begin{array}{l}\text { Deionized water } \\
\left(\mathrm{HNO}_{3} / \mathrm{NaOH}\right)\end{array}$ & $\begin{array}{c}\text { Calcite/water/ } \\
\text { air }\end{array}$ & 1440 & 8.2 & Open & N/A & 4.25 & Extrapolated & [ㅁ] \\
\hline Iceland spar & EPM & $0.571 \mathrm{M} \mathrm{NaCl}$ & Calcite/water & 24 & N/A & Closed & N/A & $\begin{array}{l}1.65- \\
1.75\end{array}$ & Extrapolated & [42] \\
\hline $\begin{array}{l}\text { Synthetic } \\
\text { calcite }\end{array}$ & EPM & $\begin{array}{c}1 \times 10^{-2}, \\
5 \times 10^{-2} \\
1.5 \times 10^{-1} \mathrm{M} \mathrm{NaCl}\end{array}$ & $\begin{array}{c}\text { Calcite/water/ } \\
\text { air }\end{array}$ & N/A & N/A & Open & $\begin{array}{c}-15.2 \\
-12.8 \\
-9.3\end{array}$ & 4.5 & Extrapolated & [21] \\
\hline $\begin{array}{l}\text { Synthetic } \\
\text { calcite }\end{array}$ & SPM & $2 \times 10^{-3} \mathrm{M} \mathrm{NaCl}$ & Calcite/water & 48 & $9.11-9.87$ & Closed & -12.7 & 2.02 & Extrapolated & {$[\underline{78}]$} \\
\hline $\begin{array}{l}\text { Synthetic } \\
\text { calcite }\end{array}$ & SPM & $\begin{array}{c}2 \times 10^{-3} / 10^{-2} \mathrm{M} \\
\left(\mathrm{NaCI} / \mathrm{NaHCO}_{3}\right)\end{array}$ & Calcite/water & 48 & $9.11-9.87$ & Closed & -10.2 & 1.92 & Extrapolated & [묘 \\
\hline $\begin{array}{l}\text { Synthetic } \\
\text { calcite }\end{array}$ & SPM & $\begin{array}{l}2 \times 10^{-3} / 10^{-2} \mathrm{M} \\
\left(\mathrm{NaCl} / \mathrm{CaCl}_{2}\right)\end{array}$ & Calcite/water & 48 & $9.11-9.87$ & Closed & -10.1 & 3.4 & Extrapolated & [78] \\
\hline $\begin{array}{l}\text { Synthetic } \\
\text { calcite }\end{array}$ & SPM & $\begin{array}{c}2 \times 10^{-3} / 10^{-2} \mathrm{M} \\
\left(\mathrm{NaCl} / \mathrm{H}_{2} \mathrm{CO}_{3}\right)\end{array}$ & Calcite/water & 48 & $9.11-9.87$ & Closed & -10.8 & 4 & Extrapolated & [묘] \\
\hline $\begin{array}{l}\text { Synthetic } \\
\text { calcite }\end{array}$ & SPM & $\begin{array}{c}2 \times 10^{-3} / 10^{-2} / 10^{-2} \mathrm{M} \\
\left(\mathrm{NaCl} / \mathrm{NaHCO}^{\prime} / \mathrm{H}_{2}\right. \\
\left.\mathrm{CO}_{3}\right)\end{array}$ & Calcite/water & 48 & $9.11-9.87$ & Closed & -12.9 & 3.8 & Direct & {$[\underline{78}]$} \\
\hline $\begin{array}{l}\text { Synthetic } \\
\text { calcite }\end{array}$ & SPM & $\begin{array}{c}2 \times 10^{-3} / 10^{-2} / 10^{-2} \mathrm{M} \\
(\mathrm{NaCl} / \mathrm{NaHCO} 3 / \mathrm{Ca}( \\
\left.\mathrm{OH})_{2}\right)\end{array}$ & Calcite/water & 48 & $9.11-9.87$ & Closed & -12.2 & 3.8 & Direct & [78] \\
\hline $\begin{array}{l}\text { Synthetic } \\
\text { calcite }\end{array}$ & EPM & $10^{-2} \mathrm{M} \mathrm{NaCl}$ & Calcite/water & 24 & 10 & Closed & N/A & 3.3 & Direct & [54] \\
\hline $\begin{array}{l}\text { Synthetic } \\
\text { calcite }\end{array}$ & SPM & $10^{-5}-0.01 \mathrm{M} \mathrm{CaCl}_{2}$ & Calcite/water & 120 & $9.3-9.9$ & Closed & -8.34 & 4.38 & Extrapolated & [33] \\
\hline $\begin{array}{l}\text { Synthetic } \\
\text { calcite }\end{array}$ & EPM & $10^{-3} \mathrm{M} \mathrm{KCl}$ & Calcite/water & 168 & $9.8-10$ & Closed & $\begin{array}{l}-14.5 \\
\text { (in the } \\
\text { vicinity of } \\
\text { IEP) }\end{array}$ & 2.7 & Direct & [12] \\
\hline $\begin{array}{l}\text { Natural } \\
\text { calcite }\end{array}$ & EPM & $10^{-2} \mathrm{M} \mathrm{NaCl}$ & Calcite/water & 24 & 10 & Closed & N/A & 4 & Direct & [무] \\
\hline $\begin{array}{l}\text { Stevns Klint } \\
\text { chalk }\end{array}$ & EPM & $\begin{array}{c}\mathrm{CaCl}_{2} \text { and } \mathrm{NaSO}_{4} \text { in } \\
0.571 \mathrm{M} \mathrm{NaCl}\end{array}$ & Chalk/water/air & 48 & $\begin{array}{c}\text { Controlled at } \\
8.4\end{array}$ & Closed & N/A & N/A & N/A & [요 \\
\hline $\begin{array}{c}\text { Natural } \\
\text { carbonate }\end{array}$ & EPM & $\begin{array}{l}\text { Deionized water } \\
\text { (DI) }\end{array}$ & Calcite/water & 1 & $\begin{array}{c}\text { Controlled at } \\
8.4\end{array}$ & Closed & N/A & $0.2-0.75$ & Extrapolated & [11] \\
\hline $\begin{array}{c}\text { Natural } \\
\text { carbonate }\end{array}$ & $\begin{array}{l}\text { SPM in } \\
\text { intact } \\
\text { samples }\end{array}$ & $\begin{array}{c}0.05 \mathrm{M} \mathrm{NaCl} \\
0.5 \mathrm{M} \mathrm{NaCl} \\
2 \mathrm{M} \mathrm{NaCl}\end{array}$ & $\begin{array}{c}\text { Calcite/water/ } \\
\text { air }\end{array}$ & $168-720$ & 8.2 & Closed & $\begin{array}{l}-5.29 \\
-4.35 \\
-2.75\end{array}$ & $\begin{array}{l}0.61 \\
0.49 \\
0.41\end{array}$ & Direct & [4] \\
\hline
\end{tabular}




\begin{tabular}{|llll|}
\hline Property/rock & Ketton & Estaillades & Portland \\
Description & $\begin{array}{l}\text { Middle Jurassic Oolitic } \\
\text { limestone from UK }\end{array}$ & $\begin{array}{l}\text { Upper Cretaceous } \\
\text { limestone from France }\end{array}$ & $\begin{array}{l}\text { Upper Jurassic Ooparite } \\
\text { limestone from UK }\end{array}$ \\
Porosity & $23 \% \pm 0.5$ & $28 \% \pm 0.5$ & $20 \% \pm 0.5$ \\
Permeability & 1.4 Darcy \pm 0.4 & 0.13 Darcy \pm 0.2 & 0.005 Darcy \pm 0.001 \\
$\begin{array}{l}\text { Intrinsic } \\
\text { Formation }\end{array}$ & $13.87 \pm 0.5$ & $12.92 \pm 0.5$ & $22.04 \pm 0.5$ \\
Factor $(\boldsymbol{F})$ & & & \\
Compositions & $97 \%$ calcite $\left(\mathrm{CaCO}_{3}\right)$ & $97 \%$ calcite $\left(\mathrm{CaCO}_{3}\right)$ & $96.6 \%$ calcite $\left(\mathrm{CaCO}_{3}\right)$ \\
& $3 \%$ magnesium* & $3 \%$ magnesium* & $3.4 \%$ quartz \\
Dimensions & Length $(\mathrm{L})=0.076 \mathrm{~m}$ & Length $(\mathrm{L})=0.076 \mathrm{~m}$ & $\begin{array}{l}\text { Length }(\mathrm{L})=0.076 \mathrm{~m} \\
\end{array}$ \\
\hline
\end{tabular}


1087 Figure 1: (a) A schematic representation of the electrical double layer at the calcite-water interface. The surface 1088 speciation sites $\left(>\mathrm{CO}_{3} \mathrm{H}^{0},>\mathrm{CaO}^{-+},>\mathrm{CO}_{3} \mathrm{Ca}^{+},>\mathrm{CaOH}^{0},>\mathrm{CaCO}_{3}^{-}, \mathrm{CaOH}_{2}{ }^{+}\right.$and $\left.>\mathrm{CO}_{3}^{-}\right)$are from [57]. The Stern layer 1089 is described by three planes. The $\mathbf{0}$-plane $(\mathbf{x}=\mathbf{0})$ corresponds to the hydrolysis layer where $\mathrm{H}$ and $\mathrm{OH}$ are chemi1090 bonded to the bulk ions [71]. The 1-plane $(x=1)$ denotes inner-sphere complexes and corresponds to the inner 1091 Helmholtz plane (IHP), while the 2-plane ( $x=2)$ denotes outer-sphere complexes and corresponds to the outer 1092 Helmholtz plane (OHP; [ [55]). (b) A schematic representation of the variation in the electrical potential with distance 1093 from the mineral surface. Here the mineral surface is negatively charged, consistent with the surface complexation

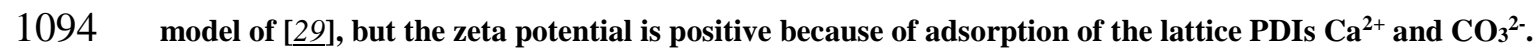


Figure 2: Zeta potential of (a) Iceland spar and synthetic calcite and (b) natural calcite and carbonate rocks in indifferent electrolytes as a function of $\mathrm{pH}$. Measurements were obtained using the electrophoretic mobility method (EPM), with the exception of Somasundaran and Agar [67] (diamonds) and Thompson and Pownall [78] (squares). Error bars are shown when reported by the source.

1099 In (a), data from Somasundaran and Agar [67] in deionized water after different mixing times ( $\bullet$ : no mixing; $\diamond$ : after 1

1100 week; $\diamond:$ after two months of mixing); Sampat Kumar et al. [60] in deionised water (+); Siffert and Fimbel [63] in

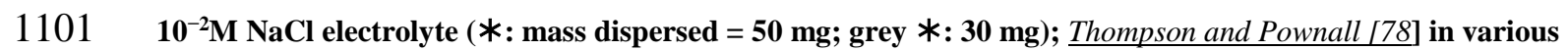

1102 electrolytes $\left(n: \mathrm{NaCl}\left(5 \times 10^{-3} \mathrm{M}\right) ; \square: \mathrm{NaCl}\left(5 \times 10^{-3} \mathrm{M}\right) / \mathrm{NaHCO}_{3}\left(1 \times 10^{-3} \mathrm{M}\right) ; \square: \mathrm{NaCl}\left(5 \times 10^{-3} \mathrm{M}\right) / \mathrm{NaHCO}_{3}\right.$

$\left.1103\left(\mathbf{1} \times \mathbf{1 0}^{-3} \mathbf{M}\right) / \mathbf{H}_{2} \mathbf{C O}_{3} / \mathbf{C a}(\mathbf{O H})_{2}\right) ;$ Cicerone et al. [12] in $\left.\mathbf{1 0}^{-3} \mathbf{M} \mathbf{~ K C l ~ e l e c t r o l y t e ~ ( ~} \mathbf{\Delta}\right) ; \underline{V d o v i c ́ ~ a n d ~ B i s ̌ c ́ a n ~[81] ~ i n ~ 10 ~}{ }^{-3} \mathbf{M} \mathbf{N a C l}$

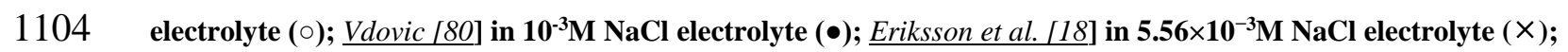

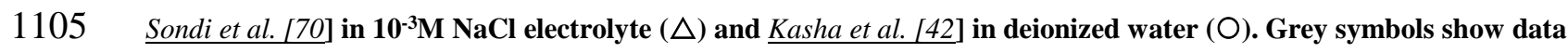

1106 from Mahani et al. [47] in various electrolytes ( $\Delta$ : formation brine; $\$$ : seawater; $\square: 25$ times diluted seawater).

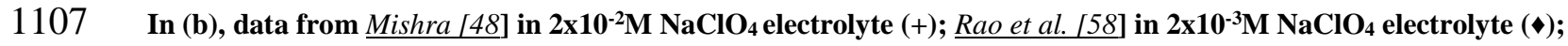

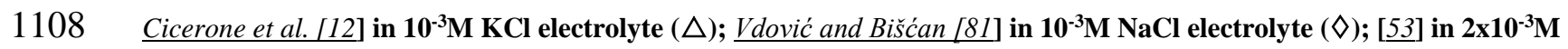

$1109 \quad \mathrm{NaNO}_{3}$ electrolyte (*); $\underline{\text { Vdovic [80] }}$ in $\mathbf{1 0}^{-3} \mathbf{M} \mathbf{~ N a C l}$ electrolyte ( $\circ$ : limestone; $\bullet$ : lake sediment) and $\underline{\text { Somasundaran et al. }}$

$1110[69]$ in $\mathbf{1 0}^{-3} \mathbf{M ~ K N O}_{3}$ electrolyte (๘). Grey symbols show data on natural carbonate rocks in various electrolytes (•:

1111 deionized water containing $0.09 \mathrm{M} \mathrm{CaCl}_{2}$ from [11]; $\Delta$ : formation brine; ४: seawater; $₫$ : 25 times diluted seawater,

1112 all from [47]). 
1113 Figure 3: Zeta potential and electrophoretic mobility of synthetic calcite and Iceland spar as a function of pH in 1114 experiments with (a) constant pCa and (b) controlled $p \mathbf{C O}_{2}$. Error bars are shown when reported by the source.

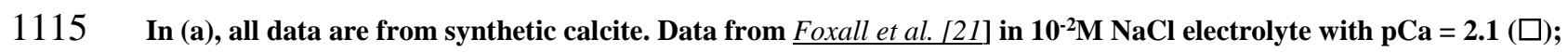

1116 Thompson and Pownall [78] in $5 \times \mathbf{5 0}^{-4} \mathbf{M ~ C a C l}_{2}$ electrolyte with $\mathbf{p C a}=\mathbf{3 . 3}(\times)$; Cicerone et al. [12] in $\mathbf{1 0}^{-3} \mathbf{M} \mathbf{~ K C l}$

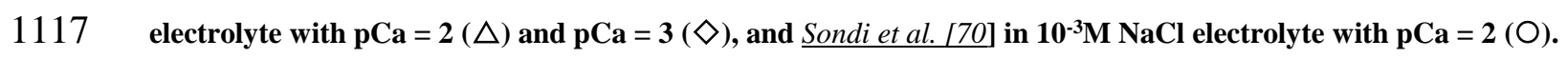

1118 In (b), all data are from powdered Iceland spar in deionized water with various $p \mathbf{C O}_{2}$. Data from Moulin and Roques

$1119[51]\left(\diamond: p \mathbf{C O}_{2}=\mathbf{0 . 0 2 3} ; \diamond: p \mathbf{C O}_{2}=\mathbf{0 . 2 3 4}\right)$ and Heberling et al. $[29]\left(\triangle: p \mathbf{C O}_{2}=1 ; \bigcirc: p \mathbf{C O}_{2}=10^{-3.44} ; \square: p \mathbf{C O}_{2}=10^{-5.2}\right)$. 
1120 Figure 4: Zeta potential of synthetic calcite and natural carbonate in indifferent electrolytes as a function of pCa, at 1121 (a) low Ca concentration only and (b) low to high Ca concentration. Error bars are shown when reported by the 1122 source.

1123 In (a), all data are from powdered synthetic calcite with the exception of Alroudhan et al. [4] (grey symbols). Data

1124 from Thompson and Pownall [78] in different aqueous compositions ( $\square$ : $\mathbf{N a C l}\left(2 \times 10^{-3} \mathbf{M}\right) / \mathrm{NaHCO}_{3}\left(10^{-2} \mathbf{M}\right) ; \square: \mathrm{NaCl}$

$1125 \quad\left(2 \times 10^{-3}\right) ; \square: \mathrm{NaCl}\left(2 \times 10^{-3} \mathrm{M}\right) / \mathrm{NaHCO}_{3}\left(10^{-2} \mathrm{M}\right) / \mathrm{Ca}(\mathrm{OH})_{2}\left(10^{-2} \mathrm{M}\right)$; $\square: \mathrm{NaCl}\left(2 \times 10^{-3} \mathrm{M}\right) / \mathrm{NaHCO}_{3}\left(1^{-2} \mathrm{M}^{-} / \mathrm{H}_{2} \mathrm{CO}_{3}\left(10^{-2} \mathrm{M}\right)\right)$;

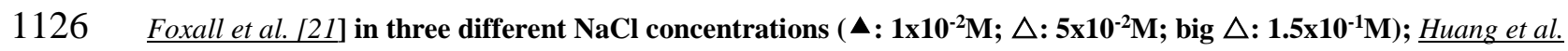

1127 [33] in $0.01 \mathbf{C a C l}_{2}$ electrolyte $(\times)$ and Cicerone et al. [12] in $\mathbf{1 0}^{-3} \mathrm{M}$ KCl electrolyte $(\circ)$. Grey diamonds show data

1128 from Alroudhan et al. [4] on natural carbonate in $0.05 \mathrm{M} \mathrm{NaCl} \mathrm{electrolyte} \mathrm{at} \mathrm{high} \mathrm{pCa} \mathrm{(४:} \mathrm{SPM} \mathrm{data;} \diamond$ : EPM data);

1129 the full span of these data is shown in Figure $2 \mathbf{b}$.

1130 In (b), all data are from natural calcite and carbonate rocks, with the exception of Kasha et al. [42] (filled symbols).

1131 Data from Zhang and Austad [88] on powdered Stevns Klint chalk in 0.571M NaCl electrolyte ( $\times$ ); Chen et al. [11] in

1132 deionized water $(\circ) ; \underline{\text { Kasha et al. }[42]}$ in synthesized brines equivalent to seawater composition $(\bullet)$ and $\underline{\text { Alroudhan et }}$

1133 al. [4] in $\mathbf{0 . 0 5} \mathbf{M ~ N a C l ~}(\diamond)$. Grey symbols show data from Alroudhan et al. [4] in intact natural carbonate rocks in

1134 various $\mathrm{NaCl}$ concentrations ( $\bullet: 0.05 \mathrm{M} ; \boldsymbol{\Delta}: \mathbf{0 . 5 M}$; $\square: 2 \mathrm{M}$; all from; error bars are the same size or smaller than the

1135 symbols). 
1136 Figure 5: Zeta potential of synthetic calcite and natural carbonate as a function of (a) pMg and (b) pSO4. Error bars 1137 are shown when reported by the source.

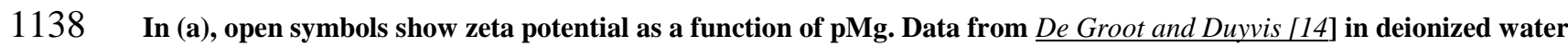

$1139(\triangle)$; Smallwood [64] in deionized water $(\square)$; Zhang et al. [87] in 0.571M NaCl electrolyte $(\times)$; Chen et al. [11] in

1140 deionized water $(O)$ and Alroudhan et al. [4] in intact natural Portland carbonate in 0.05M NaCl electrolyte $(\diamond ;$ error

1141 bars for these data are the same size or smaller than the symbols). For comparison, filled symbols show

1142 measurements as a function of pCa when available from the same studies.

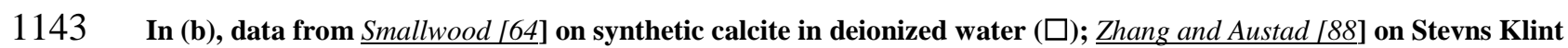

1144 chalk in 0.571M NaCl electrolyte $(X)$ and Alroudhan et al. [4] in intact natural Portland carbonate in various NaCl

1145 electrolytes $(\diamond: 0.05 \mathrm{M} ; \diamond: 0.5 \mathrm{M}$; error bars are the same size or smaller than the symbols; data from). 
1146 Figure 6: Calcite-water- $\mathrm{CO}_{2}$ equilibrium. Plot (a) shows calcium concentration (expressed as pCa) and pH measured 1147 as a function of time during equilibration of natural Portland rock samples with deionised water. Plot (b) shows 1148 carbonate speciation into $\mathrm{H}_{2} \mathrm{CO}_{3}, \mathrm{HCO}_{3}$, and $\mathrm{CO}_{3}{ }^{2-}$ as a function of $\mathbf{p H}$. Modified from Alroudhan et al. [4].

1149 
$1150 \quad$ Figure 7: (a) Effect of $\mathrm{NaCl}$ concentration on zeta potential on the Ketton (squares) and Estaillades (triangles)

1151 samples. Data obtained on the Portland carbonate sample by Alroudhan et al. [4] are shown for comparison (grey

1152 diamonds). The inset plots (b) and (c) show typical example measurements of voltage and pressure against time from

1153 the SPM used to determine the zeta potential. When pressure and voltage respond in the same sense the zeta potential

1154 is positive and vice-versa. The polarity of the zeta potential is accurately determined even when its value is close to

1155 zero. 
1156 Figure 8: Zeta potential versus (a) $\mathbf{p C a}$ and $\mathbf{p M g}$, and (b) $\mathrm{pSO}_{4}$ for the Ketton (squares) and Estaillades (triangles and 1157 circles) samples at different $\mathrm{NaCl}$ concentrations. Data obtained on the Portland carbonate sample by Alroudhan et al. $1158[4]$ are shown for comparison (diamonds). 
1159 Figure 9: (a) Relationship between pH and pCa or pMg obtained from all the experiments shown in Figure 8, along

1160 with linear regressions to the data. (b) Data shown in Figure 8 replotted against pH using the linear regression shown 1161 in (a). 
1162 Figure 10: Equilibrium pCa (a) and $\mathrm{pSO}_{4}$ (b) versus $\mathrm{NaCl}$ concentration for the Ketton (squares) and Estaillades

1163 (triangles) samples. Data obtained on the Portland carbonate sample by Alroudhan et al. [4] are shown for comparison 1164 (diamonds). 
1165 Figure 11: Impact of $\mathrm{pSO}_{4}$ on pCa and zeta potential measured on the Estaillades sample. (a) pCa measured during 1166 the experiments shown in Figure $8 \mathrm{~b}$ in which $\mathrm{SO}_{4}{ }^{2-}$ was added to pre-equilibrated NaCl brine plotted against

1167 measured pSO4. (b) Zeta potential from the experiments shown in Figure 8b plotted against the measured pCa 1168 recorded in (a).

1169 
$1170 \quad$ Figures

Stern layer

Hydrolysis layer

a)

b)

1171

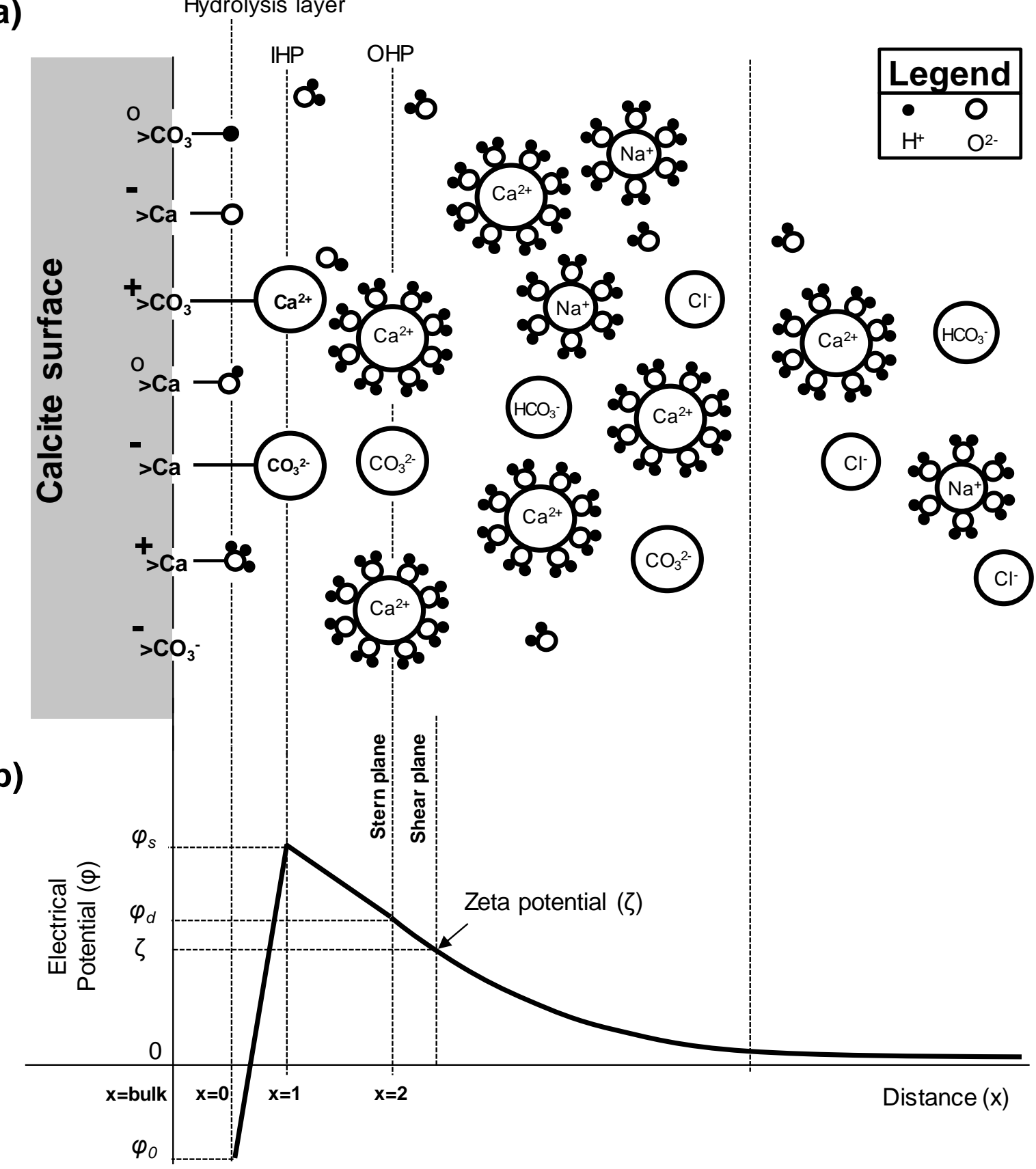

Free electrolyte

Diffuse layer 
(a) Iceland Spar and synthetic calcites

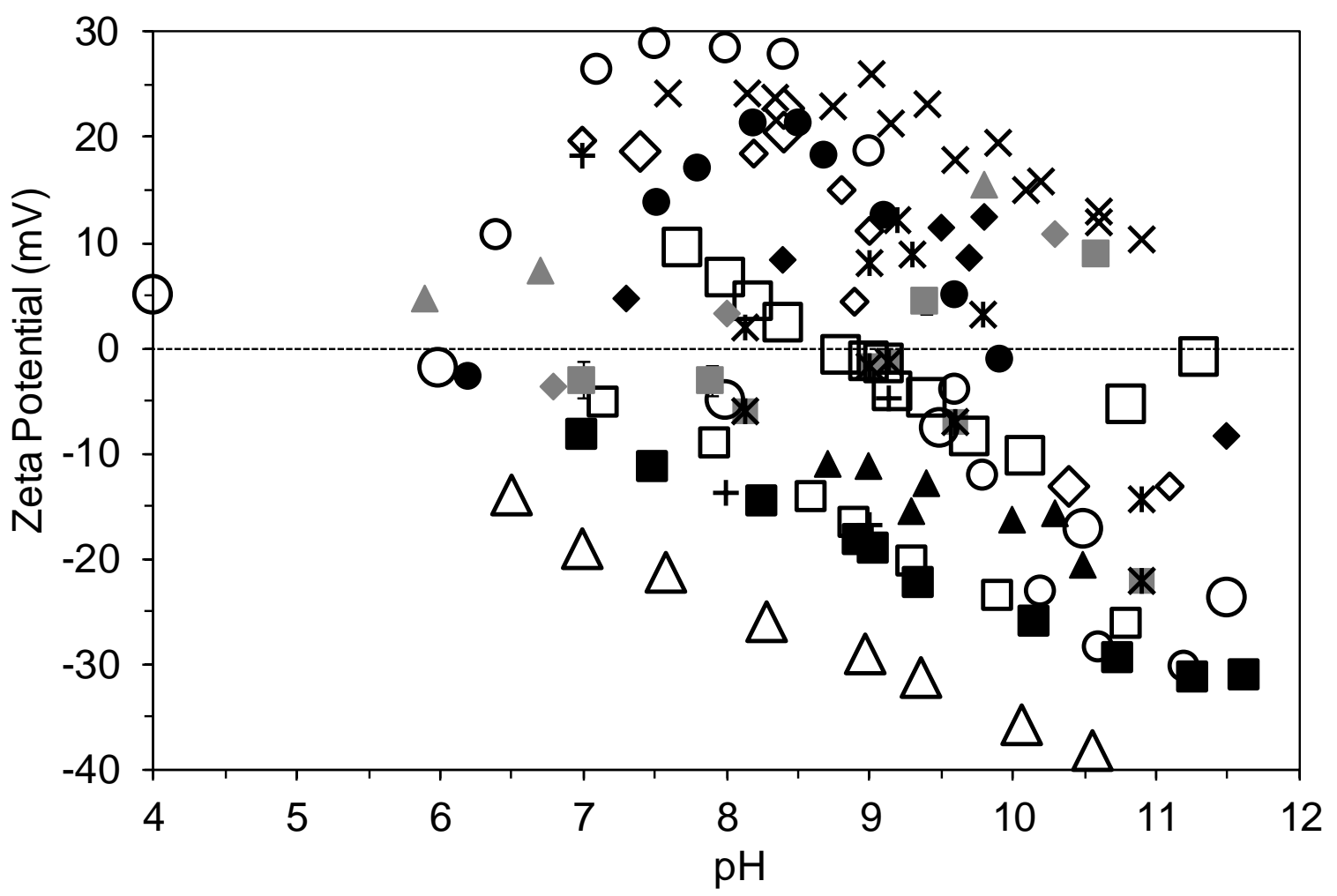

(b) Natural calcites and carbonates

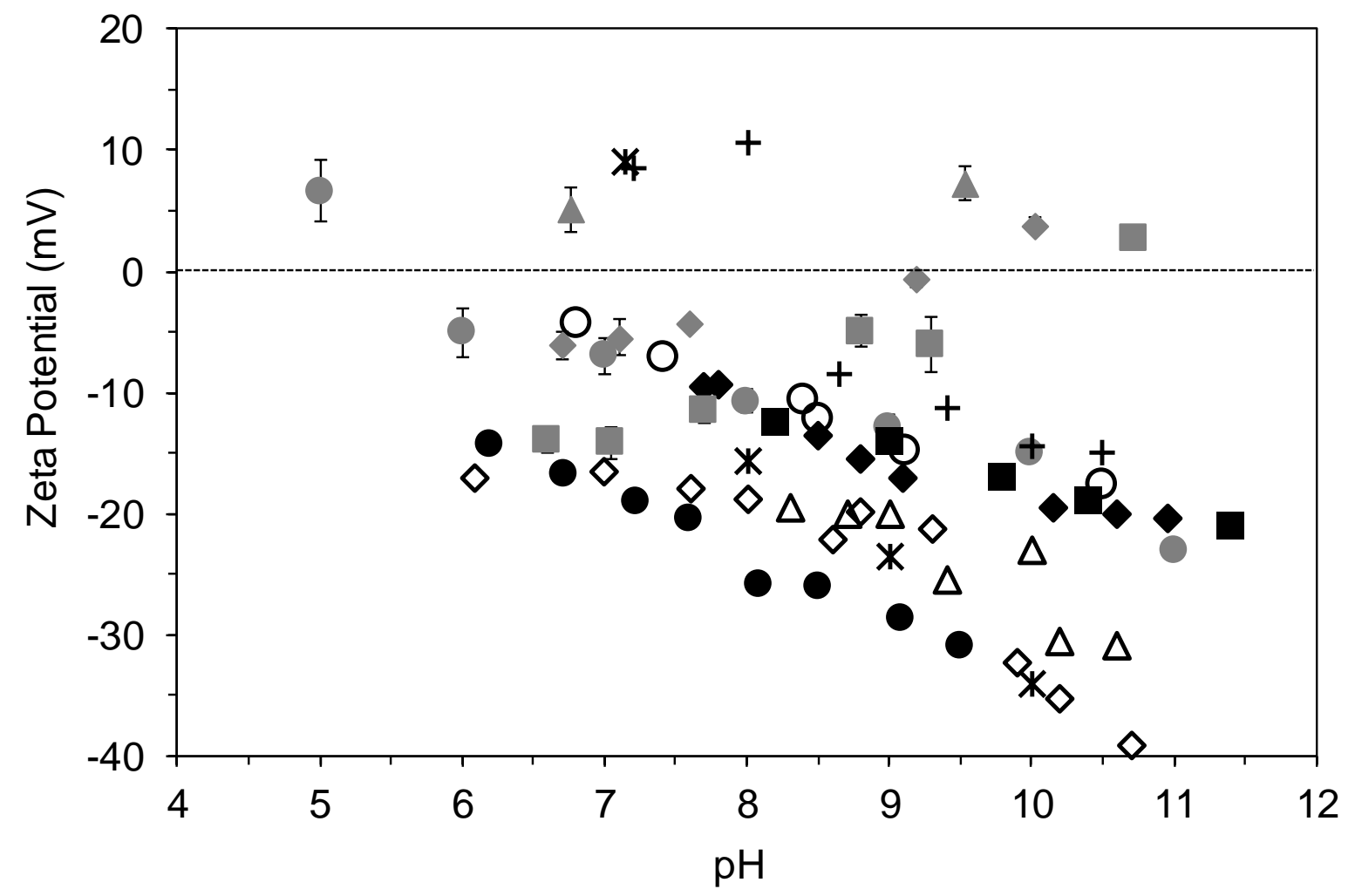

1172 
(a) Constant pCa

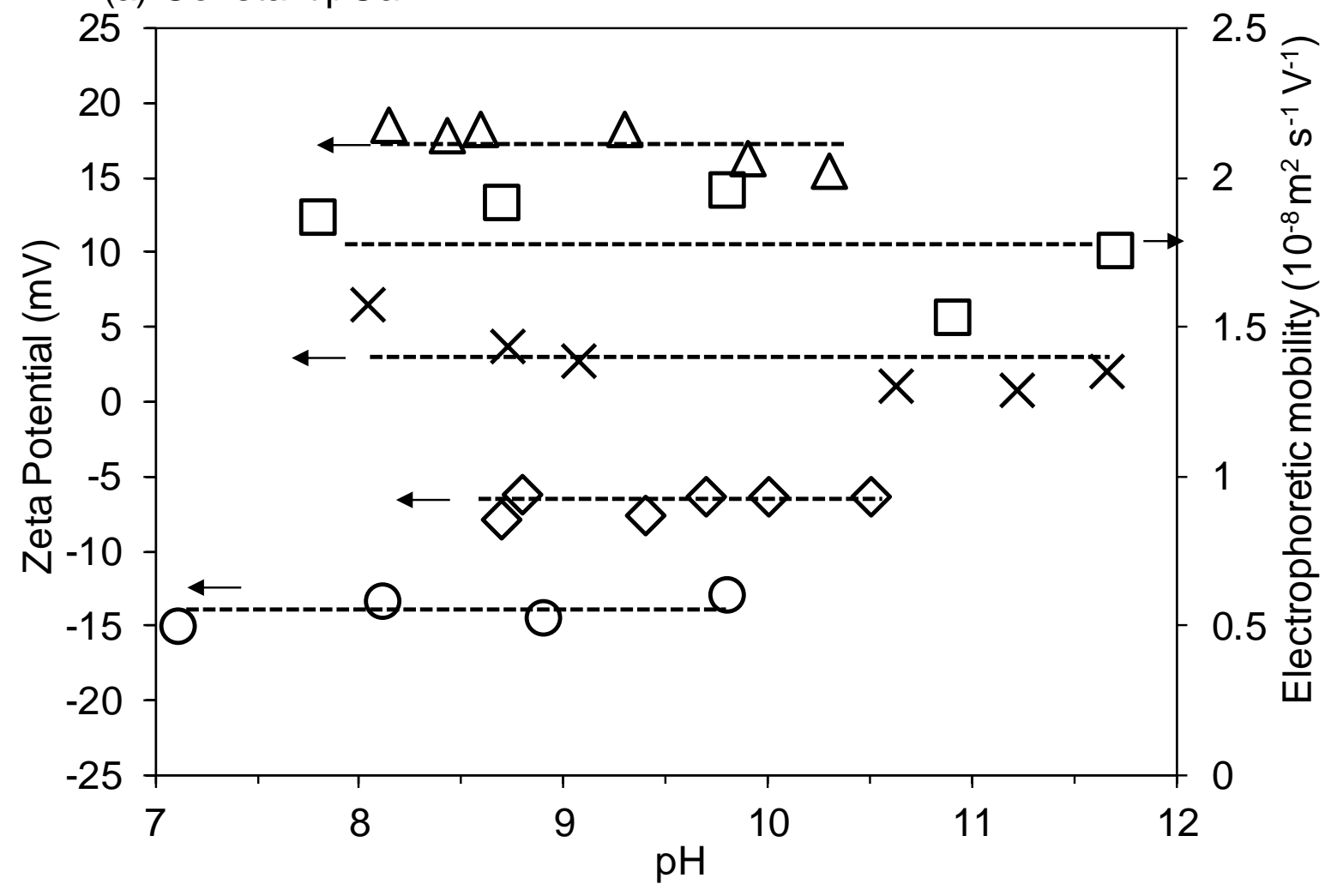

(b) Controlled $p \mathrm{CO}_{2}$

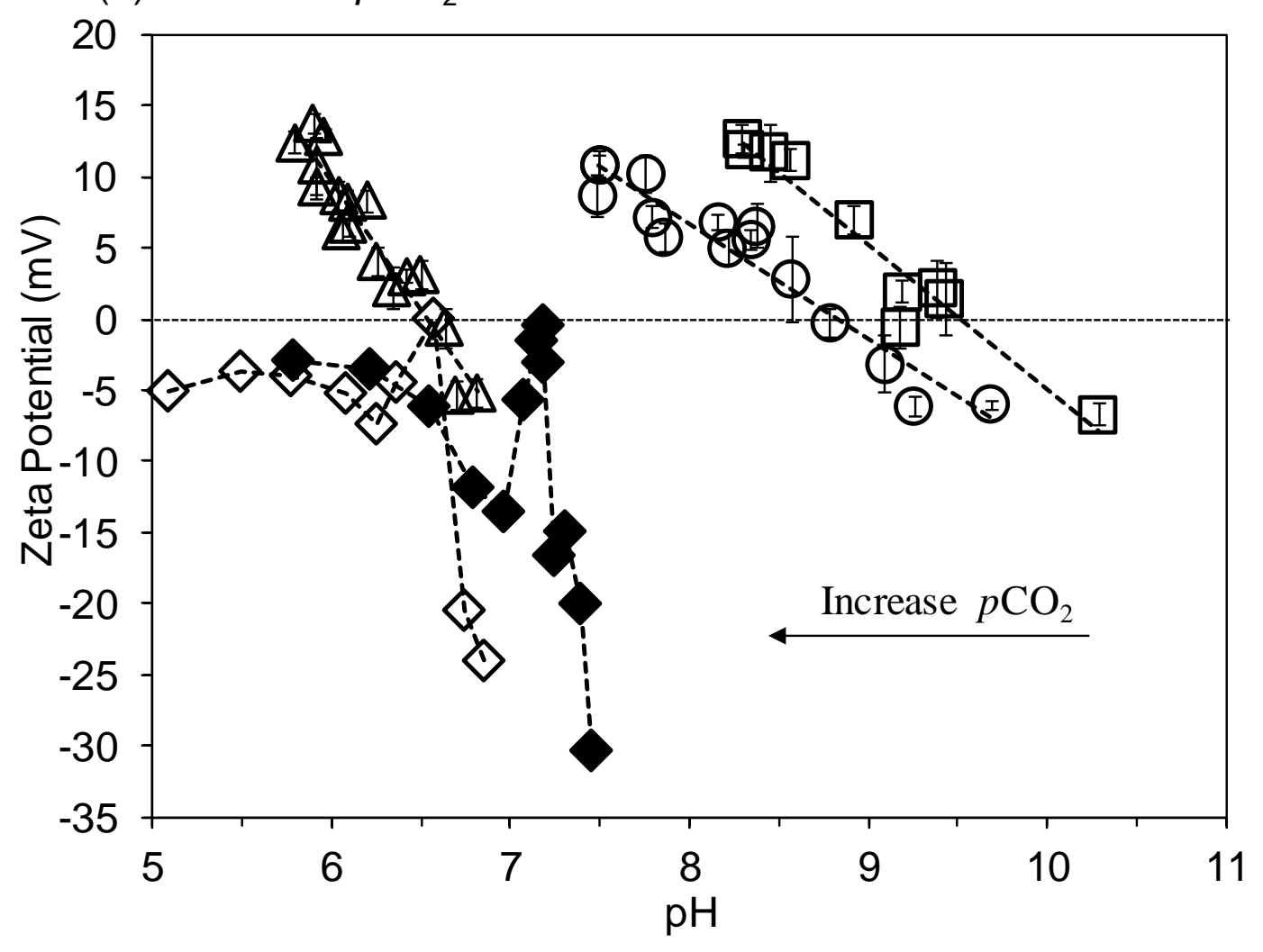


(a) Low Ca concentration

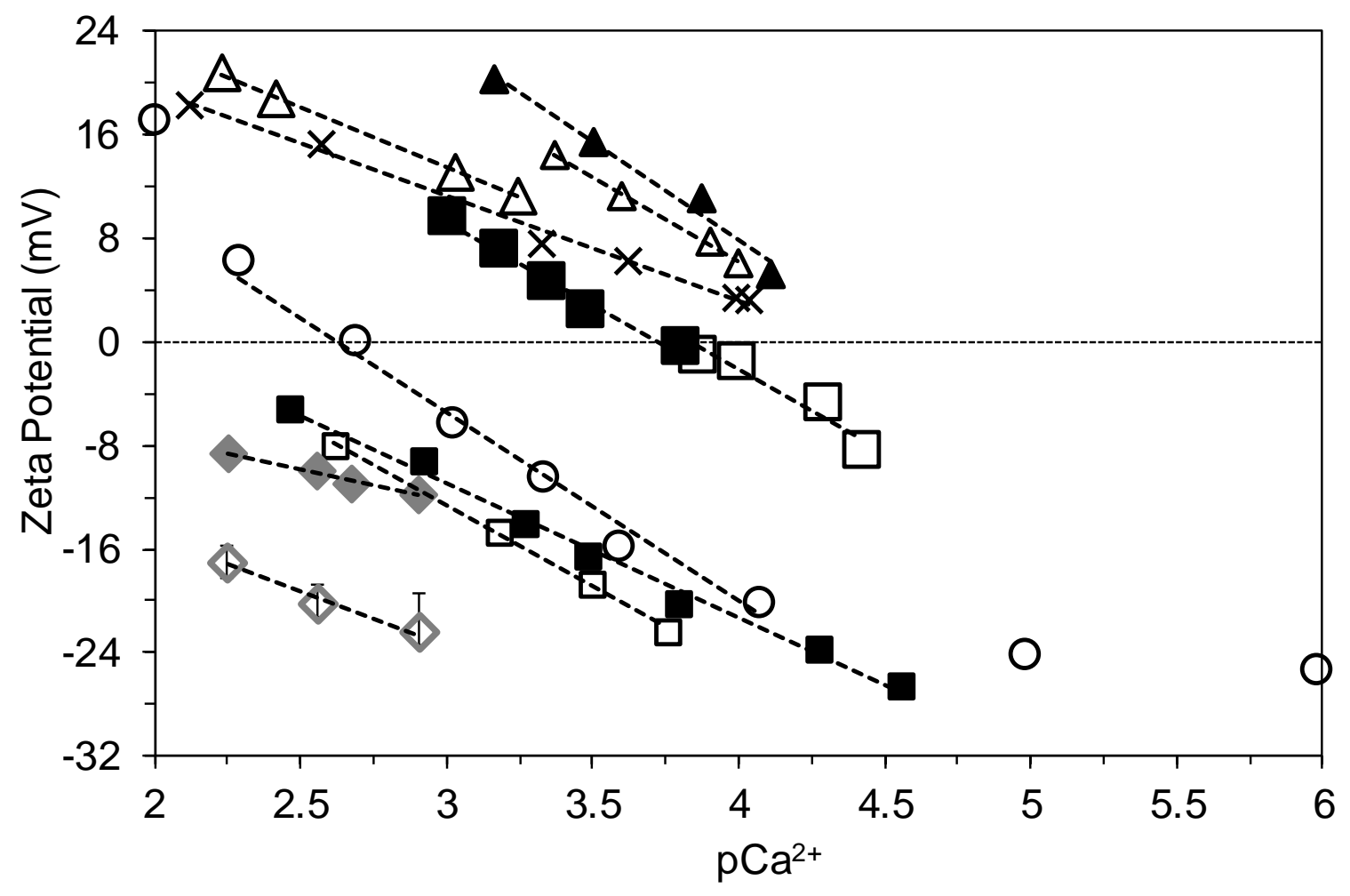

(b) Low to high Ca concentration

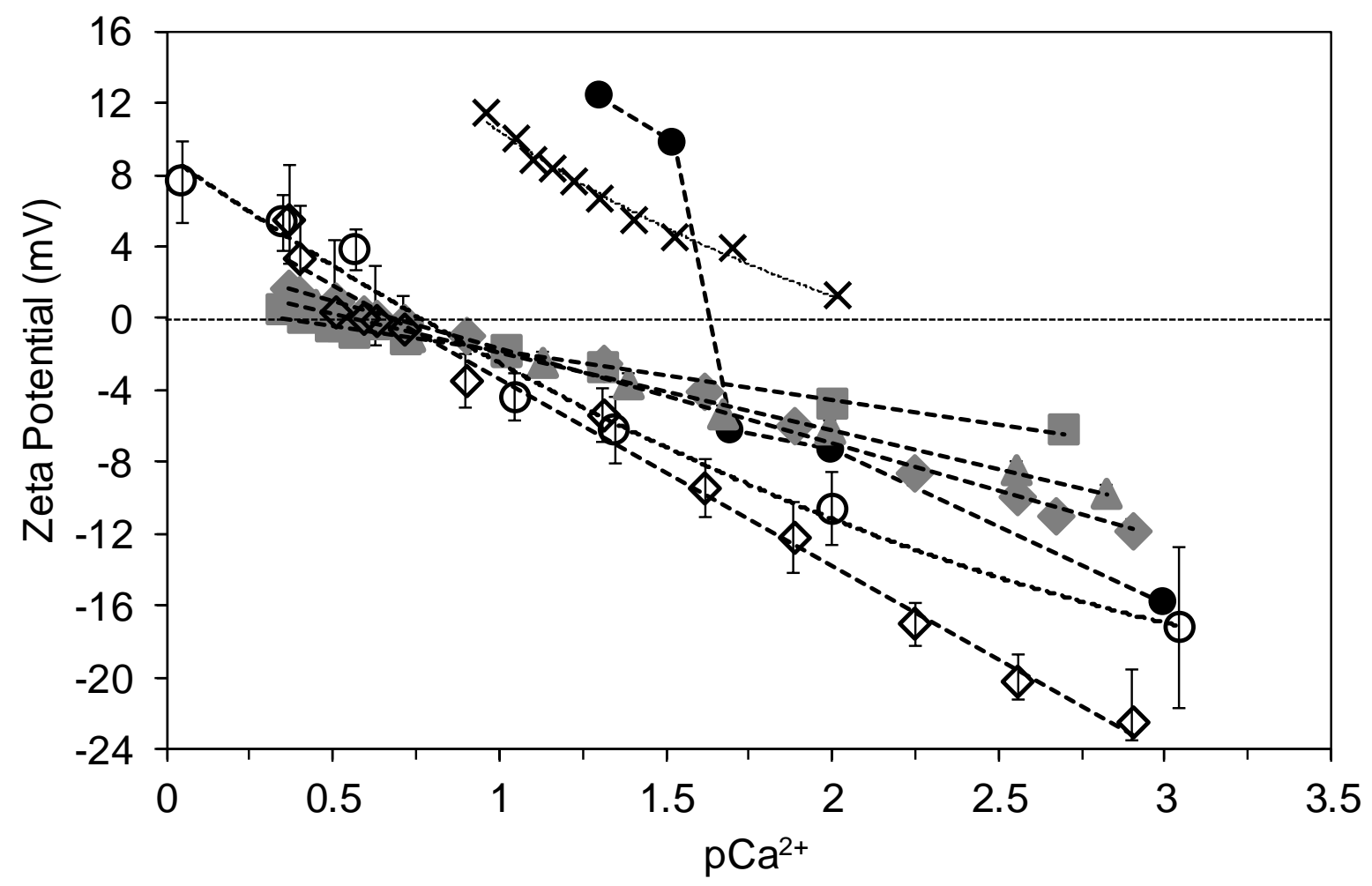

1174 
(a) Effect of Mg on zeta potential of calcite

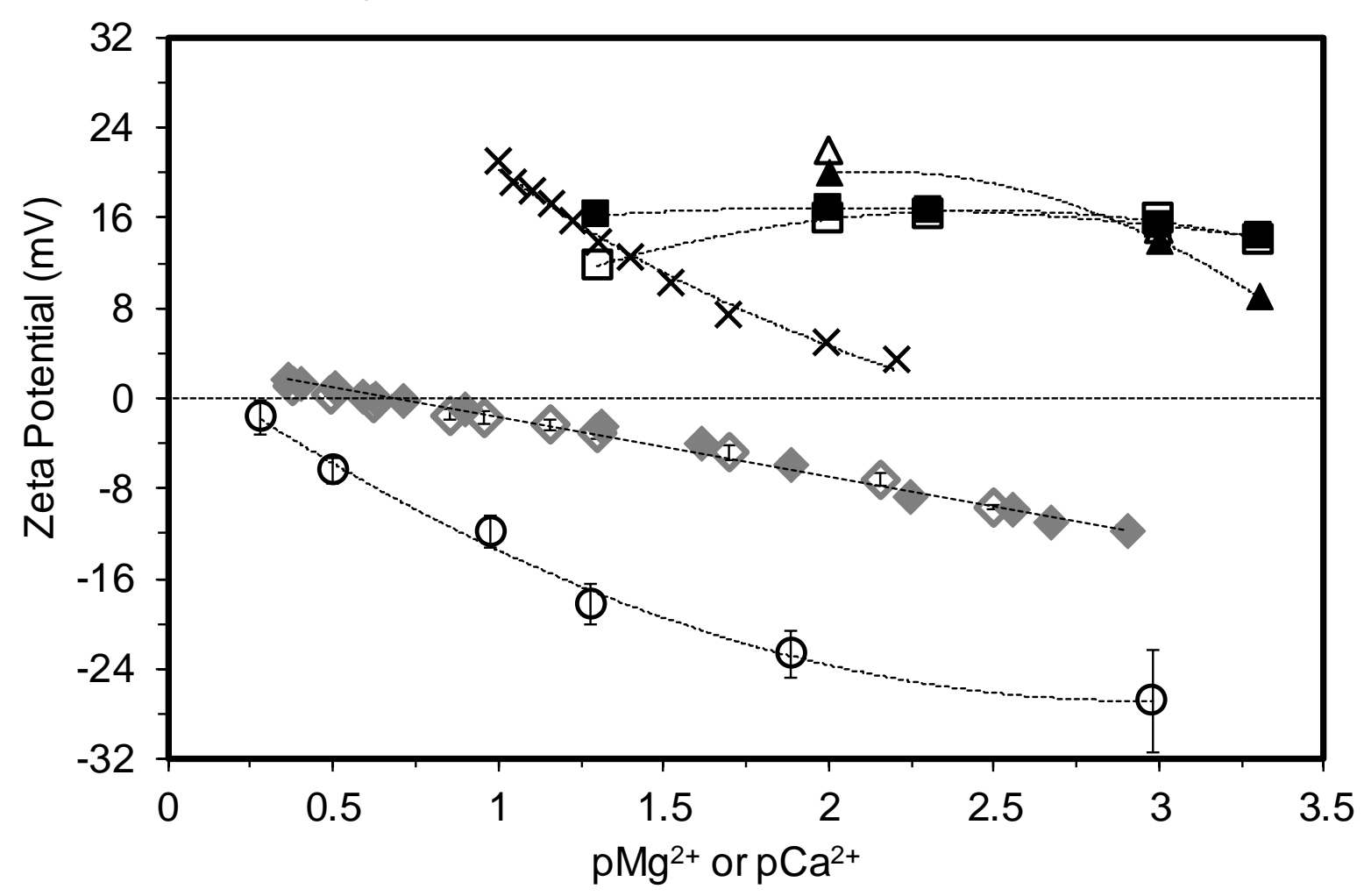

(b) Effect of $\mathrm{SO}_{4}$ on zeta potential of calcite

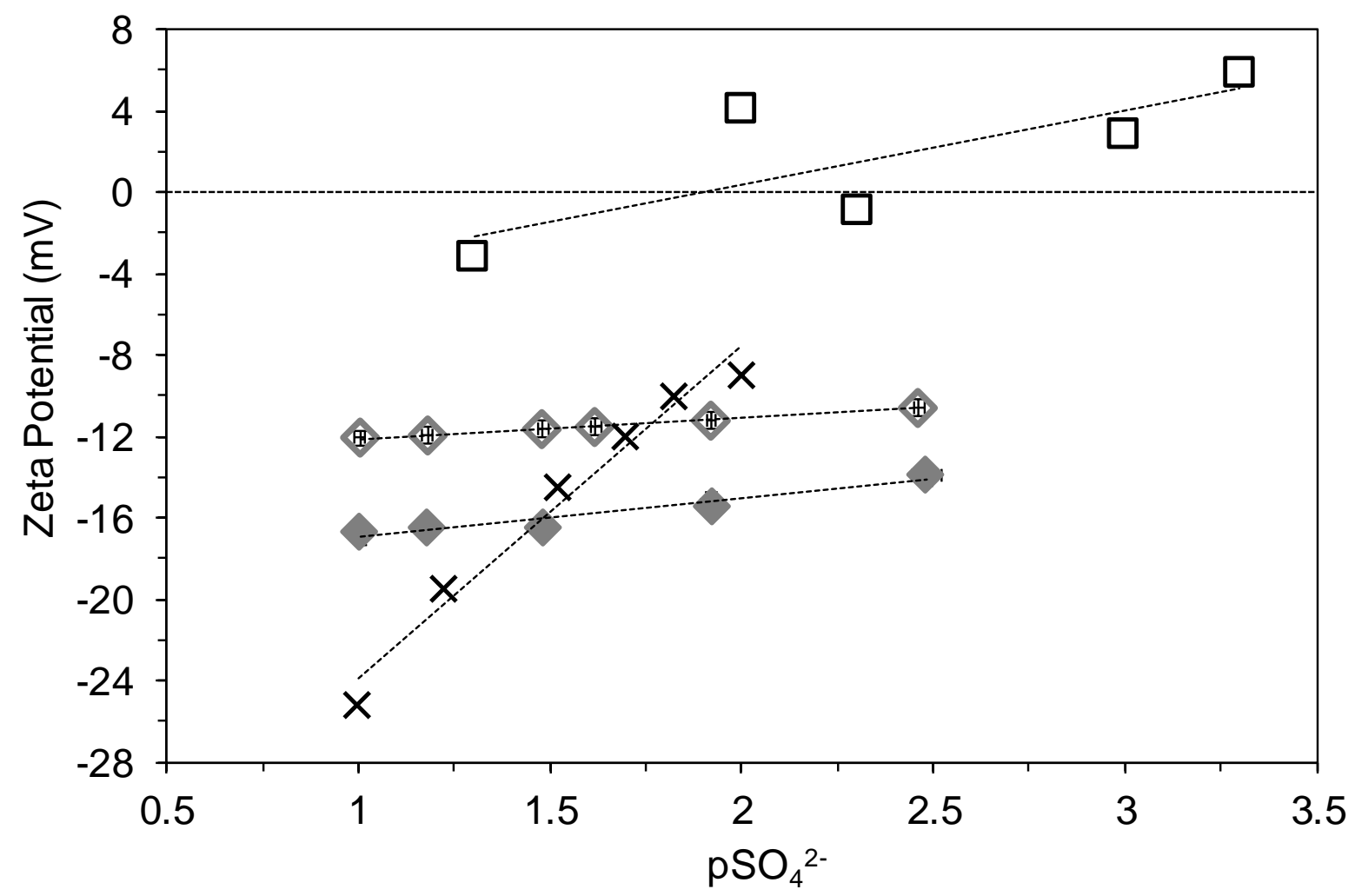


(a)

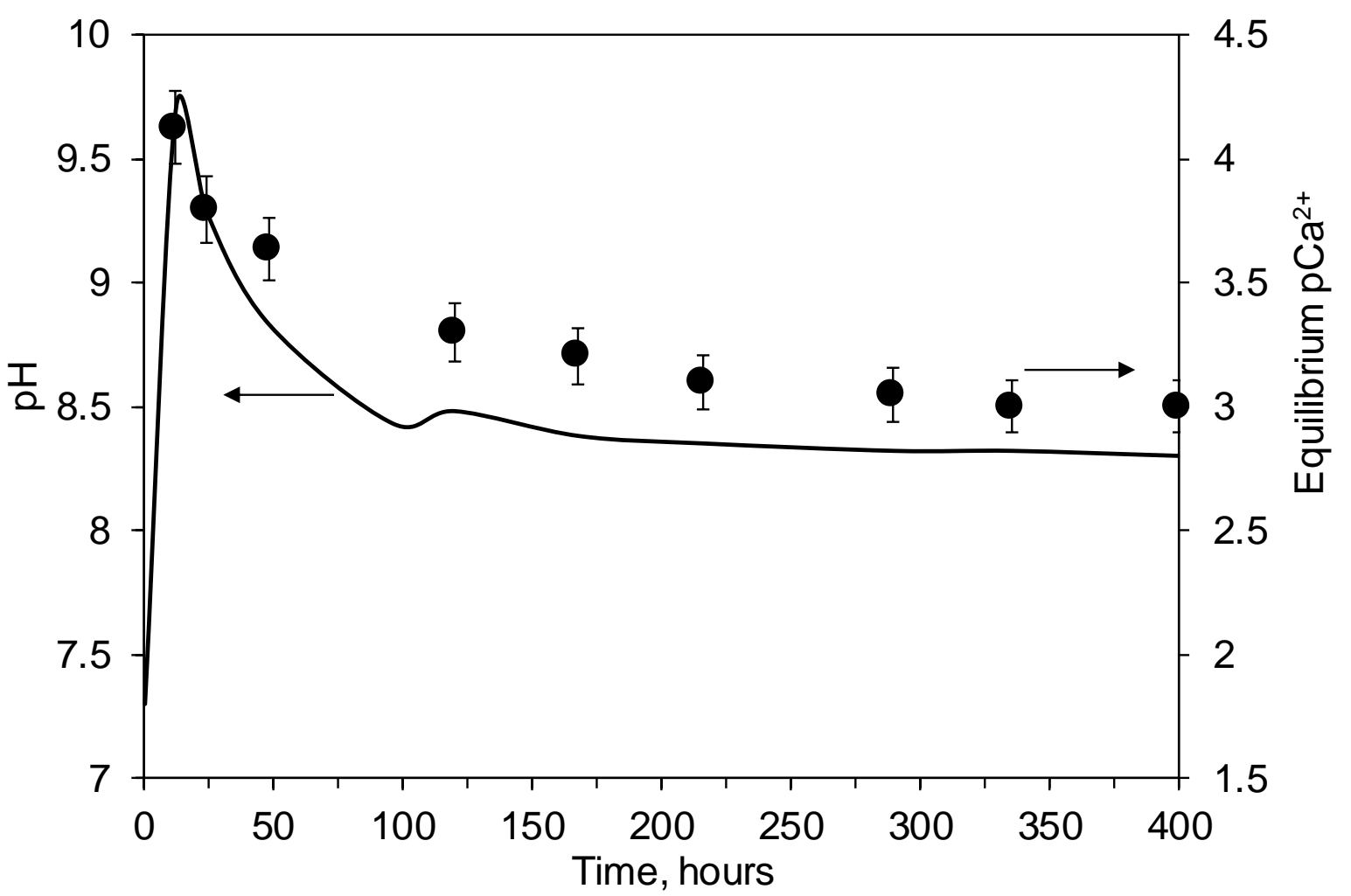

(b)

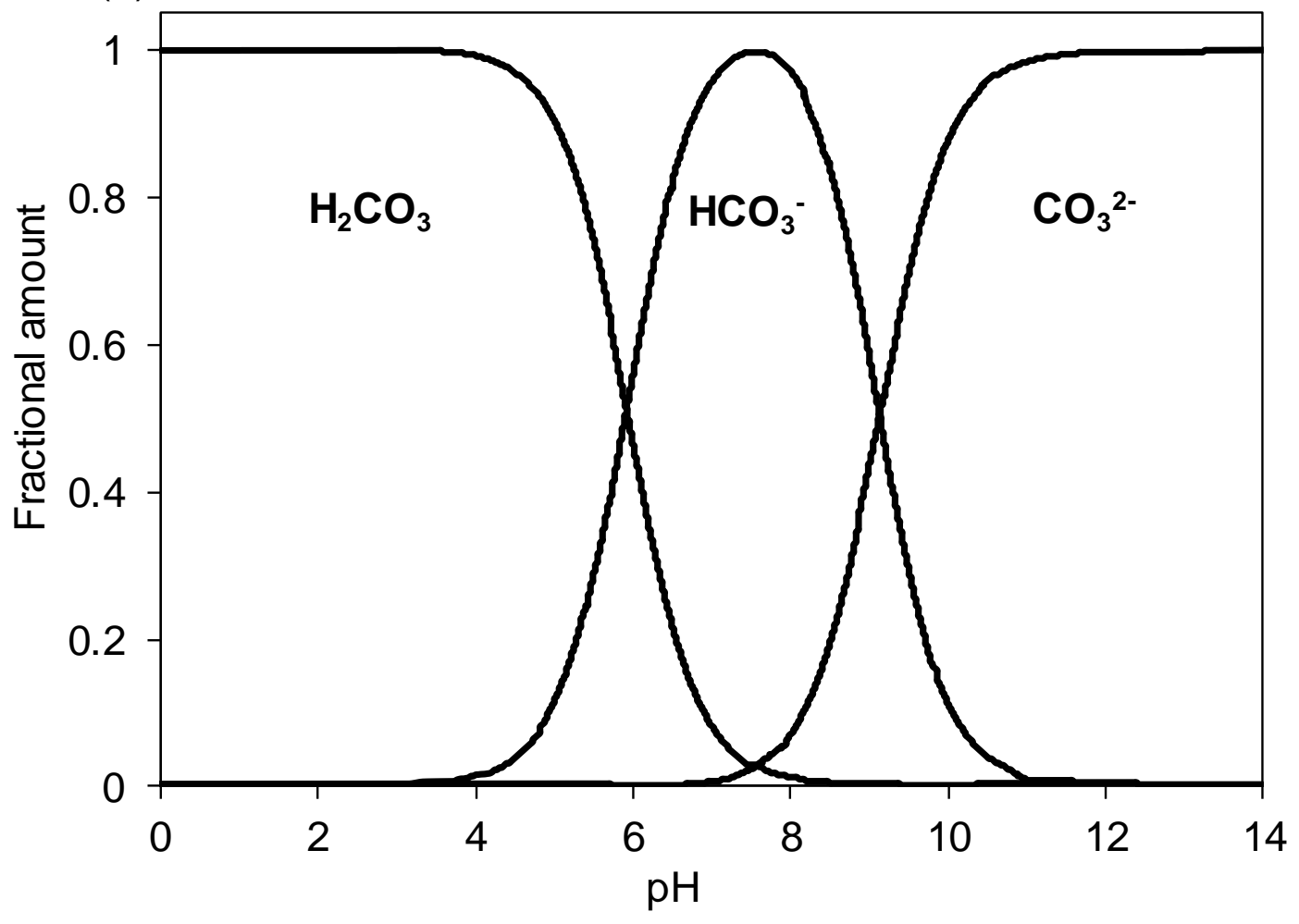

1176 


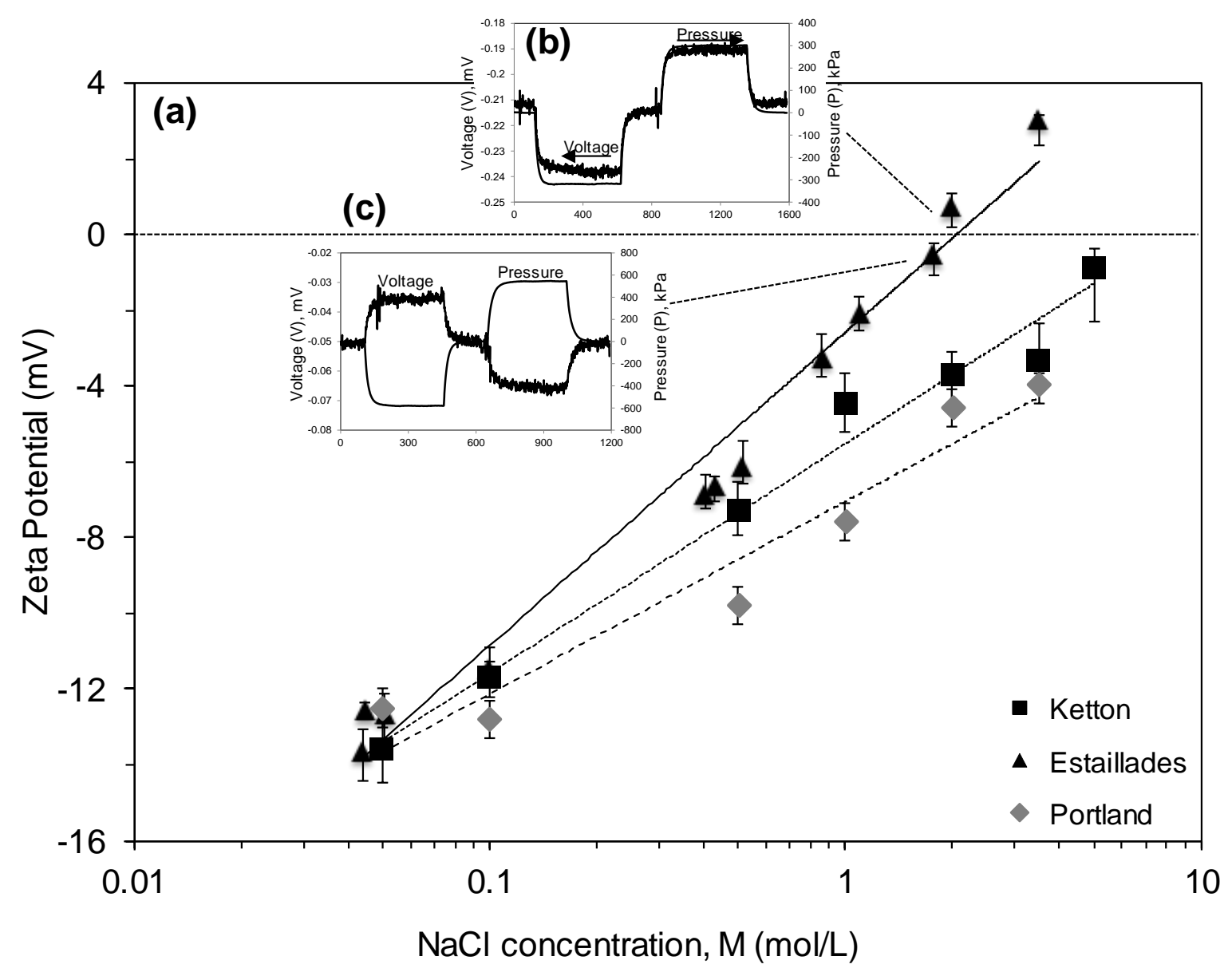

1177 
(a)

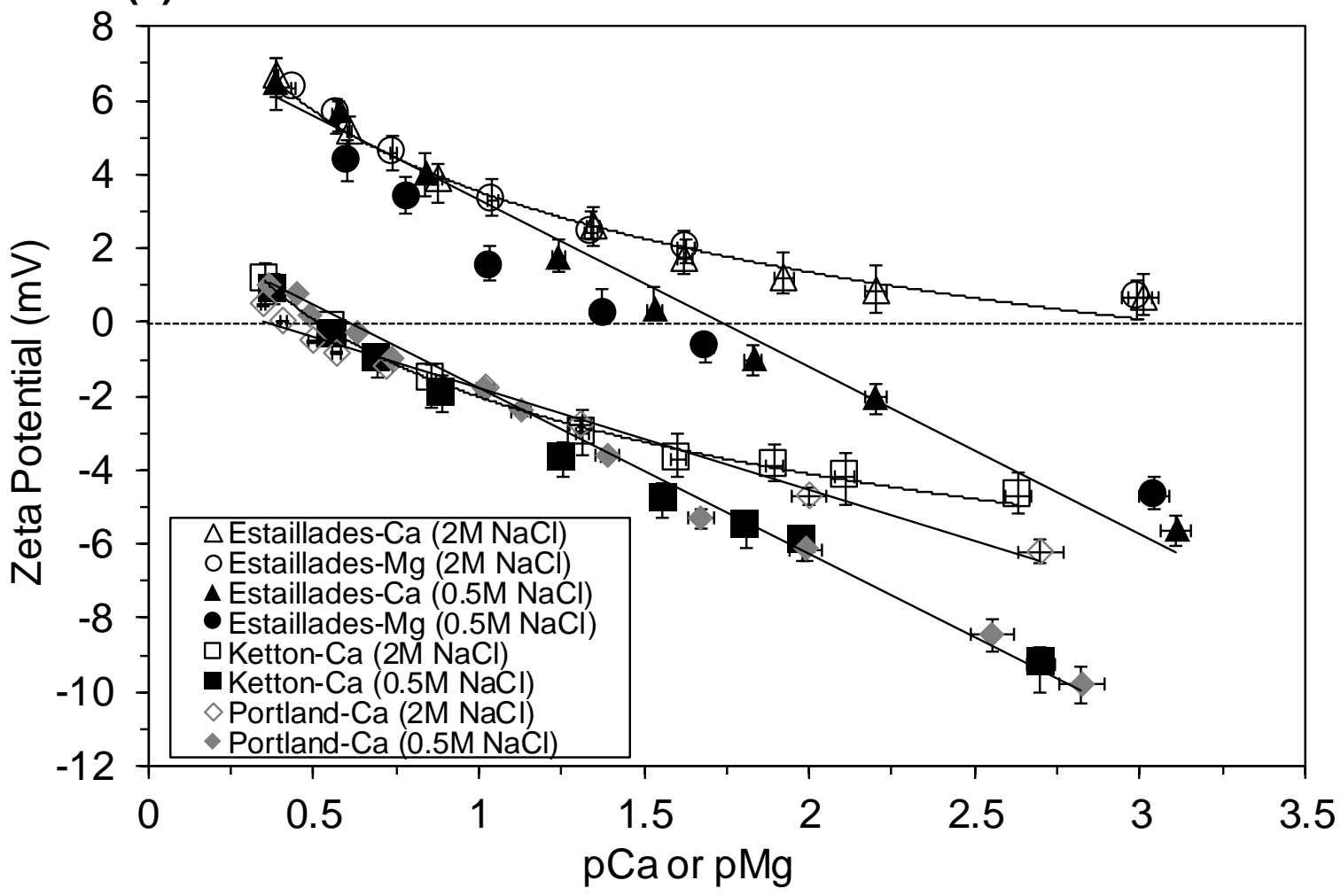

(b)

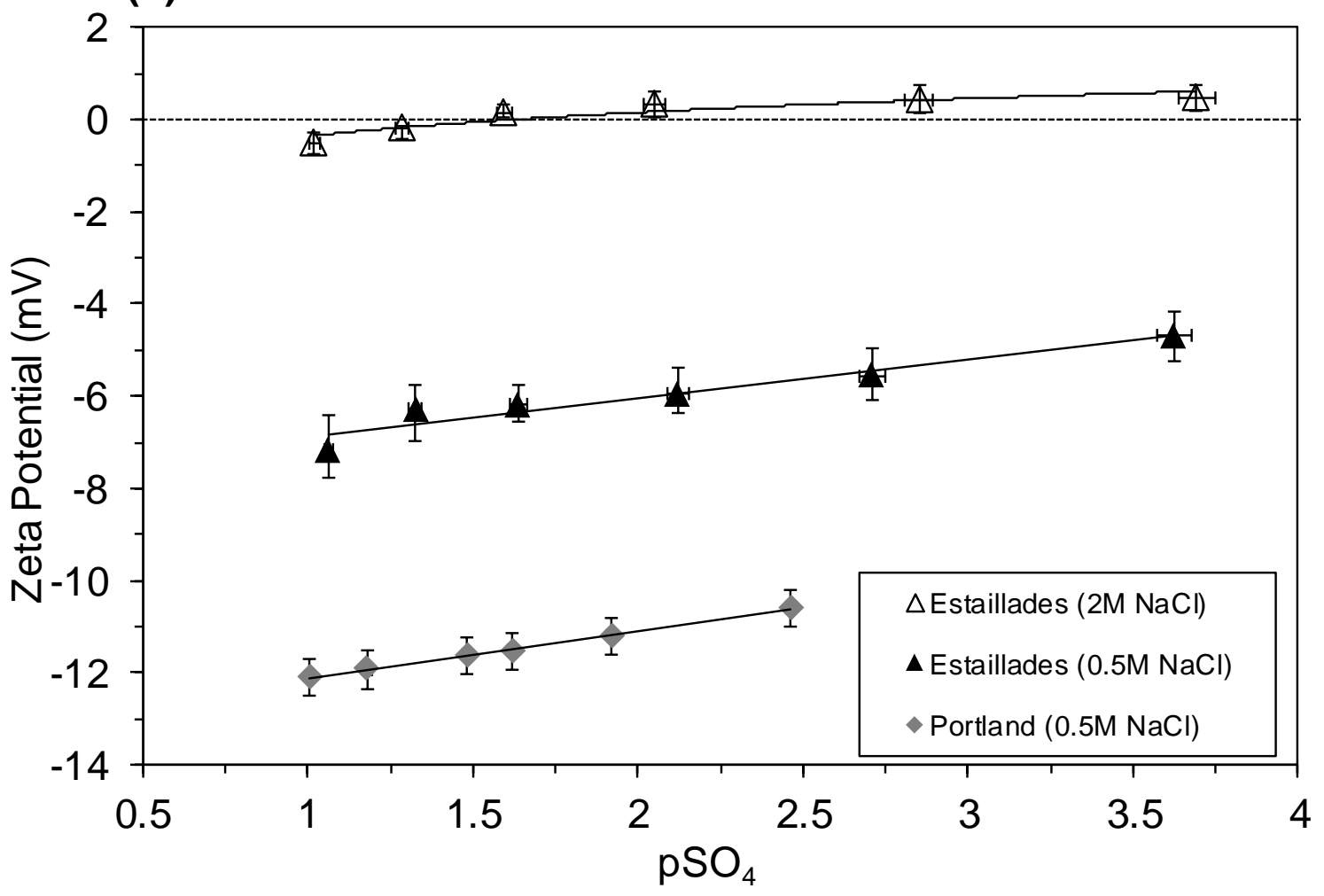

1178 
(a)

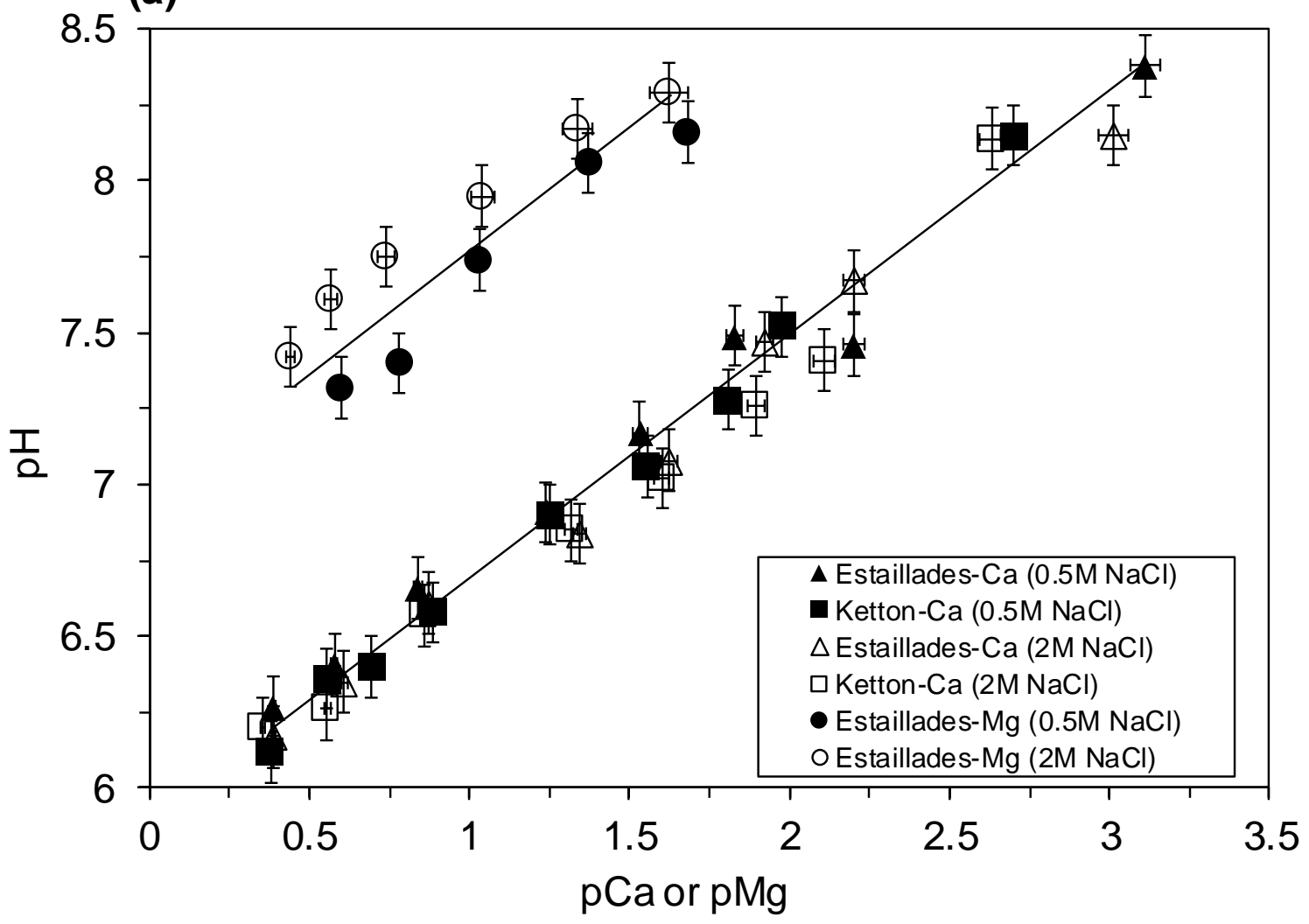

(b)

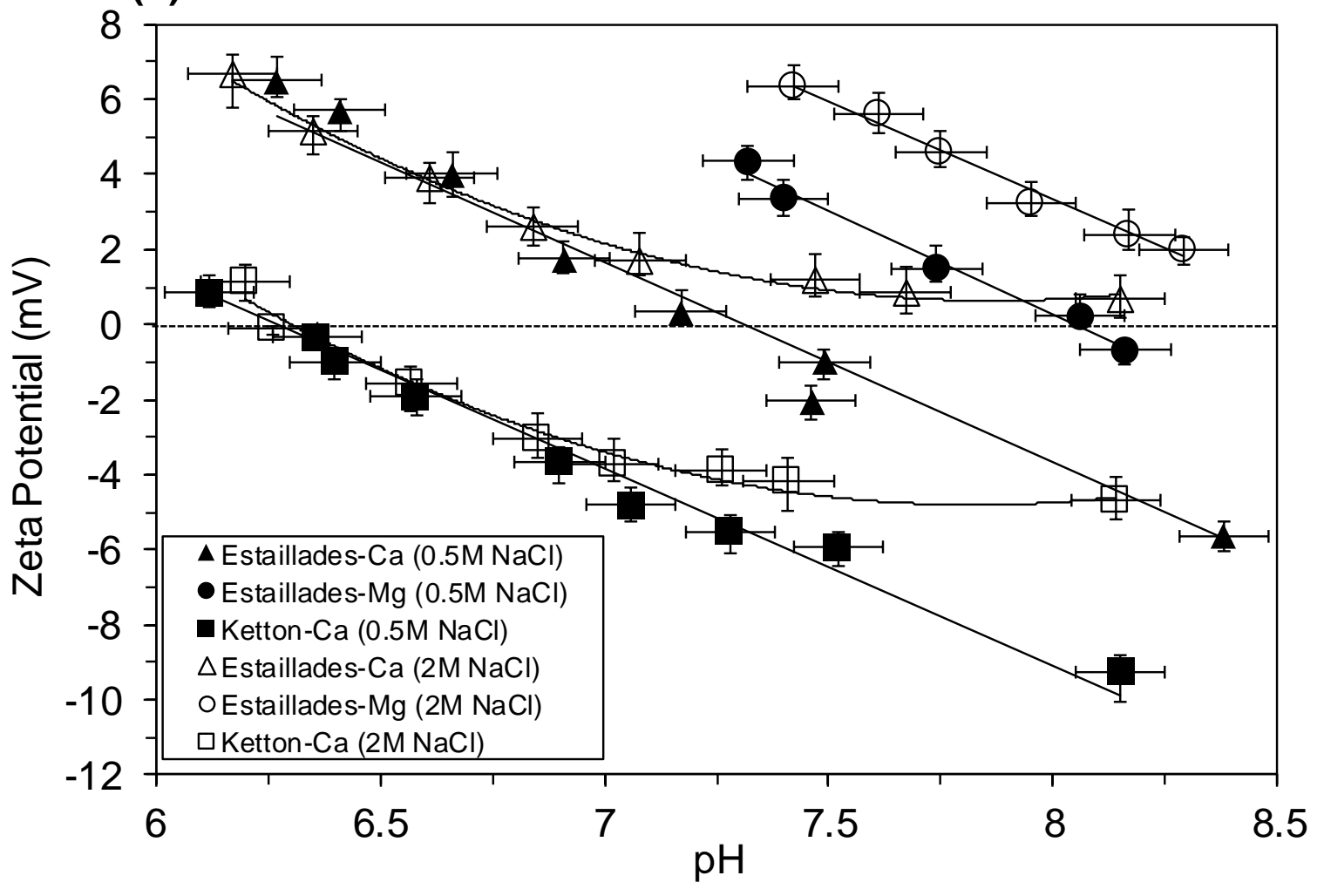


(a)

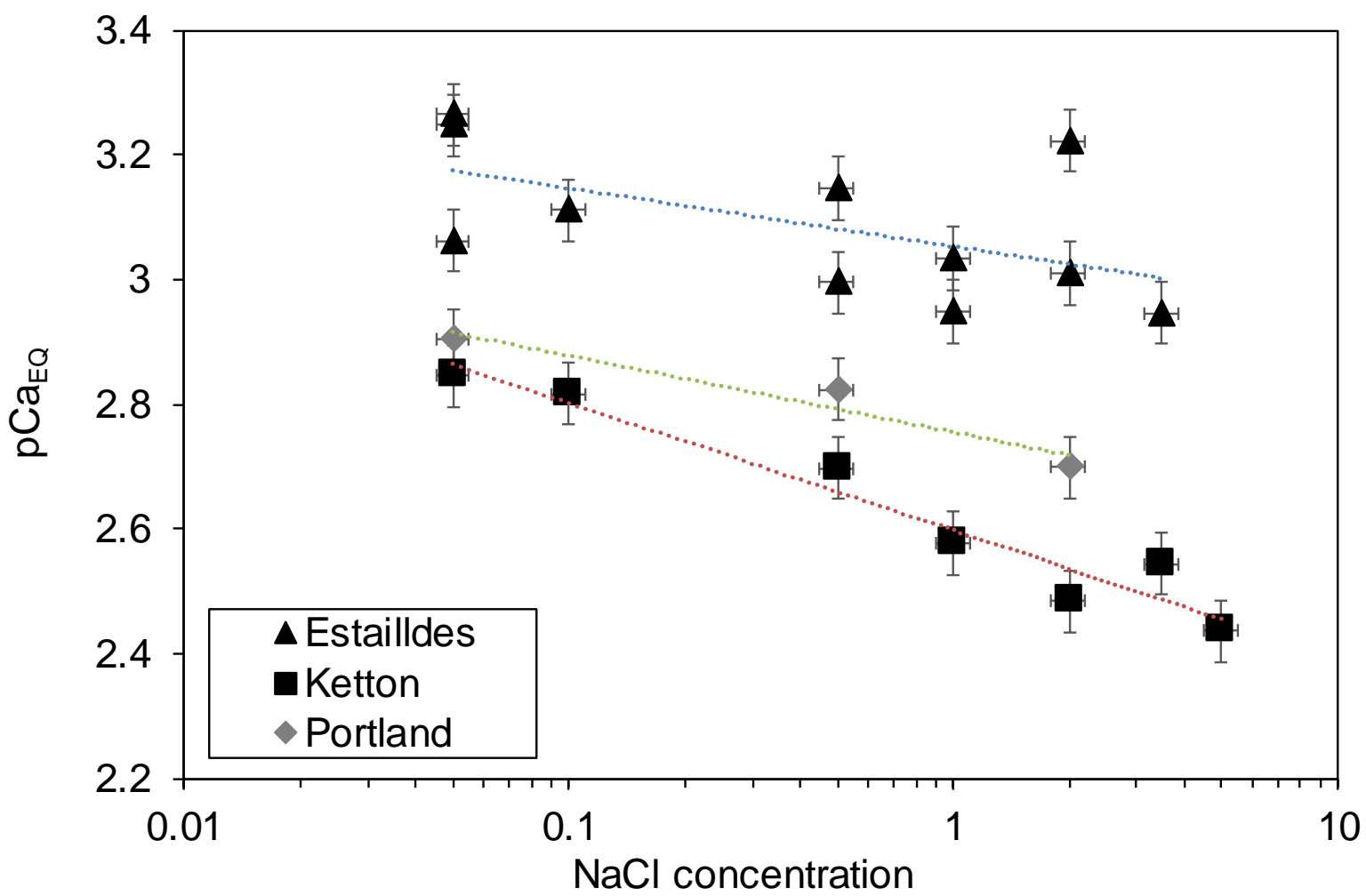

(b)

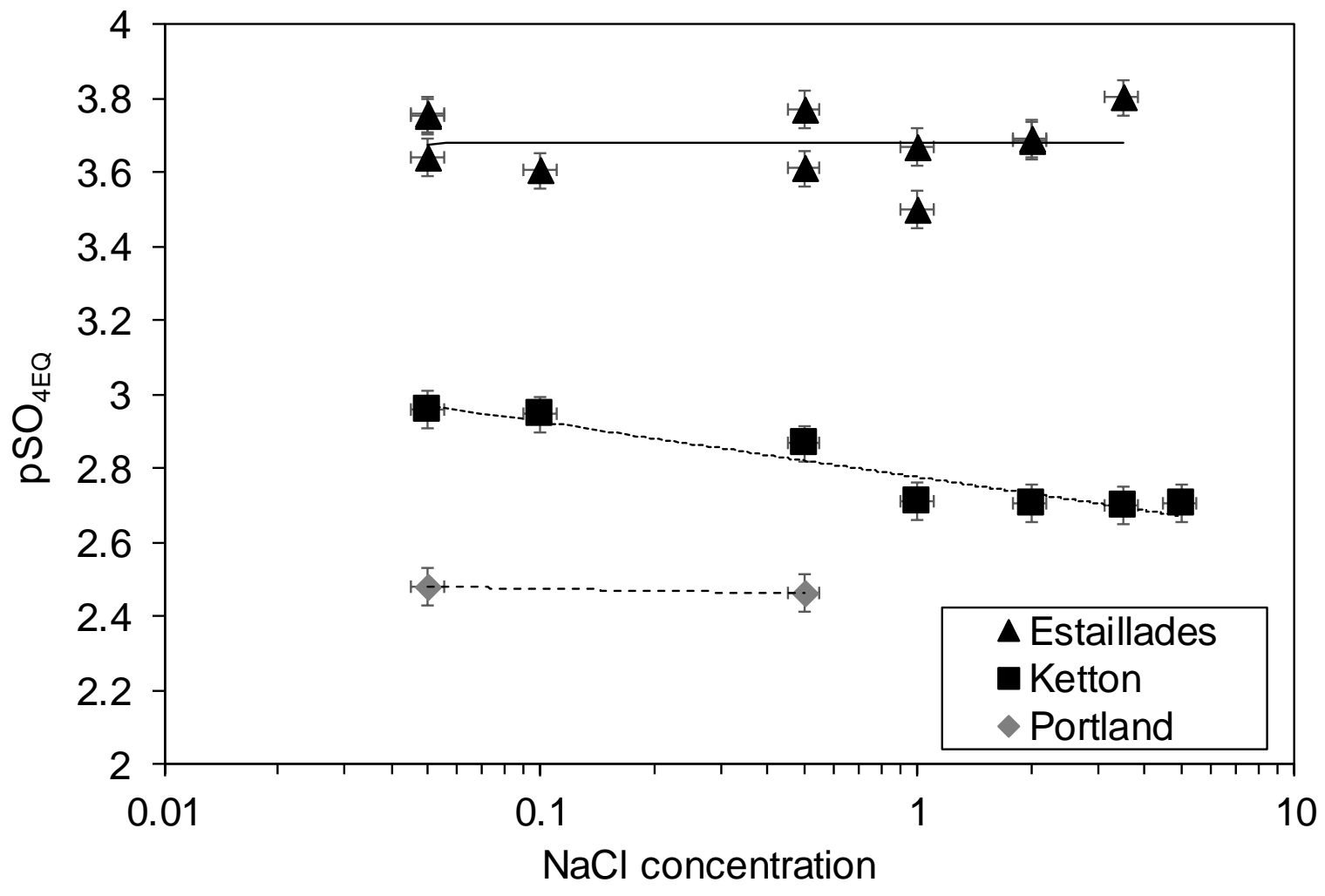

1180 
(a)

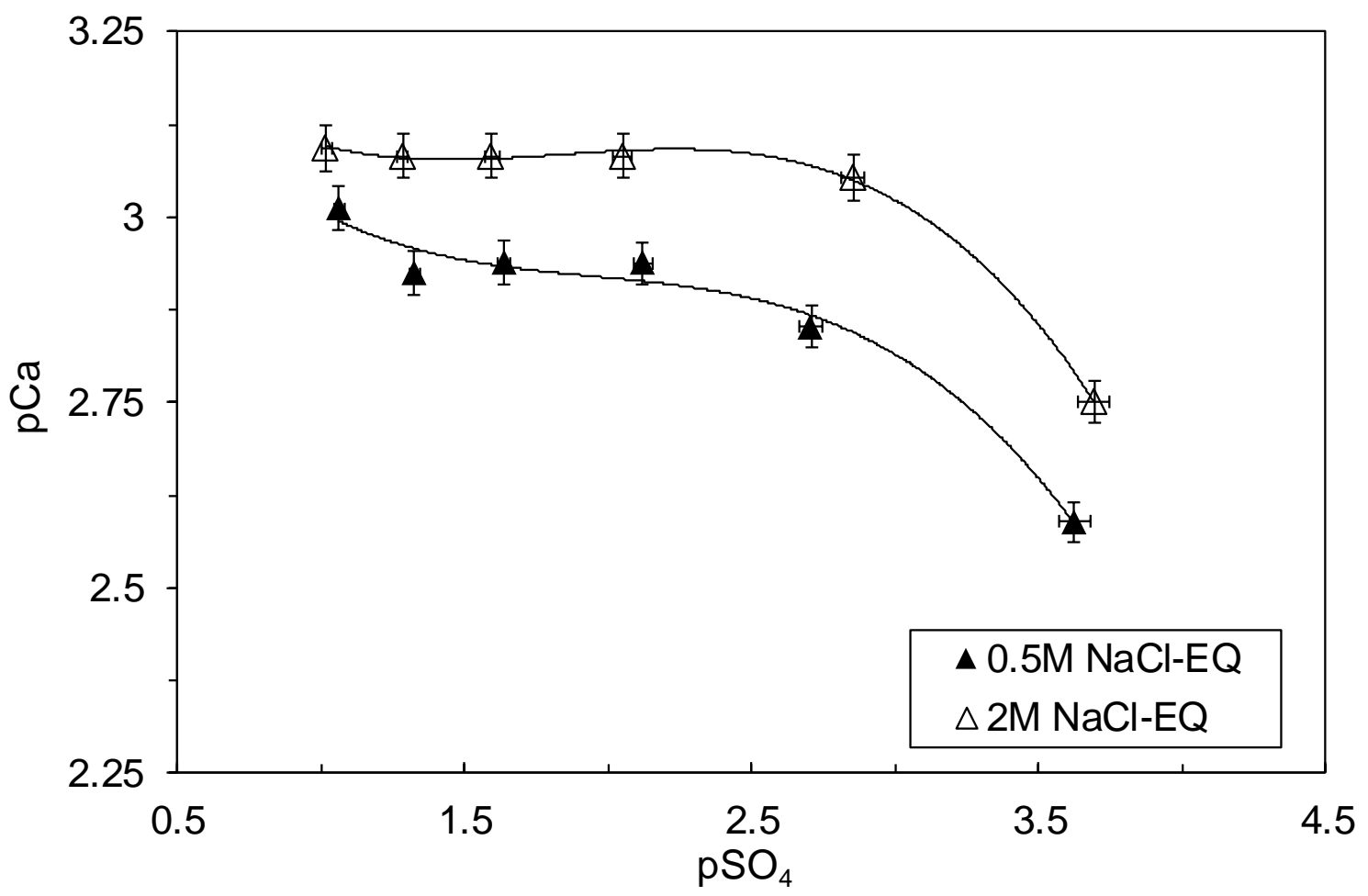

(b)

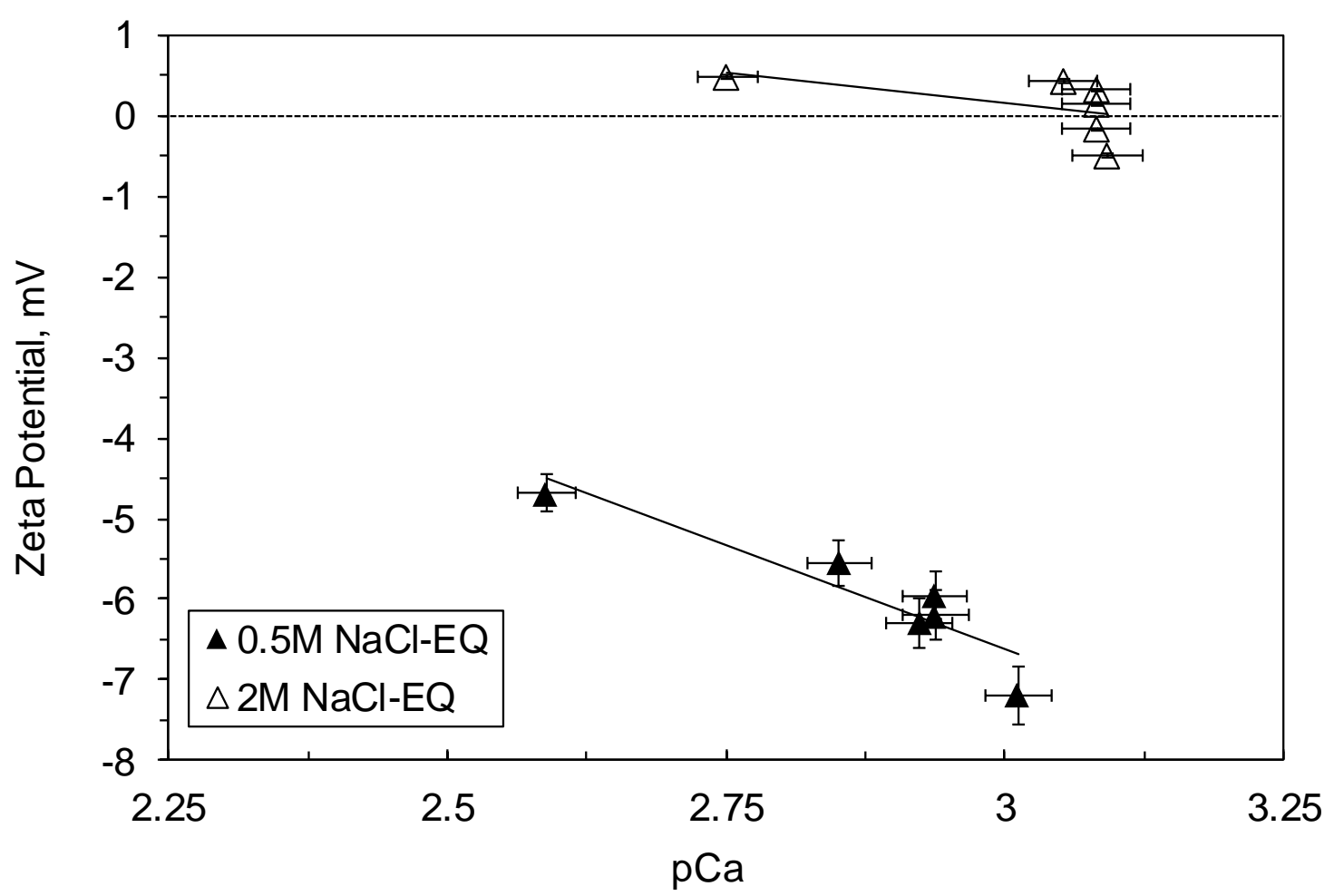

1181 